REFRAMING THE INDIVIDUAL STRESS RESPONSE

\author{
by \\ Jenny Jing Wen Liu \\ MA, Ryerson University, 2015 \\ BA, Ryerson University, 2013 \\ A dissertation presented to \\ Ryerson University \\ in partial fulfillment of the \\ requirements for the degree of \\ Doctor of Philosophy \\ in the program of \\ Psychology (Psychological Science)
}

Toronto, Ontario, Canada, 2019

CJenny Jing Wen Liu, 2019 


\section{AUTHOR'S DECLARATION FOR ELECTRONIC SUBMISSION OF A DISSERTATION}

I hereby declare that I am the sole author of this dissertation. This is a true copy of the dissertation, including any required final revisions, as accepted by my examiners.

I authorize Ryerson University to lend this dissertation to other institutions or individuals for the purpose of scholarly research.

I further authorize Ryerson University to reproduce this dissertation by photocopying or by other means, in total or in part, at the request of other institutions or individuals for the purpose of scholarly research.

I understand that my dissertation may be made electronically available to the public. 


\title{
Reframing the Individual Stress Response
}

Doctor of Philosophy, 2019

Jenny Jing Wen Liu

Psychology (Psychological Science)

Ryerson University

\begin{abstract}
Our society is preoccupied with stress. Previous research demonstrates that the majority of the sampled population perceives the consequences of stress to be primarily negative. By reframing the consequences of stress to highlight both positive and negative effects of stress, individuals may experience more efficient and adaptive stress responses (Liu et al., 2017). The extent to which we can reframe the consequences of stress to elicit more adaptive responses thus merits further investigation. This dissertation investigated the effects of reframing (positive, negative, balanced, and control) on stress responsivity, while also priming individuals on personal strengths (resilient strengths or non-resilient/control strength) to further enhance coping. Through two studies, the current dissertation examined whether different information presented on the consequences of stress via reframing contributes to improved responsivity to stressors, and whether priming an individual to believe in select strengths further enhances receptivity to reframing and reactivity to stressors. Outcome measures included both objective, physiological indexes of stress (heart rate, blood pressure, and electrodermal activity), test performance on stressor-task, and subjective ratings of stress (self-report responses via visual analogue scales). Mixed-ANOVA, linear regression, and exploratory hierarchical modelling were used to analyze the data. Results via visual analogue scales support the efficacy of balanced reframing in reducing self-reported stress, and provide some evidence for its efficacy across physiological
\end{abstract}


parameters of stress via electrodermal activity. Across measures, results provide little support for the efficacy of strength priming in eliciting more adaptive responsivity to stressors. However, balanced framing and resilient strength priming may interact to reduce perceptions of stress as threatening and uncontrollable. Taken together, findings across two studies suggest that reframing stress by presenting both positive and negative information on the outcomes of stress may be an important step in the education of stress to better manage everyday stressors. Further, efforts to personalize this intervention approach by tailoring it to individual may be an area worthy of future research.

Key Words: Beliefs; Coping; Personal Strengths; Reframing; Responsivity; Stress 


\section{Acknowledgement}

I would like to express my sincere gratitude and thanks to my supervisor, Dr. Kristin Vickers. Your selfless dedication, commitment, and guidance have been one of the pillars of support throughout my graduate school journey. My sincere gratitude and appreciation also go out to my supervisory committee members, Dr. Maureen Reed and Dr. Stephen Want for their insight and help in shaping this dissertation since conceptualization. I would also like to thank Dr. Kenneth Fung for appearing in the framing videos, Natalie Ein for being there every step of the way, and Julia Gervasio for her assistance with the preparation and cleaning of data. Finally, I would like to thank members of the examination committee - Dr. Janet Yamada, and Dr. Myriam Mongrain. 


\section{Table of Contents}

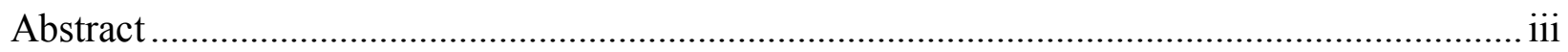

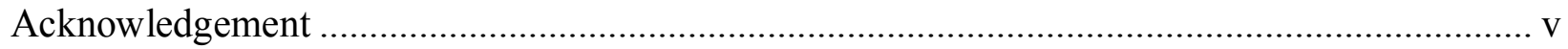

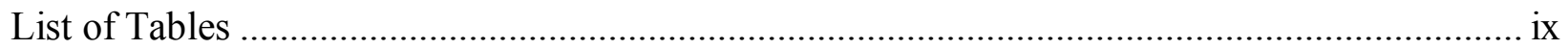

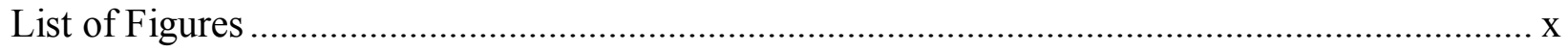

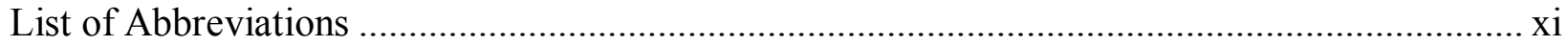

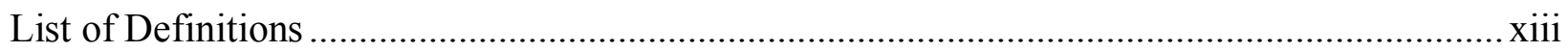

BACKGROUND AND INTRODUCTION ................................................................. 1

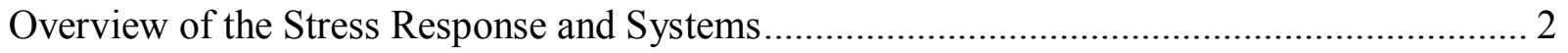

Perceptions of Stress Matter .................................................................................... 4

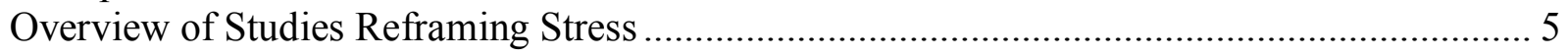

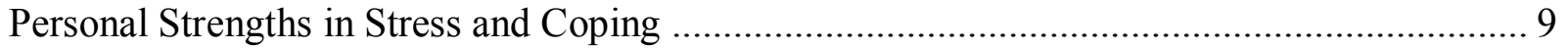

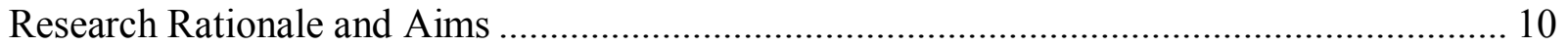

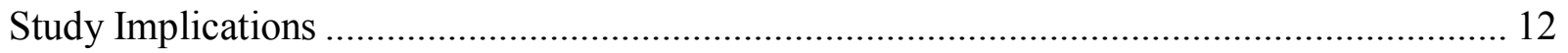

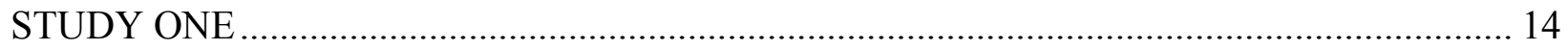

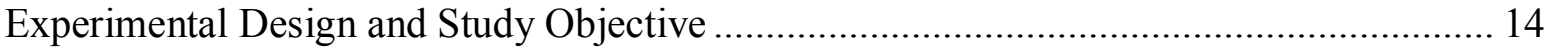

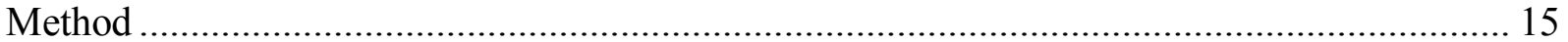

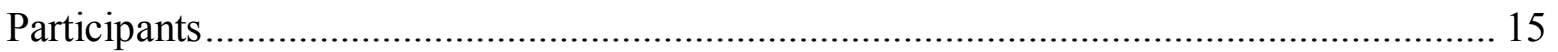

Experimental Manipulations .................................................................................... 16

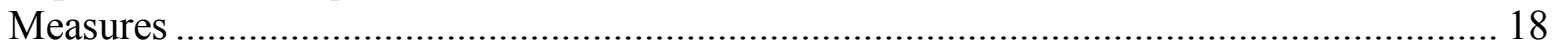

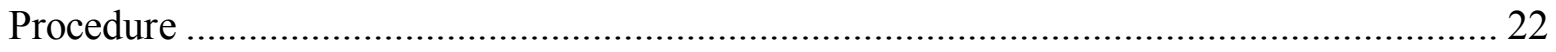

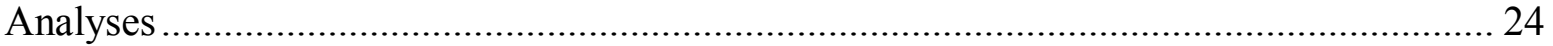

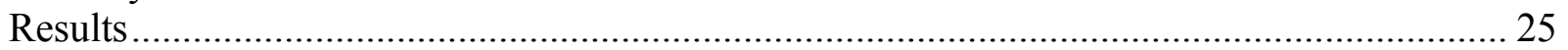

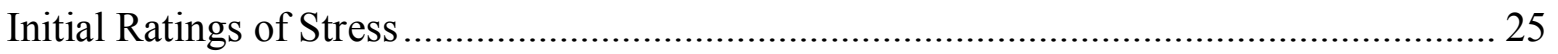

Relationship between Pretest Measures and Stress Responsivity................................... 27

Reframing of Stress on Self-Reported Responses to Stress......................................... 28

Effects of Reframing Stress on Physiological Responses to Stress ................................. 30

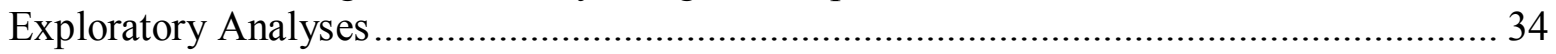

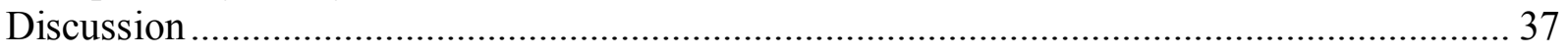

Stress Perceptions on Responsivity to Stress ............................................................. 38 


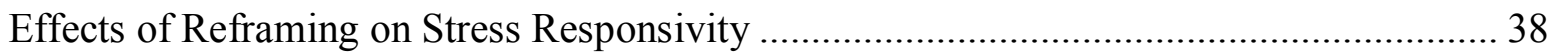

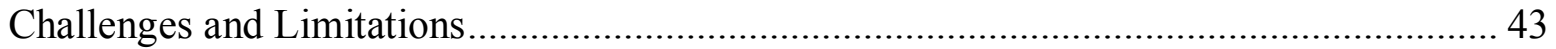

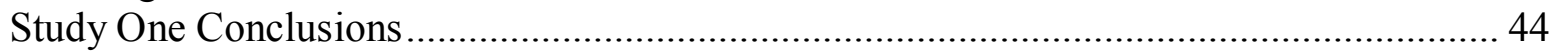

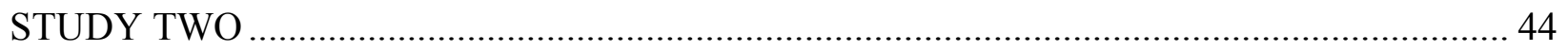

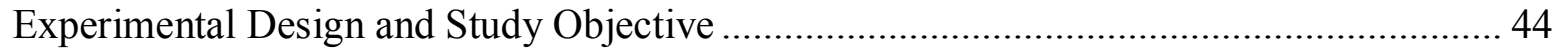

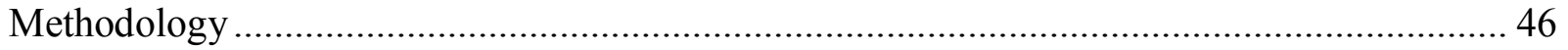

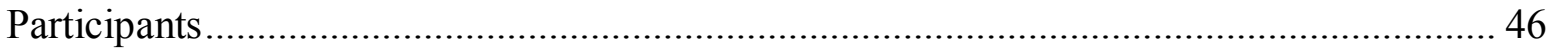

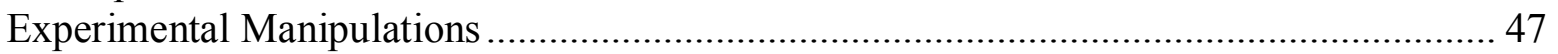

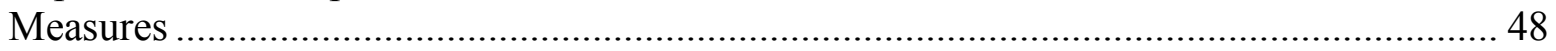

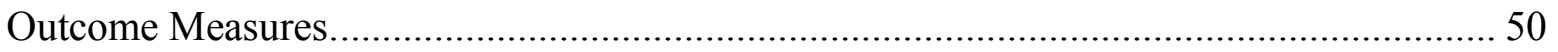

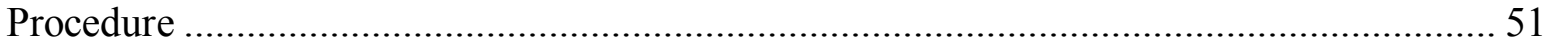

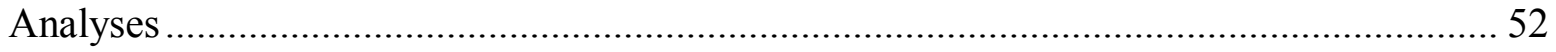

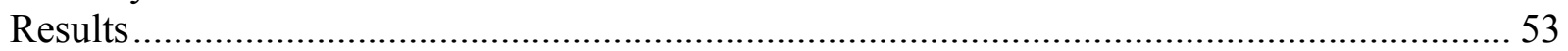

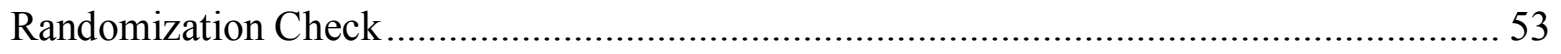

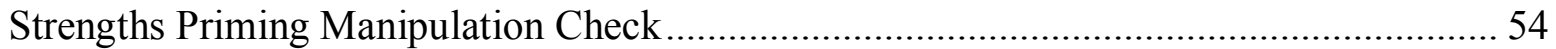

Effects of Strengths Priming on Subjective Stress Measures ............................................... 55

Interactive Effects of Stress Framing and Strengths Priming on Subjective Stress Outcomes

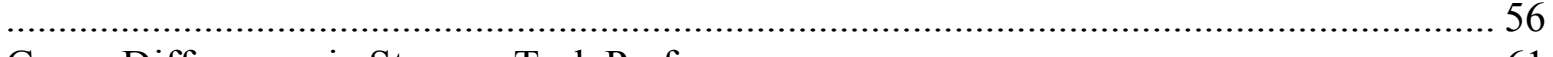

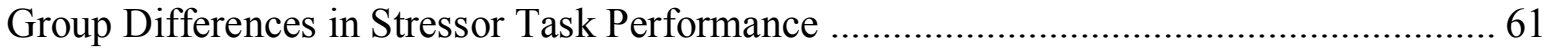

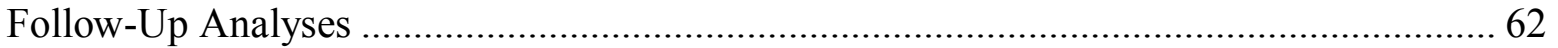

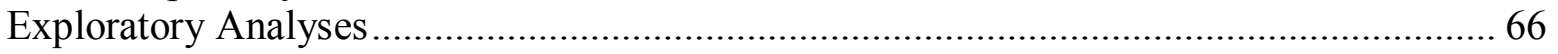

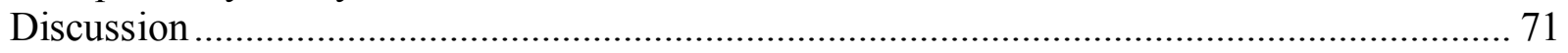

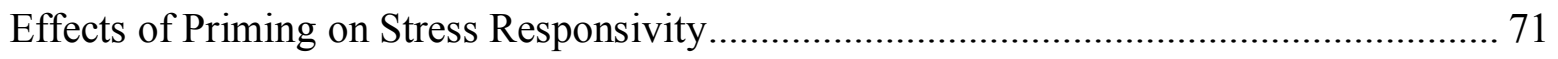

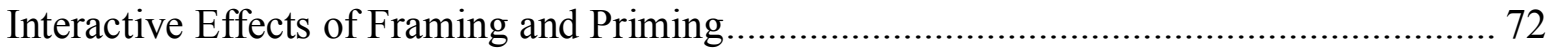

Durability of Experimental Manipulations ……………………………………………...... 75

Complexity of the Individual Stress Response ………........................................................ 76

Challenges and Limitations.............................................................................................. 77

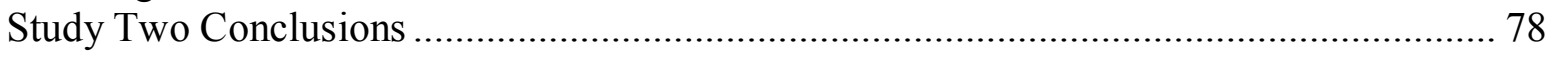

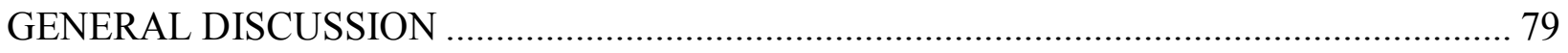

Perceptions of Stress Amongst Participants ……………...................................................... 79

The Effects of Reframing Stress on Stress Outcomes .......................................................... 79

The Effects of Strengths Priming on Stress Outcomes ........................................................... 82

Challenges in Optimizing the Individual Stress Response ..................................................... 84

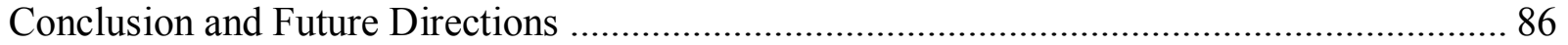

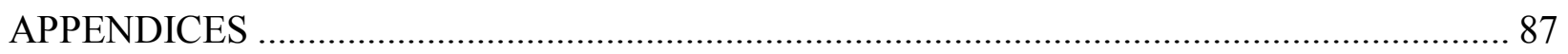

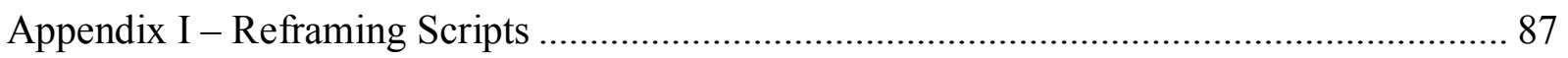

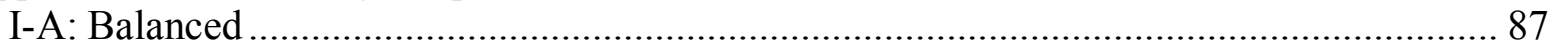

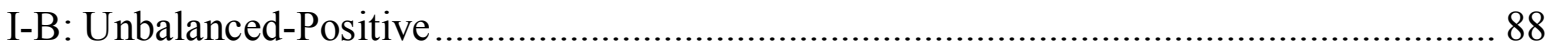

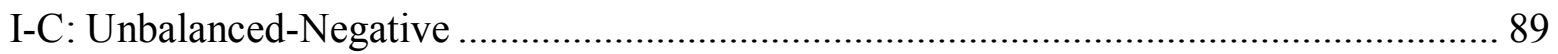

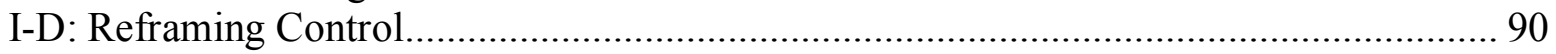

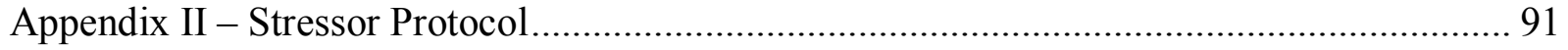

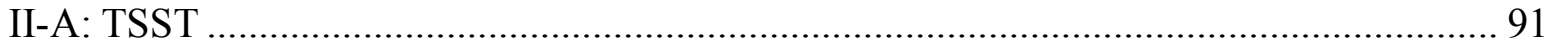




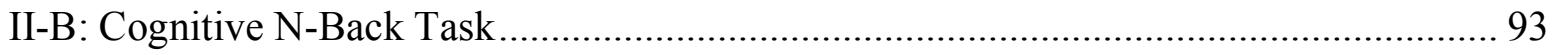

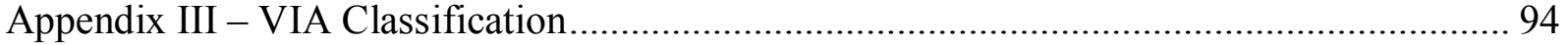

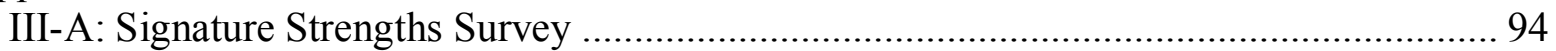

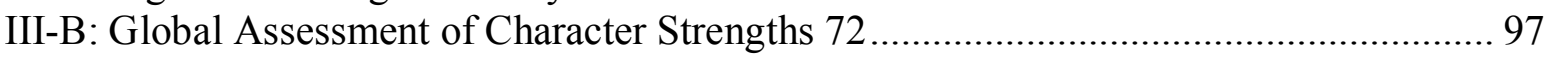

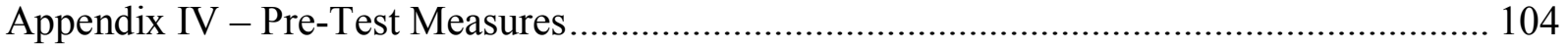

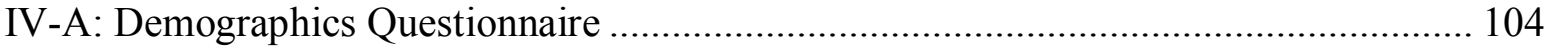

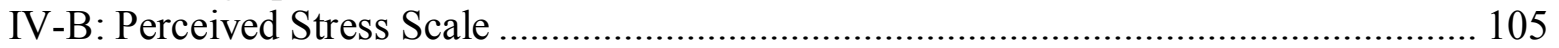

IV-C: Multidimensional Assessment of Interoceptive Awareness ................................ 106

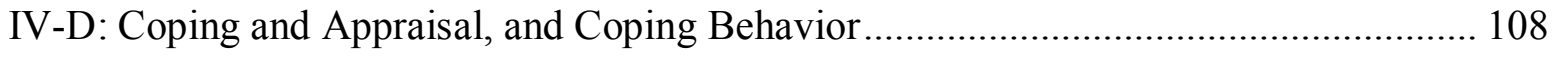

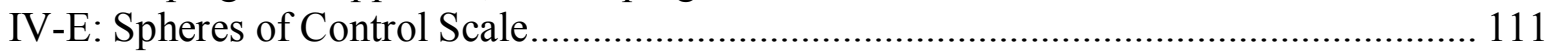

IV-F: Schutte Self-Report Emotional Intelligence Test................................................. 113

Appendix V - Subjective Measures of Stress and Performance ........................................ 114

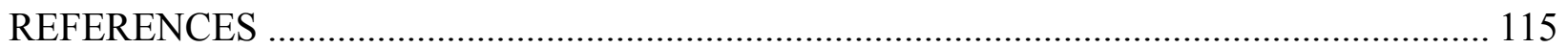




\section{List of Tables}

Table 1. Ratings of Words Associated with Stress

Page 26

Table 2. Covariate Analyses for Pre-Test Measures.

Page 28

Table 3. Pearson's Correlations for outcome variables.

Page 35

Table 4. Model Summaries for Predictors of Self-Reported Stress.

Page 36

Table 5. Beta ( $\beta)$ Values for Predictors in Model One.

Page 36

Table 6. Study two participant demographics for visit two.

Page 46

Table 7. Study two questionnaire means, standard deviations, and Cronbach's alphas.

Page 50

Table 8. Covariate Analyses for Pre-Test Measures.

Page 54

Table 9. Between-subject effects and means across groups.

Page 62

Table. 10. Pearson's Correlations for outcome variables for study two, visit one.

Page 67

Table. 11. Pearson's Correlations for outcome variables for study two, visit two.

Page 68

Table 12. Exploratory model fit summary indexes.

Page 69

Table 13. Standardized model parameters for the SEM model.

Page 70 


\section{List of Figures}

Figure 1. Procedure diagram for study one.

Page 24

Figure 2. Change scores in self-reported stress (VAS-S) levels pre- and poststressor across reframing conditions.

Page 30

Figure 3. Changes in Sympathetic Nervous System measures (HR, SBP, and DBP) during study.

Figure 4. Event-Related Skin-Conductance Responses (ER-SCR) during stressor (left) and post-stressor (right) across reframing conditions.

Figure 5. Procedure for study two across both visits.

Figure 6. Changes in reported strength across framing conditions.

Figure 7. Changes in self-reported stress perception (VAS-SP) across experimental conditions.

Figure 8. Changes in self-reported stress (VAS-S) across framing conditions.

Figure 9. Changes in Systolic Blood Pressure (SBP) during Study Two, visit one. $\quad$ Page 60 Figure 10. Group Differences in Event-Related Skin-Conductance Responses (ERSCR) across framing (left) and priming (right) manipulations.

Figure 11. Self-Reported Changes in Coping (VAS-C) across two visits by priming groups.

Figure 12. Changes in Heart Rate (left) and Systolic Blood Pressure (b) across framing conditions during follow-up. 


\section{List of Abbreviations}

\begin{tabular}{|c|c|}
\hline ANOVA & Analysis of Variance \\
\hline ANS & Autonomic Nervous System \\
\hline $\mathrm{BP}$ & Blood Pressure \\
\hline BPS & BioPsychoSocial Model of Challenge and Threat \\
\hline $\mathrm{CACB}$ & Coping and Appraisal and Coping Behaviour Questionaire \\
\hline CFI & Comparative Fit Indexes \\
\hline CNAP & Continuous Non-Invasive Arterial Pressure System \\
\hline DBP & Diastolic Blood Pressure \\
\hline EDA & Electrodermal Activity \\
\hline ER-SCR & Event-Related Skin Conductance Response \\
\hline HPA & Hypothalamic-pituitary-adrenal axis \\
\hline HR & Heart Rate \\
\hline GAS & General Adaptation Syndrome \\
\hline MAIA & Multidimensional Assessment of Interoceptive Awareness \\
\hline MANOVA & Multivariate Analysis of Variance \\
\hline N-Back & The N-Back Task \\
\hline PNS & Parasympathetic Nervous System \\
\hline PSS & Perceived Stress Scale \\
\hline RMSEA & Root Mean Square Error of Approximation \\
\hline SAM & Sympathetic-adrenal-medullary axis \\
\hline SBP & Systolic Blood Pressure \\
\hline SCS & Spheres of Control Scale \\
\hline
\end{tabular}


SEM

SNS

SONA

SPSS

SRMR

SSEIT

TLI

TSST

VIA

VIF

VAS

VAS-C

VAS-S

VAS-SP
Structural Equations Modelling

Sympathetic Nervous System

Online Psychology Student Participation Pool

Statistical Package for Social Sciences

Standardized Root Mean Square Residual

Schutte Self-Report Emotional Intelligence Test

Tucker Lewis Index

Triers Social Stress Test

Values-In-Action Strengths

Variance Inflation Factor

Visual Analogue Scale

Visual Analogue Scale - Coping

Visual Analogue Scale - Stress Response

Visual Analogue Scale - Stress Perception 


\section{List of Definitions}

"Acute Stress" - refers to the short-term outcomes of the stress experience, often lasting for minutes.

"Adaptive Stress Response" - in the context of this dissertation, will be defined as a quick return to baseline values in response to an acute stressor.

"Chronic Stress" - refers to the longer-term outcomes of the stress experience, ranging from weeks and months to years.

"Coping" - refers to individual responses to stress, and is used synonymously with the stress response to encompass both psychological and physiological changes following exposure to stressor.

"Reframing" - refers to a novel approach to the cognitive reappraisal of information on stress. Within the context of this dissertation, reframing refers to the process of presenting different types of information on outcomes stress, whereby the effects of stress are highlighted differently in order to elicit adaptive response to stress.

"Stress" - refers to the comprehensive experience, including initial identification and evaluation of a stressor, subsequent short and long-term responses to the stressor, and beliefs and associations an individual may hold regarding the experience. 
"Stressor" - refers to any event, stimulus, or situation whereby an individual may perceive to be challenging or threatening, and requires adaptation both psychologically and physiologically.

"Stress Response" - refers to the subsequent psychological and physiological responses that follow the exposure to stressor. Within the context of this dissertation, the stress response examined is acute (i.e., minutes) following the stressor, and is evaluated psychologically and physiologically. 


\section{Reframing the Individual Stress Response}

\section{BACKGROUND AND INTRODUCTION}

Many believe the effects of stress to be primarily negative and detrimental to one's health and wellbeing, with consequences ranging from a common cold to chronic illnesses (Crum, Salovey, \& Achor, 2013; Keller et al., 2015; Liu, Vickers, Reed, \& Hadad, 2017; McEwen \& Schmeck, 1994; Sapolsky, 1998; Schneiderman, Ironson \& Siegel, 2005). However, acute, shortterm stress often serves an adaptive function, mobilizing energy and bodily resources and distributing them throughout the body where needed (Schneiderman, Ironson \& Siegel, 2005). In addition, other research demonstrates that stress can have positive psychological consequences, including inspiring subjective meaning and personal growth (Folkman, 2008; Folkman et al., 1997). Despite these findings, the belief that stress is negative is pervasive across cultures (Souza-Talarico, Wan, Santos, Fialho, Chaves, Carmelli, Bianchi, Santos, \& Lupien, 2016).

Typically, individuals are cautioned against experiencing excessive stress. Whether through media, service providers, or through casual conversation, individuals are warned not to have too much stress to avoid having to deal with the repercussions of distress. Efforts to reduce or manage stress could contribute to the premise that any stress, whether acute, intermittent, or chronic, is entirely negative or detrimental to one's health or wellbeing (see Crum, Salovey, \& Achor, 2013 for review). Research efforts, education, and media may even perpetuate beliefs that stress should be eliminated or avoided. Yet, it is impossible to completely avoid stress in life. Emphasis placed on the elimination of stress may decrease the individual's efforts and ability to become more resilient. Further, stress-reduction strategies and research may propagate a cyclical process of the deficit-orientation of stress, whereby these negative beliefs and expectations compel us to further fear and avoid stress (Crum, Salovey, \& Achor, 2013). This cycle may then 
hinder individuals from developing adequate coping strategies, rendering them more prone to being incapacitated by stress when it inevitably occurs.

\section{Overview of the Stress Response and Systems}

The definition of stress has been greatly contested in the literature. While no clear-cut definitions of stress have been adopted by all researchers, there are several dominant approaches that guide design and methodology when selecting outcome measurements in research.

Early understandings of the experience of stress considered it as a set of physiological symptoms (General Adaptation Syndrome [GAS]; Selye, 1950). Similarly, the Adaptive Calibration Model of Stress defines stress primarily as a set of complex biophysiological responses within the individual, drawing emphasis to changes in the hypothalamic-pituitaryadrenal (HPA) axis and the sympathetic-adrenal-medullary (SAM) axis, the body's primary stress systems, along with the immune and gastrointestinal systems (Del Giudice, Ellis \& Shirtcliff, 2011). While the effects of stress can be adaptive and useful in the short-term, continuous and chronically activated stress systems can lead to maladaptive outcomes, such as the wear and tear of the body (Schneiderman, Ironson \& Siegel, 2005; Shirtcliff et al., 2014). Research adopting physiological definitions of stress often uses only biophysiological measures as parameters of the stress response (e.g., changes in cortisol concentrations in response to challenge tasks; Widmer, Puder, Konig, Pargger, Zerkowski, Girard, \& Muller, 2005), thus limiting our understanding about subjective influences that may impact these responses.

Moving beyond physiological approaches to operationalize stress, Lazarus and Folkman's (1984) Transactional Model of Stress and Coping highlights the interactive nature of stressor and response. This approach defines a stressor as anything that requires an individual to adapt to meet its demands using internal and external resources (Lazarus \& Folkman, 1984). The 
experience of acute stress may not always be experienced simultaneously as psychological and physiological by all individuals. It is thus important to emphasize both aspects, psychological and physiological, when considering stress and its responses. Indeed, a recent report found that higher congruency between subjective stress experience and physiological stress responses were related to psychological and physical well-being (Sommerfeldt, Schaefer, Brauer, Ryff, \& Davidson, 2019).

The current dissertation adopts the approach of understanding stress as both the event and the individual response to the stressor, and considers the stress experience to be both psychological and physiological in nature. To date, few lines of research have examined the stress response through both psychological and physiological measures. Studying the stress and coping response with respect to physiology alone is not reflective of the complex mechanisms of both psychological and physiological stress. Stress and its responses should be examined in terms of complex physiological and psychological responses, with emphasis placed on facilitating more adaptive responses to challenges, rather than a threat response. These adaptive responses can include faster declines or returns to baseline following stressors both psychologically and physiologically, and the examination of effortful regulation of individual arousal (Andersen \& Gustafsberg, 2016; Jamieson et al., 2012; Seery, 2013).

This dissertation contextualizes stress in acute settings (e.g., laboratory studies), and will utilize methodologies representative of acute, short-term psychosocial stressors to mimic daily stressful encounters, with the goal of exploring more adaptive coping strategies for everyday stress. In line with this approach, the research will also use a mixture of subjective and objective measures of stress to measure both the psychological and physiological variations in stress responses across individuals. 


\section{Perceptions of Stress Matter}

The beliefs we hold about stress play an important role in determining how we cope with stress (Scult, Knodt, Swartz, Brigidi, \& Hariri, 2017). Indeed, deciding whether an event or stimulus is a threat or challenge (primary appraisal), and whether we have the resources to cope (secondary appraisal), are the sequential steps that affect how we respond to stress in one prominent theory (Lazarus \& Folkman, 1984). Research also suggests that mindset is an important domain within stress and coping (Crum \& Lyddy, 2014; Crum, Salovey, \& Achor, 2013). Mindset refers to the set of lenses through which individuals understand the world, organize incoming information, and guide future actions (Dweck, 2008). In the context of stress, mindsets may differentially influence individuals to consider stress to be debilitating, or enhancing, thereby predicting future psychological appraisal of stressors and behavioural outcomes of stress.

With limitations discussed below, researchers have suggested that mindsets regarding stress may be altered through presentation of information about stress in the absence of experiencing any stressors (Crum \& Lyddy, 2014). Information is presented through videos or written materials to encourage individuals to reappraise, or reframe, their negative views of stress and anxiety. A number of studies support the efficacy of these reframing interventions on stress and anxiety-related outcomes (Jackson, Compton, Thornton, \& Dimmock, 2017; Jamieson et al., 2010; 2013; Liu, Ein, Gervasio, \& Vickers, 2019; Liu, Vickers, Reed, \& Hadad, 2017; Mendes et al., 2013).

Although there is great variability in the content of information presented about stress across these reframing studies, this line of research highlights the importance of information about stress in shifting the experience of events, challenges, and stressors, and in aiding with 
subsequent coping. Taken together, these findings represent tentative evidence that merits further empirical investigation, and suggest the possible importance of education in altering beliefs regarding stress, and generating more adaptive responses to stressors. Importantly, this method of reframing, when incorporated into study designs with acute stressors, may aid in coping with novel stressors through the development of self-efficacious beliefs about stress. Additionally, the use of reframing may shift perspectives on stress and ultimately lead to better coping outcomes (Crum \& Lyddy, 2014).

\section{Overview of Studies Reframing Stress}

Decades following the conceptualization of the Transactional Model of Stress and Coping, Folkman revised the definition of stress and coping to include positive outcomes of stress (Folkman, 1997; Lazarus \& Folkman, 1984). Researchers have since explored alternative ways to reframe the stress response to experimentally induce positive outcomes of stress and reshape individual stress beliefs on different outcomes (Crum et al., 2013, 2014; Jamieson et al., 2010; 2011).

For example, Crum et al. $(2013,2014)$ used three different stress-related videos comprised of words, images, and music that were three minutes in length. To engender positive coping, stress was referred to as enhancing, such that pressure fuels performance. Outcome measures consisted of a series of questionnaires, including measures on mindset and selfreported stress (Crum et al., 2013, 2014). The intervention successfully attenuated HPA activation (i.e., cortisol) in participants undergoing stressful tasks.

In another approach, Jamieson et al. $(2010,2011)$ used a set of written instructions that instructed participants to re-interpret their physiological stress response as signs of positive and successful coping. Outcome measures included both objective and subjective measures, such as 
test performance, salivary alpha amylase, and psychometric scales (Jamieson et al., 2010; 2011).

This series of studies demonstrated better performance outcomes and attenuation in stress responses in participants who received the reappraisal instructions.

Finally, other research presented a balanced reframing of stress through a video, whereby positive and negative effects of stress were presented; the balanced video helped individuals better cope with subsequent stressors (Liu et al., 2017). This line of research also found that individuals receiving a balanced reframing of stress recovered quicker (to baseline values) following physiological and psychosocial stressors in comparison to those who did not receive balanced information on stress. Importantly, this study also highlighted the problematic nature of providing an overly-positive reframing of stress on subsequent responsivity to stressors. In this study, participants receiving the positive reframing of stress reported more stress, and were physiologically stressed for longer following the stressor (Liu et al., 2017). These findings were attributed to the likelihood of expectation violations, whereby participants receiving positive reframing likely expected the stressor experience to be less stressful as a result of the video, but later experienced the violation of expectations upon experiencing the actual task (Liu et al., 2017; Telch, Harrington, Smits, \& Powers, 2011).

Together, the evidence for studies examining the efficacy of reappraisal interventions on stress responsivity highlights its utility as a potential tool in effectively reducing distress following stress (Liu et al., 2019). However, meta-analytic and systematic review evidence also indicate the large variations in study approach, design, and findings (Liu et al., 2019). Despite the efficacious findings in support of reframing interventions, results from the above-mentioned studies should also be regarded in light of several challenges and limitations. These challenges are further discussed below. 
First, studies reframing stress often lack a control group and/or a follow-up period to determine the degree of change, and the sustainability of the intervention over time (Liu et al., 2017). This is problematic as the immediate improvement in stress response found by these studies (e.g., Jamieson et al., 2010, 2012) could be a placebo effect, social desirability response, or researcher bias. Further, the long-term changes, if any, in beliefs and attitudes regarding stress may be an important outcome for studies reframing stress, and are often overlooked during study designs. It may be important to examine the feasibility of a follow-up to determine whether effects of reframing can endure over time. Finally, successful responses to these reframing interventions are considerably varied across studies, including the attenuation of physiological arousal during stress, moderating the effects of the stressor by decreasing the magnitude of a subsequent physiological response, faster recovery post-stressor, and/or increased task-specific performance. To address this challenge, it is important to use multiple outcome measures that relate to differential processes (i.e., self-reported stress, sympathetic arousal, parasympathetic arousal, and performance measures) in order to understand the effects of the intervention, if any, on various components of stress responsivity.

A second methodological issue is that the reframing interventions to date have often contained only information or instructions tailored to the particular upcoming stressor, with limited outcome measures to examine the transfer of knowledge from interventions across different contexts. Few of the above-mentioned studies have used outcome measures that directly examine changes in beliefs of stress pre-and post-study (Crum et al., 2013). Instead, researchers often assess only changes in physiological stress responses across groups, thereby limiting the conclusions that can be drawn from these findings. 
Importantly, reframing stress to be exclusively positive (Crum et al., 2013; Jamieson et al., 2010, 2011) may continue to perpetuate biased representations of stress, and therefore could hinder adaptive coping. Indeed, biased mindsets regarding stress may set up unrealistic expectations. Accordingly, a biased, albeit positive, representation of stress may create an expectation that could be quickly shattered by reality, and cause further distress to the individual (Liu et al., 2017; Telch et al., 2011). These overly positive expectations can interfere with the stress response and recovery process. More specifically, the violation of expectations, set forth by a biased representation of stress, can exacerbate the magnitude of stress responses, impair coping abilities, or even subsequently trigger further distress (Telch et al., 2011). While the beneficial and adaptive effects of stress should not be overlooked or dismissed, it is important to emphasize that exposure to stress often has both positive and negative consequences.

Finally, in studies using relatively small samples in which randomization might fail and result in group differences (e.g., in stress perception and coping) at baseline, it could be important to control for those differences with baseline measures of stress. Perceived stress, vigilance to bodily changes, and perceived coping skill/control may affect stress responsivity and/or the degree to which individuals subscribe to the reframing interventions and would be important to examine if randomization fails. For instance, the levels of perceived stress experienced by participants prior to the study may affect both how an individual perceives stress, and how he or she respond to subsequent stressors (Schneiderman, Ironson, \& Siegel, 2005). Further, individual awareness of and vigilance to bodily changes and discomfort may influence perceived responsivity to stressors (Schulz \& Vogele, 2015). Finally, perceived coping appraisal, coping behaviors, and perceived control over one's own actions and surroundings (Bollini, Walker, Hamann, \& Kestler, 2004; Delawalla, 2010) could all influence the outcomes of 
individual stressors. Given their possible influence, these factors will be measured in the current dissertation and used as possible covariates to control for potential baseline differences and heterogeneities within study participants in the case of failed randomization, as well as explored through mediation analyses.

\section{Personal Strengths in Stress and Coping}

In addition to reframing of stress, other ways to effectively cope with stress are suggested by several key lines of research in Positive Psychology. Central to Positive Psychology is an emphasis on individual characteristics and self-perceived strengths in coping. Past research has examined the role of personality correlates in an individual's receptivity to new information (see Mazis, 1973; McGuire, 1968). These correlates can be studied through the Values in Action (VIA) character strengths survey, an assessment of individual strengths that contribute to life satisfaction and well-being (Peterson \& Seligman, 2004). The VIA inventory is a robust psychometric assessment designed to identify top strengths within the individual. VIA factors such as persistence, love of learning, and self-regulation, all contribute to positive outcomes in attitudes, beliefs, and resilience (Hausler, Strecker, Huber, Brenner, Höge, \& Höfer, 2017; Höfer, Gander, Höge, \& Ruch, 2019).

Research has shown that self-reflections about one's self-resources to cope can attenuate neuroendocrine responses to stress and reduce subsequent responses to stressors (Creswell Welch, Taylor, Sherman, Gruenewald, \& Mann, 2005). Further, research has found that positive self-affirmations reduce threat perception (Sherman \& Cohen, 2002) and rumination (Koole, Smeets, van Knippenberg, \& Dijkesterhuis, 1999). In a replication study conducted on findings from interventions that used positive psychology exercises, the authors concluded that brief interventions and those that are perceived to be relevant to the user are likely to be efficacious 
(Mongrain \& Anselmo-Matthews, 2012). Taken together, these findings suggest that reframing the stress response may, in part, be enhanced if the individual were to perceive the framing to be more relevant to their own strengths in coping. Thus, an avenue to induce perceived relevance may be via priming an individual to hold more self-efficacious beliefs regarding their own strengths. Indeed, research has demonstrated that strength-based resource priming in therapeutic sessions, during which mental health professionals focus on a client's strengths prior to a therapeutic session, results in positive therapeutic outcomes, increased use of strengths, and more experiences of accomplishments (Fluckiger \& Grosse, 2008; Fluckiger et al., 2010). Resiliencebased strength priming, coupled with reframing the stress response in more balanced, adaptive manners, may ultimately provide the individual with the information, self-efficacy, and sense of control needed to cope with stress in more adaptive, efficient manners.

Simply reappraising arousal may not be enough; coping involves more adaptive cognitions and strengthened personal beliefs in individual resilience. However, to further control for possible confounds, it is also important to examine the emotional intelligence of individuals as this may affect how perceptive they may be to the priming of personal strengths (Schutte \& Maloufff, 2012). To extend beyond previous research that has emphasized physiological symptoms of stress, it is important to examine personality-correlate factors that may enhance both willingness to take in novel information, as well as factors that may motivate an individual to develop adaptive individual responses to stress.

\section{Research Rationale and Aims}

The purpose of the current dissertation is to examine the impact of reframing and priming interventions on the individual stress response, with the goal of evoking a more adaptive acute stress response. Within the scope of the current dissertation, an adaptive acute stress response is 
defined as a robust and elastic response consisting of a pronounced reaction after a stressor that quickly dissipates to baseline levels both physiologically and psychologically. Key questions to be answered include: Can beliefs about stress and subsequent stress responses be reframed? How do beliefs about the self, about coping, and about stress, influence the stress response? And would the effects of reframing be enhanced if individuals were primed on individual strengths?

The current research will adopt key ideas from both the Transactional Model of Stress and Coping (Lazarus \& Folkman, 1986), and the Adaptive Calibration Model of Stress Responsivity (Del Giudice, Ellis, \& Shirtcliff, 2011). Both models understand the stress response and coping mechanisms to be malleable and contextually dependent on various biopsychosocial factors. In addition, both models recognize the stress response to be complex, involving both psychological and physiological outcomes. This key understanding of stress underlies the rationale for the current experimental design

The current dissertation will advance stress intervention research by including a novel approach to reframing stress that deviates from the existing biased (i.e., overly positive) reframing interventions, as well as by including priming of individual strengths. This dissertation will challenge the view that the effects of acute stress are entirely negative. First, different presentations of stress will be tested, including selectively negative, selectively positive, and a balanced presentation of stress that provides both positive and negative information about outcomes of stress. Additionally, individual characteristics that foster resilience will be primed with the hopes of furthering the effects of stress reframing. Through two studies, the overarching goal of the proposed research program is to examine factors that contribute to more adaptive responsivity to stress through both reframing and priming. Ultimately, the goal of the 
experimental manipulations is to foster a more adaptive view of stress and thereby produce more adaptive responses to stressors.

The first study of the research program will enable the examination of the following research questions:

1. Does how one think about stress influence coping behaviours and stress responses?

2. Does different information on the consequences of stress (presented via a reframing video) contribute to improved responsivity in acute instances of stress?

The second study of the research program will build upon findings from the first study by examining additional factors that may contribute to improved stress responsivity. This second study will seek to answer the following research questions:

1. Does priming an individual to believe in resilience-based strengths affect later responses to stress?

2. How does priming an individual to believe in individual strengths (e.g., temperance strength that protects against excess) interact with different information presented on stress through reframing?

\section{Study Implications}

The current dissertation emphasizes that the mere attenuation of stress (e.g., decreases in physiological response to stressor) does not equate to adaptive coping with stress. Rather than taking an avoidance-based approach to facilitating coping with stress, this research seeks to reframe the individual stress experience to generate more efficient, adaptive, and resilient stress responses via faster return to baseline values. Further, the proposed study intends to delineate interpersonal factors that may contribute to enhanced stress resilience within the individual, such 
as personal strengths, as well as inter-individual factors, such as appraisal of stressors and individual coping styles, which may predict differences in stress responses.

The inevitability of stress compels the need for research to facilitate adaptive, rather than maladaptive, responses to stress. Indeed, stress, whether physiological, psychological, or a combination of both, may stem from anything that requires an adaptation to change (Lazarus \& Folkman, 1984). Thus, despite researchers' efforts to find novel ways to alleviate stress, it remains a constant of everyday life. Interestingly, efforts to reduce or mitigate stress may perpetuate perceptions that all stressors, regardless of their context, are negative and detrimental to one's health and well-being. Although efforts to relieve stress should not be overlooked or negated, it is important to consider the potentially long-term deleterious effects in considering stress to be only negative. This may foster a culture intolerant of stress, whose adherents thereby seek to avoid it, rather than relying on individual resources and coping strategies to manage stress. As stress is an inescapable part of everyday lives, perpetuating negative beliefs regarding the consequences of stress may only hinder individual coping, rather than encourage the development of capacities to adequately respond to stressors. 


\section{STUDY ONE}

\section{Experimental Design and Study Objective}

Study one explored the effects of reframing manipulations on stress responsivity, and examined whether different information presented on stress can affect variability in the stress response following an acute stressor. In addition, to address the limitations of lacking a control group and follow-up in previous research (my Master's thesis; Liu, Vickers, Reed, \& Hadad, 2017), the current study compared experimental groups against a control group, and explored the feasibility of a follow-up to examine whether any lasting effects of the reframing manipulation persist in a one-week follow-up. This study utilized a Mixed-ANOVA design, with reframing condition as the between-groups factor, and time as the within-subject factor.

\section{Study Hypotheses}

Hypothesis 1: Based on past research documenting the deficit-orientation of stress in study participants, as well as research suggesting that beliefs about stress affect reactivity to stress, two specific hypotheses can be formulated:

Hypothesis $1 \mathrm{a}-\mathrm{a}$ large portion of individuals will hold negative beliefs regarding stress, and;

Hypothesis $1 \mathrm{~b}$ - individuals who believe that stress is negative will experience a larger psychological and physiological stress response to the stressor, compared to individuals who think stress is positive or neutral prior to the reception of any experimental manipulations.

Hypothesis 2: While all groups are expected to experience acute stress via self-reported and physiological measures, it is hypothesized that a balanced stress reframing intervention (emphasizing both the positive and neutral aspects of stress) will result in improved responsivity 
to stress, compared to other groups. Specific hypothesized differences in the groups are as follows:

Hypothesis $2 \mathrm{a}-$ The balanced condition will experience the least psychological stress increase, compared to other conditions;

Hypothesis $2 b$ - The balanced condition will demonstrate a faster return to baseline levels of physiological stress during post-stressor period compared to other conditions, such that the measured stress parameters during post-stressor will return to the prestressor values;

Hypothesis $2 \mathrm{c}$ - The positive reframing group will experience a greater increase in subjective and physiological stress compared to the negative reframing group; and finally,

Hypothesis $2 \mathrm{~d}$ - The control condition receiving no stress reframing information will have the highest subjective and objective stress, compared to the other experimental groups.

[Exploratory] Hypothesis 3: Relationships between variables will be explored through additional analyses, including correlations, regression, mediation, and analysis of the results from the optional follow-up.

\section{Method}

\section{Participants}

A total of 77 participants with no major health conditions successfully completed the study. Participants were students from a variety of disciplines (e.g., Psychology, Early Childhood Education, Nursing, and Social Work). Participants were recruited through SONA, an online 
participant pool for university students enrolled in Introductory Psychology courses at Ryerson University. Participants received course credit for completing the study.

Most participants were female (96\%), and in their first year of study (83\%). Participants ranged in age from 17 to 45 , with a mean age of $19(S D=3.49)$, and varied across their selfdisclosed ethnic backgrounds.

\section{Experimental Manipulations}

Reframing of Stress. Participants were randomly assigned to receive one of four conditions, each of which had a different five-minute video. The three experimental videos framed stress as balanced, unbalanced-negative, or unbalanced-positive. The control video discussed healthy sleep. The videos all featured the same "expert psychologist" (who was, in fact, a prominent male Psychiatrist) discussing research in Psychology.

The balanced reframing video consisted of detailed description of the adaptive short-term benefits of stress, the challenges of maintaining a state of chronic stress, and its potentially deleterious effects on the mind and the body. The reframing dialogue was identical to the script successfully utilized previously (Liu et al., 2017). Importantly, the balanced reframing video highlighted equally the positive and negative effects of coping with acute stressors. Emphasis was placed on the individual developing coping skills through effective stress management. Coping with stress was likened to the experience of mastering a video game, with practice contributing to future success.

The unbalanced-negative reframing video followed a similar format but with different content on stress presented. Rather than discussing both the positive and negative effects of acute stress, the unbalanced-negative reframing video heavily focused on the deleterious effects of 
chronic stress, highlighting the physiological and psychological negative outcomes related to stress, such as heart disease, cancer, depression, and anxiety.

The unbalanced-positive reframing video, like the unbalanced-negative, emphasized a biased view of stress and responses. The video discussed, in detail, the acute effects of stress, highlighting its adaptive purposes in an evolutionary paradigm, such as allowing for retrieval of energy storage, and the redistribution of energy throughout the body, including enhanced blood flow to mobilize exterior limbs for action (Schneiderman, Ironson, \& Siegel, 2005). The positive video also discussed the possibility for stress-related growth, such as enhanced self-confidence.

The control video on sleep followed the format of information in the three active reframing videos of stress. It first discussed the biological systems that regulate sleep, and ended by offering tips on how to achieve a more restful sleep. This video serves as an active control to the other experimental reframing videos. Scripts of the reframing videos are in Appendix I, A-D. Method of Stress Induction. The Trier Social Stress Test (TSST) is a well-validated and robust method to provoke psychosocial stress in a laboratory setting (Kirschbaum, Pirke \& Hellhammer, 1993). The TSST consists of three tasks: an anticipatory period, a speech task, and a mental arithmetic task (Kirschbaum et al., 1993). In the anticipatory period, the participant is asked to prepare a speech on a topic provided by the experimenter. The participant then delivers the speech in front of the experimenter, who gives neutral, non-supportive, and non-committal feedback. Following the speech, the participant completes a mental arithmetic task, consisting of a backwards subtraction math test out loud by progressively subtracting sevens starting from 2071. During these tasks, participants are informed that their individual session will be filmed for educational purposes to induce further psychosocial, evaluative stress. 
The TSST contains social-evaluative elements that many individuals perceive to be stressful, such as receiving non-supportive feedback on the speech task and corrections on the mental arithmetic task (Dickerson \& Kemeny, 2004). The TSST has been shown to be robust despite modifications to its content and length (Liu et al., 2017). A shortened version of the TSST has been used widely in research to induce physiological and psychological responses (e.g., Skoluda et al., 2015). To keep the length of the lab visit under 60-minutes in the current study, each task within the TSST was shortened to five minutes, a minor deviation from the standard length of 10 minutes for preparation task, and five minutes per speech and mental arithmetic task. As noted, modifications from the standard protocol of the TSST have been demonstrated to elicit similar responses in stress and do not affect the overall efficacy of the stressor (Goodman, Janson, \& Wolf, 2017; Kirschbaum et al., 1993; Liu et al., 2017).

No adverse effects have been documented when using the TSST. Nevertheless, to ensure the safety of the participants, they were told prior to the commencement of the TSST that they could discontinue their participation, pause the experiment, or skip any part of the tasks without any penalty or consequence. Further, if at any time a participant expressed discomfort or wished to withdraw their participation, the experimenter would stop the experiment. Finally, if the participant became visibly upset during any part of the experiment, the experimenter would contact Dr. Vickers to consult, and would provide the participant with information about a counselling centre for students and additional mental health resources. The detailed protocol for the TSST is given in Appendix II-A.

\section{Measures}

Pre-Test Measure. The pre-test measure (Appendix IV-A) contains demographic questions to identify the study sample's characteristics, such as participant sex, age, ethnicity, 
number of years in Canada, and year of study. This questionnaire has been used in previous research (Liu et al., 2017). The pre-test measure also asks participants to list up to four words that they associate with the word "stress"; identify up to five stressors they currently experience; and then to rate the stress associated with each stressor on a scale from zero to ten, where zero represents not at all stressful, and 10 means extremely stressful. These questions provided information about the levels of stress experienced by participants and the types of stressors frequently encountered.

The Perceived Stress Scale (PSS) is a 10-item scale measuring participants' current levels of stress experienced over the past month (Cohen, 1983; Cohen \& Williamson, 1988). The PSS is a well-used and validated measure, most often presented to student cohorts, with normative scores ranging from 12.1 to $14.7, S D=5.0$ to 7.2 (Cohen \& Williamson, 1988; GonzálezRamírez, Rodríguez-Ayán, \& Hernández, 2013; Lee, 2012). The questionnaire is scored based on a 5-point Likert-type scale ranging from $0-4$, and has an internal reliability of $\alpha=0.78$ (Cohen \& Williamson, 1988). On the PSS, higher scores correspond to greater perceived stress. The PSS served as a covariate in this study, and was used to control for possible differences in the daily stresses perceived and experienced by individuals in the sampled population. The internal consistency of the PSS in the sampled population was $\alpha=0.67$. This questionnaire can be found in Appendix IV-B.

The Multidimensional Assessment of Interoceptive Awareness (MAIA) is a self-report measure on interoceptive body awareness (Mehling, Price, Daubenmier, Acree, Bartmess, \& Stewart, 2012). The MAIA focuses on the mind/body awareness and connection, and assesses the degree of sensitivity for physiological sensations and changes, the quality of those selfassessments, an individual's attitudes regarding these observations, and finally, the overall 
integration of the body and mind (Mehling et al., 2012). The MAIA consists of 32 items, covering eight domains, including noticing, not distracting, not worrying, attention regulation, emotional awareness, self-regulation, body listening, and trusting, with mean subscale scores ranging from 3.13 to $4.13, S D=0.6$ to 0.94 in student populations (Mehling et al., 2012). This questionnaire has good internal consistency, with reliabilities ranging from Cronbach's $\alpha=.66$ to .82. The MAIA was used to assess for interoceptive awareness and self-reflection in this study. Group differences in MAIA scores were assessed at baseline, and MAIA scores were controlled for in subsequent analyses. The internal consistency of the MAIA in the sampled population was good, $\alpha=0.85$. This questionnaire can be found in Appendix IV-C.

The Coping and Appraisal, and Coping Behavior (CACB) questionnaires are a set of self-report questionnaires that measure an individual's cognitive and emotional approach to coping and problem-solving at times of stress (Holahan, \& Moos, 1987; Spitzberg \& Cupach, 2008). The CACB contains 17 items, with internal consistency estimates ranging from Cronbach's $\alpha=.55$ to .89 . The CACB was used to assess coping behaviors of the sampled participants, and as a covariate in subsequent analyses. The internal consistency of the CACB in the sampled population was good, $\alpha=0.81$. This questionnaire can be found in Appendix IV-D.

The Spheres of Control Scale (SCS) measures three domains of control, including personal efficacy (e.g., "I can learn almost anything if I set my mind to it"), interpersonal control (e.g., "I have no trouble making and keeping friend"), and socio-political control (Paulhus, 1983). The SCS consists of 30 items ranked on a Likert-type scale of 1-7. This scale has an internal reliability of Cronbach $\alpha=.75-.80$. Student responses on the SCS average between 37 to 51 across three subscales (Spittal, Siegert, McClure, \& Walkey, 2002). Only the personal efficacy and interpersonal control subscales were relevant and used for this study. Responses 
were used as a covariate in analyses examining participants' overall stress reactivity and task performance. The internal consistency of the SCS in the sampled population was good, $\alpha=0.81$. This questionnaire can be found in Appendix IV-E.

Subjective Dependent Measures of Stress. A VAS is a commonly-used, well-validated, and reliable instrument for the assessments of characteristics and values along a continuum (Wewers \& Lowe, 1990). A Visual Analogue Scale - Stress Perception (VAS-SP) was used to identify changes in the perception of stress throughout the study. The VAS-SP asks participants to rate their beliefs regarding stress ranging from 0 (stress does not bother me) to 100 (I find stress to be extremely bothersome and threatening). The VAS-SP was given to participants four times throughout the course of study one: prior to the start of the study, immediately following the reframing video, immediately following the stressor, and finally during the online follow-up.

A VAS - Stress Response (VAS - S) was used to assess subjective evaluation and appraisal of stressors. The VAS-S asks participants to rate their current levels of stress ranging from 0 (not at all stressed) to 100 (extremely stressed). The VAS is a commonly-used assessment of stress that has as much discriminating power as questionnaires in differentiating different levels of stress across groups (Lesage, Berjot, \& Deschamps, 2012). This measure was given to participants two times in this study: prior to the start of the study, and immediately following the stressor.

A VAS - Coping (VAS - C) was used to assess subjective evaluation of coping. The VAS-C asks participants to rate their self-evaluated degree of coping efficacy ranging from 0 (not good at coping at all) to 100 (copes extremely well). This measure was given to participants a total of four times throughout this study: prior to the start of the study, immediately following the reframing video, immediately following the stressor, and finally during the online follow-up. 
All subjective measures of stress are found in Appendix V.

Objective Dependent Measures of Stress. Heart Rate (HR) and Blood Pressure (BP) were used to measure sympathetic activity during the experiment. The Biopac CNAP blood pressure system is a non-invasive measure of sympathetic activity that uses a two-finger press, paired with an upper arm calibration cuff. The CNAP system was connected to the participant upon his or her arrival at the Psychophysiology Lab, and took a continuous measure of HR and BP at oneminute intervals. The physiological outputs were then exported to the computer, and organized using the AcqKnowledge (ACK100W) software, version 4.2.

Electrodermal Activity (EDA) is one of the only direct measures of parasympathetic activation across physiological markers of stress (Zygmunt \& Stanczyk, 2010). EDA was collected using the Biopac Electrodermal Activity Amplifier (EDA100C), a measure of skin conductance through variations in sweat gland activity as a result of stress or arousal. The EDA100C utilizes a continuous voltage stimulation to measure skin conductance. Outputs were exported to the computer, and organized using the AcqKnowledge (ACK100W) software, version 4.2.

\section{Procedure}

Participants who signed up for the study were invited for a one-hour laboratory visit, plus an optional online follow-up study of 30 minutes, to be completed one week later. Participants received a one percent credit in their introductory psychology courses for the completion of the laboratory component of study one, and another 0.5 credit for the completion of the online follow-up. A total of 77 participants took part in this study, and were randomly assigned to either the positive reframing condition $(n=19)$, balanced reframing condition $(n=20)$, negative reframing condition $(n=20)$, or the control condition $(n=18)$. 
Upon arriving at the laboratory, each participant was briefed on the study and provided written consent. Subsequently, participants were connected to the Biopac system, which includes the CNAP blood pressure system, and the EDA skin conductance system. During calibration, participants completed the demographics questionnaire and VAS-SP, VAS-S, and VAS-C.

Following calibration, participants viewed a video about stress (see Reframing of Stress under Experimental Manipulations). Following this video, the experimenter asked the participant to answer the VAS-SP and VAS-C for the second time. Thereafter, participants underwent an acute psychosocial stress induction (see TSST under Experimental Manipulations), and responded to all three VAS measures (VAS-SP, VAS-S, and VAS-C) following the completion of the stressor. Outcome measures included both subjective and objective indicators of the stress response. Finally, participants were thanked for completing the study, consented to be contacted for an online follow-up via email, and debriefed in full.

In a week's time, participants were sent an email to a link of the online 30-minute followup questionnaire. The follow-up gauged the extent to which participants retained their beliefs regarding stress, and included both the VAS-SP and VAS-C. The follow-up questionnaire also asked participants to list and rank the top five stressors they had experienced over the course of the week. Following the completion of this online questionnaire, participants were thanked and debriefed online, and given 0.5 course credit for their participation. Figure 1 below details study procedures for study one. 
STUDY ONE: PART ONE VISIT
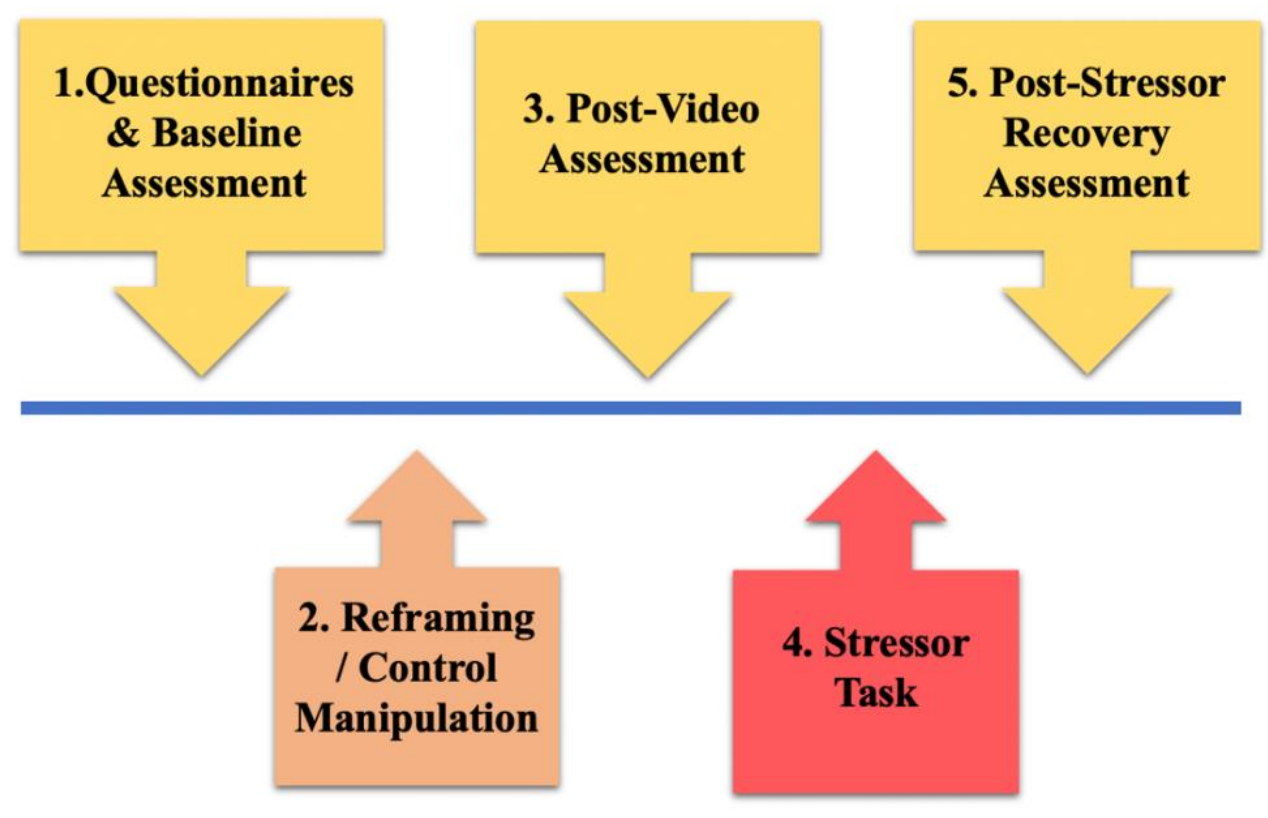

PART TWO: ONE WEEK FOLLOW-UP

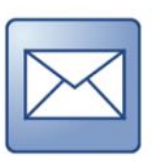

\section{Baseline \\ Questionnaires \& \\ Stress Beliefs via VAS}

Figure 1. Procedure diagram for study one.

\section{Analyses}

A post hoc power analysis using $\mathrm{G} *$ Power for a MANOVA (special effects and interactions design) with an alpha of .05 found sufficient power of 0.94 to detect small to medium effects of $d=.25$ (Cohen \& Williamson, 1988), as previously found in similar research (Liu et al., 2017). All analyses were conducted using Statistical Package for Social Sciences (SPSS, version 23). Missing data on pre-test measures (less than 1.3-3.9\% across the data matrix) were filled using the multiple imputation method (Enders, 2017). Parallel mediation analysis was conducted using PROCESS macro for SPSS (version 3.1) written by Hayes (2017) to estimate the total effects of $\mathrm{X}$ (stress framing groups) on $\mathrm{Y}$ (stress outcomes) through proposed mediators 
and covariates M (PSS, MAIA, CACB, and SCS) (Kane \& Ashbaugh, 2017). Mediation analysis used a $95 \%$ confidence interval with bootstrapping using 10,000 samples. The effects are considered significant if the $95 \%$ confidence interval of outcomes do not include zero.

Testing Hypothesis One. To address the differential effects of initial perceptions of stress on coping behaviours and outcomes, the responses on the demographic word-association task were rated by two independent raters blind to the purpose of this experiment. Raters rated whether words associated with stress were identified as positive $(+1)$, neutral $(0)$, or negative. These ratings served as grouping variables to determine whether participants differ on any stress outcome measures based on initial perceptions of stress.

Testing Hypothesis Two. To ascertain whether balanced reframing with both positive and negative information on stress presented contributes to improved stress responsivity compared to unbalanced reframing conditions and the control condition, change scores were computed and one-way ANOVAS used to examine differences in self-reported stress outcomes. MixedANOVAs with time as the repeated, within-groups variable, and reframing groups as the between-group factor, were used for physiological stress outcomes.

Testing Exploratory Hypothesis Three. To examine the relationships among variables, correlations and regression equations were used. The data from the optional follow-up were analyzed using one-way chi-square analyses.

\section{Results}

\section{Initial Ratings of Stress}

The first aim of study one was to explore the initial perceptions of stress in the sampled participants. To do so, as noted above, two independent raters blind to the purpose and hypotheses of the current study were asked to rate the words associated with stress (i.e., the 
word-association task on the Demographics measure) as either positive, negative, or neutral, which are pre-established categories hypothesized in the current study (Campbell, Quincy, Osserman, \& Pedersen, 2013; Liu et al., 2017). Inter-rater reliability across both raters ranged from $82 \%$ to $89.6 \%$ across all four words, for an average of $85 \%$ across the entire task. All inconsistencies were settled by rater consensus facilitated by the primary investigator, who pointed out differences in rating categories without influencing the discussion.

Participants were asked to identify up to four words when thinking of stress. A total of 296 words were identified, including words such as "exam", "panic", and "anxiety". Of these, $70 \%$ of the first words identified were rated as negative (e.g., "panic"), while the remaining $30 \%$ of the first words identified were rated as neutral (e.g., "school"). In addition, 66\% of all words were rated as negative, compared to $28 \%$ neutral, and $6 \%$ positive (e.g., "motivational"). Table 1 below indicates the percentage breakdown of ratings for the word association task.

Table 1. Ratings of Words Associated with Stress

\begin{tabular}{|c|c|c|c|c|c|c|c|c|c|c|}
\hline & \multicolumn{2}{|c|}{$\begin{array}{l}\text { First } \\
\text { Word }\end{array}$} & \multicolumn{2}{|c|}{$\begin{array}{l}\text { Second } \\
\text { Word }\end{array}$} & \multicolumn{2}{|c|}{$\begin{array}{l}\text { Third } \\
\text { Word }\end{array}$} & \multicolumn{2}{|c|}{$\begin{array}{l}\text { Fourth } \\
\text { Word }\end{array}$} & \multicolumn{2}{|c|}{$\begin{array}{c}\text { Total } \\
\text { Words }\end{array}$} \\
\hline & $N$ & $\%$ & $N$ & $\%$ & $N$ & $\%$ & $N$ & $\%$ & $N$ & $\%$ \\
\hline $\begin{array}{l}\text { Negatively } \\
\text { Rated }\end{array}$ & 54 & 70 & 49 & 63 & 48 & 64 & 45 & 67 & 196 & 66 \\
\hline $\begin{array}{l}\text { Neutral } \\
\text { Rating }\end{array}$ & 23 & 30 & 22 & 29 & 20 & 27 & 18 & 37 & 83 & 28 \\
\hline $\begin{array}{l}\text { Positively } \\
\text { Rated }\end{array}$ & 0 & 0 & 6 & 8 & 7 & 9 & 4 & 6 & 17 & 6 \\
\hline
\end{tabular}

To determine the degree to which existing stress perceptions affect stress responsivity, a multivariate analysis of variance (MANOVA) was used to determine potential differences across dependent measures of stress when considering individuals' initial rating of stress (i.e., ratings from the word association task). Participants' first rating was selected based on the robust evidence for the initial response demonstrating the highest reliability of associations (Nelson, 
Mcevoy, \& Dennis, 1999). As aforementioned, no participant's initial perception of stress was associated with a positive word. Thus, between-groups factors consisted of individuals who perceived stress to be negative $(n=46)$ or neutral $(n=20)$. Mauchly's test of sphericity was not violated; thus, degrees of freedom were not adjusted. Although the overall omnibus test was not significant, $F(10,55)=1.243, p=.286, \eta^{2}=.18$, follow-up between-subjects effects did detect group differences on systolic blood pressure post-stressor, $F(1,64)=4.79, p=.032, \eta^{2}=.07$. Participants whose initial ratings of stress were coded as negative experienced heightened systolic blood pressure post-stressor $(M=110.77, S D=19.03)$, compared to participants whose initial rating of stress were coded as neutral $(M=100.02, S D=16.60)$. Further, differences in systolic blood pressure post-stressor across stress rating groups persisted despite controlling for initial perception of stress at baseline, $F(1,64)=4.66, p=.035, \eta^{2}=.07$. Other measures of subjective and objective stress outcomes were not statistically different as a result of initial ratings of stress, $p<.05$. There were no group differences at baseline across measures of subjective (i.e., VAS) and objective (i.e., HR, BP, EDA) stress between the two groups (negative or neutral first responses on the word association task), $F(7,59)=0.48, p=.842, \eta^{2}=.05$.

\section{Relationship between Pretest Measures and Stress Responsivity.}

Prior to exploring group differences in response to the reframing intervention, I first tested the effects of randomization in creating groups that did not differ on pre-test measures (PSS, MAIA, CACB, and SCS). A multivariate analysis of variance with the pre-test measures as the dependent variable and the reframing condition as the independent variable examined the degree to which these scores differed across groups at baseline in order to control for them in subsequent analyses, if significant differences emerged. The overall MANOVA was not significant for any pre-test measures $(p>.05)$ and thus they were not used as covariates for 
subsequent analyses. Table 2 below illustrates the between-subject effects of each pre-test measure.

Table 2. Covariate Analyses for Pre-Test Measures.

\begin{tabular}{lcccc}
\hline & $\boldsymbol{d} \boldsymbol{f}$ & $\boldsymbol{F}$ & Sig. & $\boldsymbol{\eta}^{\mathbf{2}}$ \\
\hline PSS & 3,57 & 1.00 & .959 & .01 \\
MAIA & 3,57 & 0.95 & .425 & .05 \\
CACB & 3,57 & 0.83 & .483 & .04 \\
SCS & 3,57 & 0.79 & .523 & .04 \\
\hline
\end{tabular}

Note. PSS = Perceived Stress Scale; MAIA = Multidimensional Assessment of Interoceptive Awareness; CACB = Coping and Appraisal and Coping Behaviour; SCS = Spheres of Control Scale.

Pre-test variables were tested as mediators in model 4 of the PROCESS mediation macro for SPSS (with 10,000 percentile bootstrap confidence interval samples). Stress responsivity measures (VAS-Stress, HR, SBP, DBP, and EDA) were used as the outcomes, stress reframing condition was used as the independent variable, and pre-test measures (PSS, MAIA, CACB, and SCS) were used as mediators. Model summary statistics did not find a significant mediating effect for a path between pre-test measures and any stress responsivity measure $(p>.05)$, with the exception of SBP ( $p=.03$ ), such that coefficients for MAIA significantly negatively related to SBP outputs (effect $=-2.11, S E=0.62,95 \% C I=-3.35,-0.86, p<.01)$. There were no significant interactive or indirect effects of MAIA and framing condition on SBP (95\% CI $=-0.30,0.06)$. Given the lack of interaction with experimental conditions, MAIA was not controlled in subsequent analyses with SBP.

\section{Reframing of Stress on Self-Reported Responses to Stress}

To examine the effects of reframing on perceptions of stress, two mixed-ANOVAs with time as the within-subjects factor and reframing manipulation as the between-groups variable were conducted on VAS-SP and VAS-C. 
On measures of stress perception, a significant within-subjects effect of time was detected, $F(2,142)=12.21, p<.001, \eta^{2}=.15$. On average, participants' perceptions of stress as threatening or bothersome decreased following the presentation of video $(M=55.76, S D=$ 25.811), and increased following exposure to a stressor $(M=64.95, S D=23.46)$. Withinsubjects effects did not detect any significant time-by-framing effects, $F(6,142)=1.61, p=.149$, $\eta^{2}=.15$. Further, tests of between-subjects effects did not detect any differences across framing conditions, $F(3,71)=1.27, p=.292, \eta^{2}=.05$.

On measures of stress coping, no significant effects were detected over the course of the experiment, $F(2,142)=1.13, p=.327, \eta^{2}=.02$. There were no time-by-framing interactions, $F(6,142)=0.62, p=.717, \eta^{2}=.03 ;$ or differences across framing conditions after collapsing pre/post time-points, $F(3,71)=1.49, p=.224, \eta^{2}=.06$.

To determine whether reframing groups contributed to differences in self-reported stress changes pre- to post-stressor, change scores ${ }^{1}$ were computed by subtracting the post-stress VASStress from the baseline. A one-way analysis of variance was then used to determine differences in self-reported stress levels across reframing conditions. The overall ANOVA detected a mean difference between groups that approached significance, $F(1,72)=3.28, p=.074, \eta^{2}=.06$. Multiple comparisons also uncovered a significant difference between the self-reported stress changes of participants in the balanced reframing condition, compared to those in the control condition. On average, participants in the control condition reported an increase of 15.22 points $(S D=4.07)$ in self-reported stress levels, compared to those in the balanced reframing conditions $(M=1.75, S D=4.10), p=.033$. Further, a one-way ANOVA comparing all groups that received

\footnotetext{
${ }^{1}$ Change scores were computed rather than using a repeated-measures ANOVA or residual change scores because baseline scores on self-reported stress did not differ significantly across experimental groups, and were also not of primary interest to the current study. Instead, the purpose was to examine group differences post-intervention (Castro-Schilo \& Grimm, 2017; Fu \& Holmer, 2015; Steketee \& Chambless, 1992).
} 
stress reframing information against the control group also found a trend towards significance, $F(1,74)=3.25, p=.076, \eta^{2}=.04$. On average, participants in the stress-reframing conditions, regardless of whether they watched the positive, negative, or balanced videos of stress, experienced less increases in self-reported stress $(M=5.95, S E=2.51)$ compared to the control condition $(M=15.22, S E=4.50)$. Figure 2 below illustrates changes in self-reported stress across different reframing conditions.

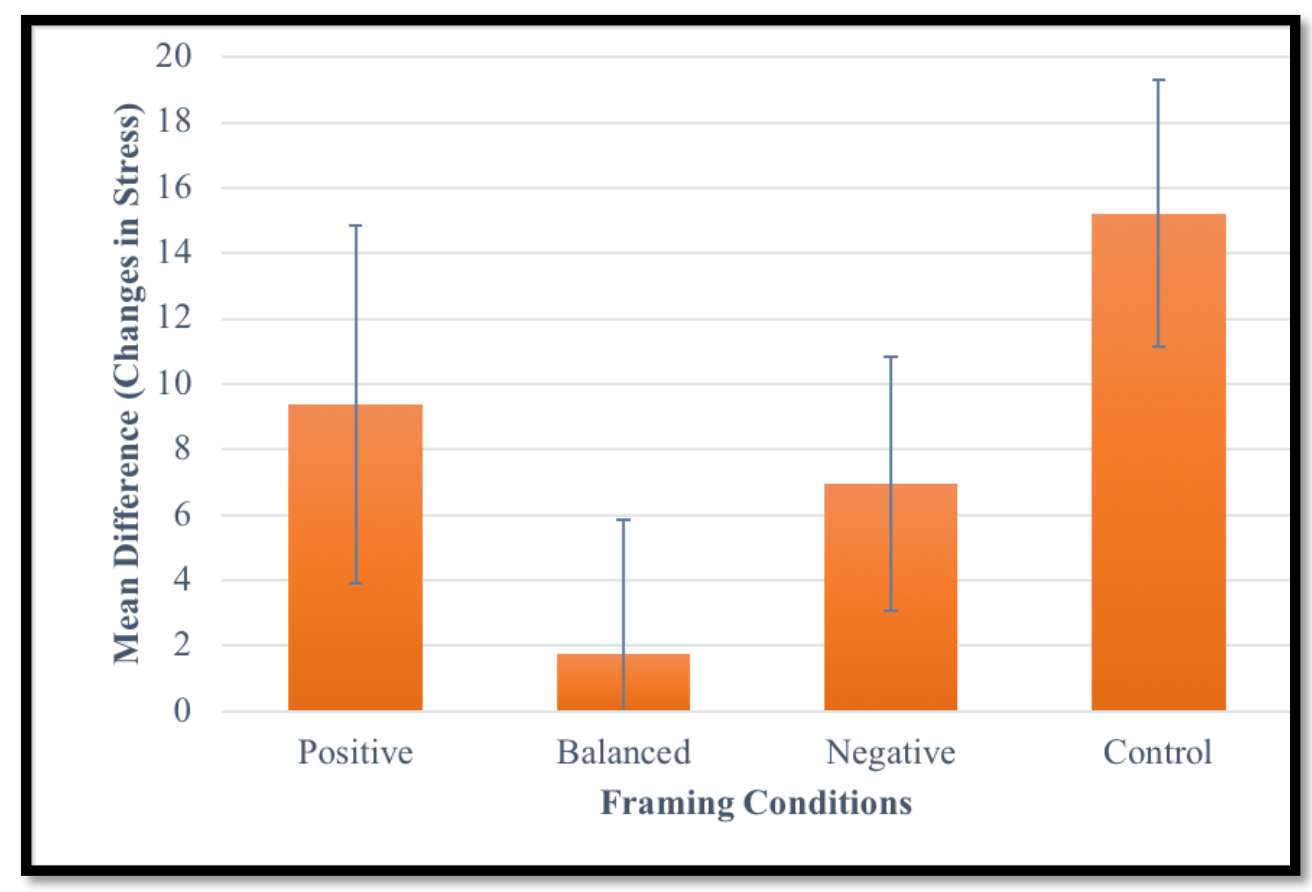

Figure 2. Change scores in self-reported stress (VAS-S) levels pre- and post-stressor across reframing conditions.

\section{Effects of Reframing Stress on Physiological Responses to Stress}

Measures of Sympathetic Nervous System (SNS). Biopac calibration errors resulted in incomplete data for 6 participants, such that there were 71 participants across experimental conditions with complete SNS data. A repeated-measures analysis of variance first examined the overall changes in heart rate and blood pressure throughout the study. Mauchly's test of sphericity was violated for all three parameters: heart rate $\left(\chi^{2}(9)=102.05, p<.001\right)$, systolic 
blood pressure $\left(\chi^{2}(9)=91.03, p<.001\right)$, and diastolic blood pressure $\left(\chi^{2}(9)=111.96, p<.001\right)$. Degrees of freedom were thus adjusted using Greenhouse-Geisser estimates $(\varepsilon=0.564$ for heart rate; $\varepsilon=0.562$ for systolic blood pressure; $\varepsilon=0.570$ for diastolic blood pressure). Univariate test of within-subjects effects found a significant effect of time on heart rate, $F(2.56,157.99)=$ 17.96, $p<.001, \eta^{2}=.20$; systolic blood pressure, $F(2.25,157.35)=6.35, p=.001, \eta^{2}=.08$; and diastolic blood pressure, $F(2.28,159.54)=18.56, p<.001, \eta^{2}=.21$. In addition, tests of withinsubject contrasts also found time to be represented through a quartic function, identifying multiple inflection points and extremes for HR, SBP, and DBP $\left(p<.001, \eta^{2}=.25-.54\right)$. Visual inspection of the data found that HR and BP decreased from baseline to post-video, and increased again during the course of the stressor, and begin to decrease again during the poststressor recovery period. Finally, a mixed-ANOVA did not detect any significant time-byframing condition interaction on $\mathrm{HR}, F(6.70,149.68)=0.69, p=.671, \eta^{2}=.03$; SBP, $F(6.66$, $148.81)=0.45, p=.858, \eta^{2}=.02 ;$ and DBP $, F(6.76,150.94)=0.77, p=.608, \eta^{2}=.03$. Figure 3 below illustrates changes in HR and BP during the course of study one.

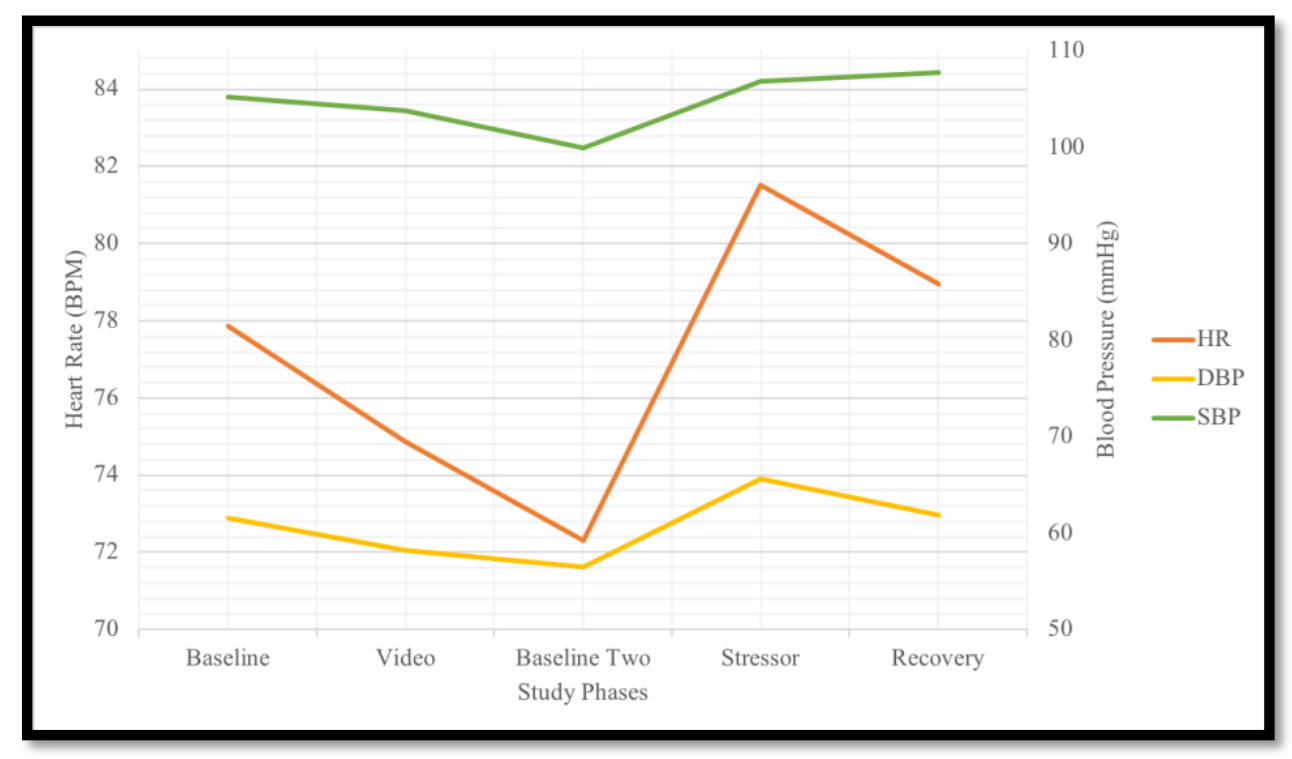

Figure 3. Changes in Sympathetic Nervous System measures (HR, SBP, and DBP) during study. 
Measure of Parasympathetic Nervous System (PNS). Due to possible channel interference and interruptions in recording mode, 22 participants' tonic skin conductance levels resulted in negative values (Biopac Systems Inc, 2018). As a result of this interference, only the eventrelated skin-conductance (ER-SCRs) measures were used for analyses, as these are unaffected by positive or negative values; ER-SCRs represent the number of times a skin-conductance response occurred in response to a specific stimulus (Braithwaite, Watson, Jones \& Rowe, 2013). EDA data were extracted for 68 participants across positive $(n=17)$, balanced $(n=16)$, negative $(n=$ 19), and control $(n=16)$ conditions, while three participants were EDA non-responsive ${ }^{2}$.

First, ER-SCRs associated with various phases (e.g., baseline, stressor, post-stressor recovery) of the experiment were identified using the Acqknowledge Software. The total number of events in each phase were then extracted along with the exact delta time (Braithwaite et al., 2013). Finally, event numbers were then divided by the change in time to standardize the number of ER-SCRs averaged per minute across various phases of the experiment and entered into SPSS for subsequent analyses.

As the number of ER-SCRs were standardized across various phases of the experiment, a multivariate analysis of variance was conducted to determine differences in the average number of ER-SCRs across phases of the experiment and between different reframing conditions. Box's test of equality of covariances matrices was not violated at the $p<.05$ level. Multivariate test detected a significant effect of reframing condition on ER-SCRs via Pillai's Trace $=.49, F=$ $2.40, d f=(15,186), p=.003, \eta^{2}=.16$. Follow-up tests of between-subjects effects examined the effect of condition across all five phases of the experiment (baseline, video, baseline two, stressor, and post-stressor recovery). No significant differences in ER-SCRs were detected across

\footnotetext{
${ }^{2}$ Typically, a small percentage of the population is classified as EDA non-responders (Farrow et al., 2013).
} 
reframing conditions during baseline, reframing video, and baseline two, $p=.141-.838$.

However, a significant effect of reframing condition was found during stressor, $F(3,64)=4.04$, $p=.011, \eta^{2}=.16$

Pairwise comparisons detected significant differences between positive and negative reframing conditions against the control condition, $p<.05$, and a trend towards significance for the balanced condition, $p=.055$, whereby the positive $(M=5.43, S D=1.48)$, negative $(M=$ $4.83, S D=1.58)$, and balanced $(M=5.55, S D=1.15)$ reframing conditions had significantly less ER-SCRs, on average, compared to the control condition $(M=6.59, S D=1.73)$. In addition, between-subjects effects also detected a significant effect of reframing condition on post-stressor recovery, $F(3,64)=4.32, p=.008, \eta^{2}=.17$. Pairwise comparisons detected significant differences between the positive and balanced reframing conditions when compared to negative and control conditions. Once again, on average, the positive $(M=2.29, S D=1.70)$ and balanced $(M=1.89, S D=1.73)$ reframing conditions experienced significantly fewer ER-SCRs during post-stressor recovery compared to those in the negative $(M=4.15, S D=3.68)$ and control $(M=$ 4.31, $S D=1.86$ ) conditions. Figure 4 below illustrates the average number of ER-SCRs experienced during stressor and post-stressor phases of study one. 

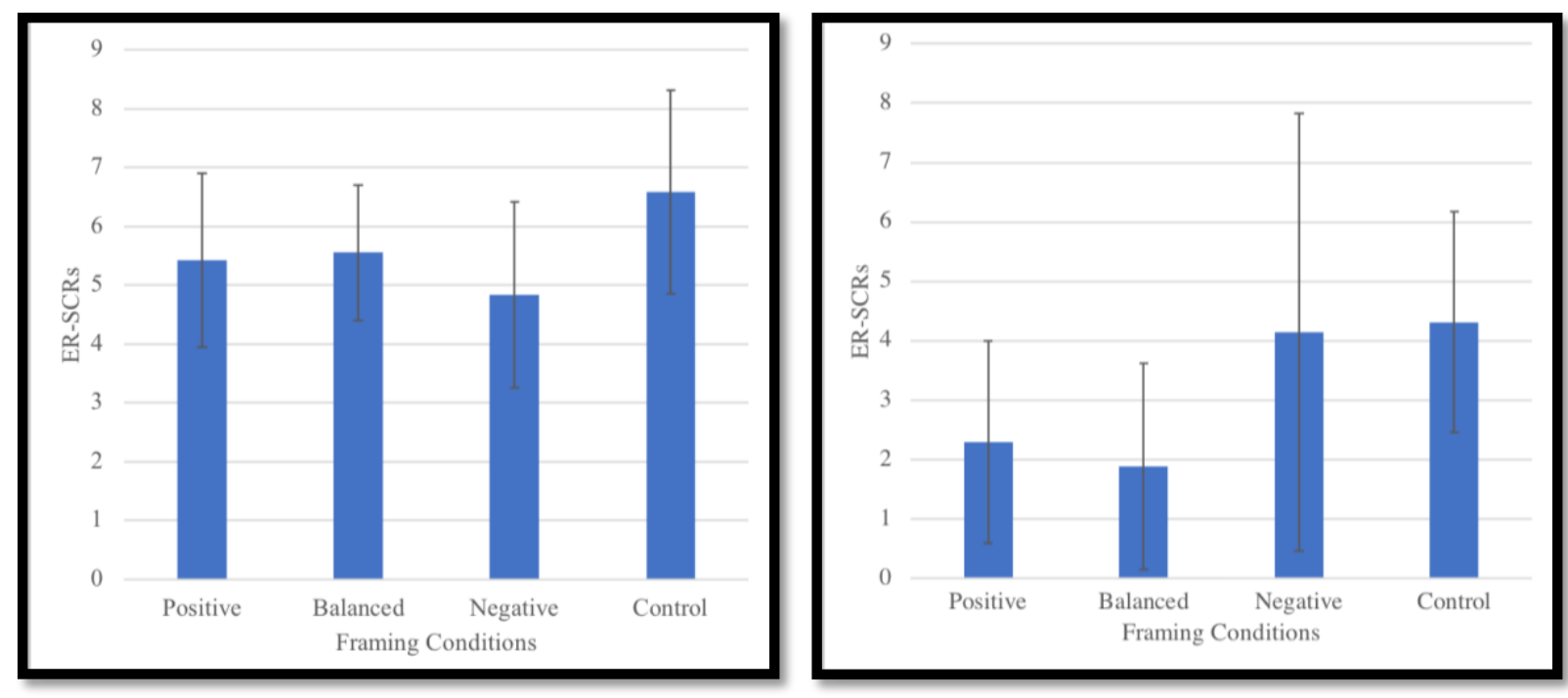

Figure 4. Event-Related Skin-Conductance Responses (ER-SCRs) during stressor (left) and poststressor (right) across reframing conditions.

\section{Exploratory Analyses}

Correlations Across Stress Reactivity Measures. Pearson's correlations were computed to determine the relationship across measures of stress perception and stress responsivity. Table 3 illustrates the relationship across various outcome measures of the current study. 
Table 3. Pearson's Correlations for outcome variables.

\begin{tabular}{|c|c|c|c|c|c|c|c|c|c|c|c|c|c|c|c|c|}
\hline & $\begin{array}{c}\text { VAS- } \\
\text { SP }\end{array}$ & $\begin{array}{c}\text { VAS- } \\
\text { S1 }\end{array}$ & $\begin{array}{c}\text { VAS- } \\
\text { C }\end{array}$ & $\begin{array}{c}\text { VAS- } \\
\text { S2 }\end{array}$ & $\begin{array}{l}\text { EDA- } \\
\text { Base }\end{array}$ & $\begin{array}{l}\text { EDA- } \\
\text { Stress }\end{array}$ & $\begin{array}{c}\text { EDA- } \\
\text { PS }\end{array}$ & $\begin{array}{l}\text { HR- } \\
\text { Base }\end{array}$ & $\begin{array}{c}\text { HR- } \\
\text { Stress }\end{array}$ & $\begin{array}{c}\text { HR- } \\
\text { PS. }\end{array}$ & $\begin{array}{l}\text { SBP- } \\
\text { Base }\end{array}$ & $\begin{array}{l}\text { SBP- } \\
\text { Stress }\end{array}$ & $\begin{array}{l}\text { SBP- } \\
\text { PS }\end{array}$ & $\begin{array}{l}\text { DBP- } \\
\text { Base }\end{array}$ & $\begin{array}{l}\text { DBP } \\
\text { Stress }\end{array}$ & $\begin{array}{c}\text { DBP- } \\
\text { PS }\end{array}$ \\
\hline VAS-SP & -- & & & & & & & & & & & & & & & \\
\hline VAS-S1 & $.62 * *$ & -- & & & & & & & & & & & & & & \\
\hline VAS-C & $\begin{array}{c}- \\
.57 * *\end{array}$ & ${ }^{-} .42^{-}$ & -- & & & & & & & & & & & & & \\
\hline VAS-S2 & $.61 * *$ & $.77 * *$ & $-.29 *$ & -- & & & & & & & & & & & & \\
\hline EDA-Base & -.01 & -.03 & .08 & .11 & -- & & & & & & & & & & & \\
\hline $\begin{array}{l}\text { EDA- } \\
\text { Stress }\end{array}$ & $.30 *$ & $.33 * *$ & -.12 & $.39 * *$ & $.37 * *$ & -- & & & & & & & & & & \\
\hline EDA-PS & -.09 & -.01 & .01 & -.03 & -.10 & .16 & -- & & & & & & & & & \\
\hline HR-Base & -.21 & -.20 & .19 & -.12 & .06 & -.12 & .09 & -- & & & & & & & & \\
\hline HR-Stress & -.04 & -.09 & -.05 & -.04 & -.01 & -.21 & .09 & $.62 * *$ & -- & & & & & & & \\
\hline HR-PS & -.06 & -.13 & -.09 & -.09 & .18 & -.12 & .09 & $.48 * *$ & $.78 * *$ & -- & & & & & & \\
\hline SBP-Base & -.19 & -.22 & .14 & -.15 & -.09 & -.22 & .13 & $.86 * *$ & $.53 * *$ & $.34 * *$ & -- & & & & & \\
\hline SBP-PS & -.05 & -.05 & -.15 & -.05 & .10 & -.03 & .08 & $.46 * *$ & $.65 * *$ & $.83 * *$ & $.48 * *$ & $.78 * *$ & -- & & & \\
\hline DBP-Base & -.11 & -.11 & .16 & -.01 & .18 & .18 & .06 & $.88 * *$ & $.51 * *$ & $.45^{* *}$ & $.58 * *$ & $.38 * *$ & $.36 * *$ & -- & & \\
\hline $\begin{array}{l}\text { DBP } \\
\text { Stress }\end{array}$ & .03 & -.04 & -.05 & .03 & -.01 & -.04 & .10 & $.50 * *$ & $.90 * *$ & $.69 * *$ & $.31 * *$ & $.54 * *$ & $.40 * *$ & $.50 * *$ & -- & \\
\hline DBP-PS & -.03 & -.16 & -.05 & -.06 & .15 & .11 & .10 & $.40 * *$ & $.73 * *$ & $.91 * *$ & .23 & $.44 * *$ & $.59 * *$ & $.43^{* *}$ & $.79 * *$ & -- \\
\hline
\end{tabular}

Note. VAS = visual analogue scale; $\mathrm{SP}=$ stress perception, $\mathrm{SR}=$ stress response; $\mathrm{C}=$ coping; $\mathrm{EDA}=$ electrodermal activity; $\mathrm{HR}=$ heart rate; $\mathrm{SBP}=$ systolic blood pressure; $\mathrm{DBP}=$ diastolic blood pressure; $\mathrm{PS}=$ post-stressor.

$* p<.05, * * p<.01$, two-tailed. 
Predictors of Self-Reported Stress. Linear multiple regression examined the extent to which various factors predicted self-reported stress post-stressor via VAS-Stress. Assumptions of regression were examined using collinearity statistics, where all the tolerance statistics were above the .2 cut-off, while the variation inflation factor (VIF) value did not exceed 10 (Field, 2009). Variables of interest were entered using a blocked, entry-format. Block one included baseline VAS-SP, VAS-C, VAS-S, and initial stress rating, while block two consisted of pre-test measures, and block three physiological measures of stress reactivity. Model summaries and change statistics are represented in Table 4 below.

Table 4. Model Summaries for Predictors of Self-Reported Stress.

\begin{tabular}{lccccc}
\hline & Adj. $\boldsymbol{R}^{\mathbf{2}}$ & $\boldsymbol{R}^{\mathbf{2}}$ Change & $\boldsymbol{F}$ Change & $\boldsymbol{d f}$ & $\begin{array}{c}\text { Sig. } \boldsymbol{F} \\
\text { Change }\end{array}$ \\
\hline Model 1 & .576 & .609 & 18.29 & 4,47 & $<.001$ \\
Model 2 & .576 & .034 & 1.02 & 4,43 & .407 \\
Model 3 & .665 & .206 & 1.57 & 20,23 & .150 \\
\hline
\end{tabular}

Of the three models, only model one significantly predicted self-reported stress levels, accounting for $57.6 \%$ of the total variance of the model, $F(4,47)=18.29, p<.001$. Within this model, only baseline perception of stress and baseline self-reported stress emerged as significant predictors. Individual beta values for predictors within model one are shown in Table 5 below. Table 5. Beta ( $\beta)$ Values for Predictors in Model One.

\begin{tabular}{lccc}
\multicolumn{1}{c}{ Variable } & $\boldsymbol{\beta}$ & $\boldsymbol{t}$ & Sig. \\
\hline (Constant) & & & \\
Stress Word Ratings & -.124 & -1.323 & .192 \\
VAS-Stress Perception & .341 & 2.820 & .007 \\
VAS-Stress & .607 & 5.347 & $<.001$ \\
VAS-Coping & .175 & 1.692 & .097 \\
\hline
\end{tabular}

Optional Follow-Up. At the end of study one, participants had the option to complete an online follow-up for additional course credit. Of the total of 77 respondents who successfully 
completed study one, only 27 chose to complete the optional follow-up. In the absence of any stressors, participants rated their current perceptions of stress, coping, and levels of stress.

A one-way chi-square analysis determined that more participants in the experimental reframing conditions completed the follow up (positive, $n=7$; balanced, $n=10$, negative, $n=8$ ) compared to control $(n=2), X^{2}(3, N=77)=6.74, p=.041$. Given the low numbers, multiple comparisons across groups were statistically underpowered. However, a one-way ANOVA on differences in VAS-Stress Perception across groups found a quadratic trend between groups that approached significance, $F(1,23)=4.04, p=.056$. On average, those in the positive reframing group rated their stress perceptions as more uncontrollable and threatening $(M=70.71, S D=$ 14.96) compared to the balanced reframing condition $(M=44.40, S D=32.32)$. No significant differences across groups were detected for self-perceived coping abilities at follow-up, $F(3,22)$ $=0.57, p=.641$.

\section{Discussion}

Study one examined the effects of different stress reframing interventions on stress responsivity, and demonstrated some support for the efficacy of a balanced stress reframing intervention in facilitating a more adaptive psychological and physiological stress response following a subsequent stressor. Findings in support of the hypothesized effects of baseline stress beliefs were observed across word association task and subsequent elevated arousal in systolic blood pressure. Findings in support of the hypothesized effects of balanced framing were observed across attenuated self-reported stress and fewer EDA ER-SCRs. Study one addressed limitations identified in previous research (e.g., lack of baseline measure of stress, lack of active control condition), and explored the effects of stress perception and reframing on responsivity to stress. In addition, study one explored the feasibility of assessing intervention effects through an 
online follow-up one week following the initial visit to examine the durability of reframing effects.

\section{Stress Perceptions on Responsivity to Stress}

The first hypothesis of a deficit-orientation of stress was confirmed by the current study findings. Consistent with previous research (Liu et al., 2017), the current study found that a majority of participants associated negatively-rated words with the word stress. Further, analyses of variance and covariance also revealed that individuals who hold more negative associations of stress initially also were observed to have heightened systolic blood pressure during recovery post-stressor, compared to individuals who held more neutral beliefs of stress. These differences persisted even after controlling for baseline differences in perceptions of stress (VAS-SP). These findings suggest that perceptions of stress may influence how individuals respond to subsequent stressors; the same stressor may evoke differential responsivity in individuals (Crum et al., 2013). Interestingly, stress beliefs did not significantly correlate with physiological outcomes, suggesting that how individuals see stress may have little relationship with how their bodies are capable of responding to stressors (Ekeberg, Kjeldsen, Greenwood, \& Enger, 1990).

Alternatively, it may be that individuals who tend to hold negative beliefs regarding stress have a history of heightened arousal in response to stress, which could contribute to their negative beliefs of stress in a feedback loop. In these instances, longitudinal designs taking into account life events and stress histories of individuals may be more appropriate to examine these relationships.

\section{Effects of Reframing on Stress Responsivity}

The second hypothesis on the overall efficacy of the balanced reframing condition in eliciting more adaptive stress responses was also partially confirmed via both subjective and 
objective indicators of stress responsivity. However, self-reported perceptions of stress as threatening or not, and self-perceived coping abilities, both measured via VAS, did not change as a result of reframing condition. This result suggests that reframing of stress responses does not affect how we see stress globally as threatening or not, nor affect our self-perceived coping abilities. Instead, results found that the stress responsivity to the stressor was affected by reframing condition via self-reported levels of stress and objective electro-dermal activity, suggesting that stress reframing reduces subsequent reactivity to stressors through mechanisms outside of individual coping efficacy.

On self-reported stress responsivity, the only difference observed between-groups was between the balanced reframing and the control group, whereby the control group reported a greater increase in self-reported stress following exposure to stressor compared to the balanced reframing group. These findings support the second hypothesis, as well as previous research, demonstrating that the balanced reframing condition is the most efficacious in eliciting adaptive stress responses (Liu et al., 2017). The balanced presentation of both positive and negative effects of stress likely helps participants to establish realistic expectations regarding stress, and thus facilitate an adaptive appraisal and response to stressors. The control group, on the other hand, was not prepared or equipped with knowledge regarding stress, thereby likely affecting their stress appraisal and response in a way that amplified their subjective report of how stressful they found the stressor to be.

Further, visual comparison of the degree of changes in subjective stress pre- and poststressor confirmed the hypothesized distinctions between different reframing groups. Specifically, differences suggest that the balanced reframing condition had the least amount of increase in subjective stress following stressor, followed by the negative reframing condition and 
the positive reframing condition. This may also be attributed to differences in the expectations set forth by the reframing conditions (Liu et al., 2017). The negative reframing condition had overly negative expectations regarding the effects of stress, and therefore participants were already prepared to be stressed. Once the stressor was presented, however, this group may have realized that their expectations of anticipated stress far exceeded the actual threat presented by the stressor, and thus they reported less subjective stress in comparison to the positive reframing group and control. In contrast, the positive reframing condition reported the highest stress following a stressor, second only to the control because their expectations set forth by the reframing video that stress was not threatening were violated once they were presented with an actual stressor. Thus, this group was ill-prepared to cope with a subsequent stressor in comparison to the negative and balanced reframing groups.

Finally, these findings also suggest that knowledge regarding stress may be efficacious regardless of content, compared to no knowledge of stress. Indeed, this was confirmed through a follow-up analysis, in which experimental reframing groups' levels of subjective stress were compared against the control group, that found a trend towards statistical significance with a moderate effect size. The experimental conditions all received messages about stress, and in a society preoccupied with stress, any information about stress may have been helpful. In that sense, the control group, having received information on sleep and not on stress, thus experienced the most drastic changes pre and post-stressor. It may be that any information on stress given prior to a stressor enabled participants to anticipate and adapt to the upcoming stressor, thereby reporting less subjective stress in comparison to a control condition.

On measures of physiology, several interesting observations can be made. First, there were no observed differences across sympathetic responsivity to stress via heart rate and blood 
pressure as a result of reframing condition. This indicates that all groups similarly responded to the stressor, regardless of reframing condition. Further, findings suggest that capacities to respond to stressors through the autonomic, sympathetic nervous system pathways are no different as a result of information presented on stressors. Instead, research has suggested that sympathetic nervous system pathways of response via cardiovascular measures are more indicative of the content and task-demand rather than a more distinct response as a result of any interventions (Seery, 2013). These findings do not support hypothesis two, nor were they consistent with previous research (Jamieson et al., 2013; Liu et al., 2017). While this may be attributed to slight changes in experimental design (discussed under limitations), it should be noted that the lack of cardiovascular group differences as a result of reframing is also supported by meta-analytic findings. Within the meta-analysis conducted across studies manipulating stress beliefs, little evidence was found to support their efficacy in eliciting robust effects across physiological parameters of stress, such as heart rate, blood pressure, and cortisol (Liu et al., 2019). Findings may suggest limited efficacy for cognitive-based interventions in their ability to influence physiological responses. Alternatively, it may be that cardiovascular responses to stressors may overshadow any potential variations as a result of reframing stress.

Measures of ER-SCRs revealed group differences consistent with hypothesized reframing effects. Specifically, event-related responses appeared to mirror the self-reported group differences observed via VAS, whereby the balanced group, on average, had the least number of event responses during post-stressor recovery, while the control group experienced the highest. Event-related skin-conductance responses represent activity of the parasympathetic nervous system, and thus can be seen as an effortful regulatory response, with high numbers of responses suggesting an increased effort to down-regulate one's own arousal (Benedek \& Kaernbach, 
2010; Undem, 2009). This is consistent with the BioPsychoSocial Model of Challenge and Threat (BPS), whereby emphasis is placed on the appraisal evaluation of a novel stressor, with individuals either responding through a threat-response (low resource, high demand), or through a challenge pathway (high resource, low demand) (Blascovich, Mendes, Tomaka, Salomon \& Seery, 2003; Seery, 2013). Based on the expectations an individual may hold about stress, he or she may exert more or less efforts in their attempts to regulate the stress response and subsequent arousal. Following this analogy, participants in the balanced reframing condition with realistic expectations of stress outcomes may feel less need to regulate their arousal as a result of the stressor compared to those in the other reframing conditions and the control groups.

Differences between heart rate and blood pressure of the sympathetic nervous system arousal, and EDA of the parasympathetic nervous system, thus may represent distinctions in effortful regulation of stress versus individual capacity to respond to stressors. The reframing intervention, in actuality, may do little to influence an individual's capacity to react to stress via SNS arousal, which is an autonomic and constantly active system of the body that responds to unconscious actions (Brodal, 2004). However, the mechanism of change whereby reframing may influence stress responsivity may entirely be subjective appraisal and effortful regulation of subsequent arousal, as found in both self-reported response to stress and EDA event-related responses during recovery following stressor. These actions are regulatory and may be more representative of the parasympathetic nervous system, which compliments and regulates SNS arousal (Brodal, 2004). Indeed, the BPS model itself emphasizes the distinction between responses to stressors in a challenge versus threat context as hinging on the need to regulate one's response/arousal (Blascovich et al., 2013; Seery, 2013). 


\section{Challenges and Limitations}

The current study and its findings should also be considered in light of some challenges and limitations. First, the subjective measures of stress and the SNS measures of stress were not correlated, such that physiological arousal levels via heart rate and blood pressure did not reflect self-reported stress levels. Although this was inconsistent with some past research demonstrating a positive correlation between sympathetic nervous system measures and self-reported stress (Liu et al., 2017), the lack of relationship between subjective and objective stress measures has also occurred in some other studies (e.g., Ekeberg et al., 1990). A careful examination of study protocol suggests that differences in correlations between subjective and sympathetic nervous system measures of stress may be an indirect result of subtle changes in experimental design; specifically, one previous study that did find correlations between objective and subjective stress measures (Liu et al., 2017) had participants sit opposite of the CNAP machine, such that participants could observe their own HR and BP rising and falling during the course of experiment. This may have contributed to indirect biofeedback in which physiological arousal was attenuated and regulated to reflect subjective feelings of stress.

Another challenge of the current study is the large attrition rate observed for the followup study. Approximately $65 \%$ of participants opted not to complete the online follow-up. This may be attributed to the nature of the participant recruitment set-up. The follow-up was an online optional study not linked to the first part of the study, and worth only half a credit, which may not have been enough compensation for participants to complete. Alternatively, it could be that by the time of the follow-up, many students had already earned their maximum research credit for the course (from other studies) and thus not could not sign up for the optional follow-up (participants are limited to obtaining three credits in the research participation system). However, 
despite the high attrition, the optional follow-up results provide preliminary evidence in support of the durability of stress reframing on stress perception, as perceptions of stress appeared to have improved for the positive reframing conditions compared to other conditions.

Finally, the pre-test measures did not appear to influence stress outcomes differentially as a result of their experimental conditions, suggesting that these variables accounted for little variability, if any, in determining how participants responded to the stressor. Although there was a small mediating effect of interoceptive awareness, such that individuals high in awareness were less stressed via SBP, the effects did not differ as a result of framing, nor did these effects interact with any experimental groupings to influence differential responsivity across groups. Future studies could thus consider whether these measures are necessary in the study design.

\section{Study One Conclusions}

Study one results partially confirmed previously-established hypotheses, and highlighted that participants' stress beliefs indeed influence later responsivity to stress. Findings support that a balanced reframing intervention is the most efficacious in attenuating stress responsivity through both subjective report of stress, and effortful regulation of physiological arousal. These findings are consistent with past research for the most part, suggesting that balanced reframing of stress is the most efficacious and helpful in coping with stress (Liu et al., 2017).

\section{STUDY TWO}

\section{Experimental Design and Study Objective}

Study two builds on the findings from study one. Having confirmed the balanced reframing to be the most efficacious in eliciting adaptive stress responses compared to other reframing conditions, study two continued using the balanced reframing condition, while examining the potential for any additive effect of the introduction of priming VIA strengths on 
acute stress responses. Specifically, study two explored the effects of priming individuals to believe in a regular strength versus the relevance of resilience-based strength, and used a followup test period to examine the durability of priming and the effect of reframing on stress beliefs and responsivity. Study two also utilized a Mixed-ANOVA design, with both reframing condition and priming groups as between-subject factors, and time as the within-subject factor.

\section{Study Hypotheses}

Hypothesis 4: Taking account the research evidence indicating that self-appraisal of resources and coping efficacy enhance stress and coping, it is hypothesized that those primed to believe that their strengths are resilience-based will report a smaller increase in psychological stress via changes in VAS-Stress in response to stressors, compared to those that have been primed to believe their individual strengths do not relate to stress and resilience.

Hypothesis 5: In addition to priming individuals to respond more adaptively to stress (i.e., faster return to baseline), it is hypothesized that differences in stress responses across experimental conditions may occur:

Hypothesis 5a - resilience-based strength priming and balanced reframing will have combined interactive effects via less psychological stress compared to other conditions Hypothesis $5 \mathrm{~b}$ - resilience-based strength priming and balanced reframing will also result in less physiological arousal via PNS activation compared to other conditions Hypothesis $5 \mathrm{c}$ - Further, the combined interaction will persist over a period of time, and will be demonstrated via lowered baseline values at follow-up.

[Exploratory] Hypothesis 6: Additional analyses will further explore relationships across stress parameters, and their relationship to overall stress responsivity. 


\section{Methodology}

\section{Participants}

Eligibility criteria closely followed those listed in study one, with participants consisting of healthy adults over the age of 17 recruited through an Online Psychology Pool (SONA). Those who completed study one were not eligible to participate in study two to avoid any potential habituation and/or ceiling effects due to prior exposures to both the experimental manipulation (framing videos) and/or the laboratory stressor (TSST). A total of 123 participants were randomized into one of two reframing conditions, balanced $(n=63)$ and control $(n=60)$. They were also randomized to receive either non-resilient/control strength $(n=61)$, or resilient strength $(n=62)$ priming.

Participants were mostly females $(80 \%)$, with a mean age of $21(S D=4.96)$. Participants were diverse in their ethnic makeup, and over half (53\%) were in their first year of postsecondary education. A total of 84 participants (68.3\%) returned to complete the optional followup. Table 6 below detail gender and experimental groupings of participants who returned for follow-up.

Table 6. Study two participant demographics for visit two.

\begin{tabular}{|c|c|c|}
\hline & $\mathbf{N}$ & $\%$ \\
\hline \multicolumn{3}{|l|}{ Sex } \\
\hline Male & 19 & $23 \%$ \\
\hline Female & 65 & $77 \%$ \\
\hline \multicolumn{3}{|l|}{ Group Conditions } \\
\hline Control, Resilient & 22 & $26 \%$ \\
\hline Control, Non-Resilient & 19 & $22 \%$ \\
\hline Balanced, Resilient & 24 & $29 \%$ \\
\hline Balanced, Non-Resilient & 19 & $23 \%$ \\
\hline
\end{tabular}




\section{Experimental Manipulations}

Reframing of Stress. Participants receive one of two reframing conditions (balanced or control). The reframing videos were identical to those used in study one. Scripts of the reframing videos are found in Appendix I, A-D.

Priming of Strengths. The VIA Character Strengths is a psychometric assessment tool comprised of an inventory of character strengths in Positive Psychology that help individuals address life challenges (Peterson \& Seligman, 2004). The VIA consists of 24 strengths that are universally identified across cultural, gender, or age variations, and are organized under six domains: wisdom, courage, humanity, justice, temperance, and transcendence (Peterson \& Seligman, 2004). These character strengths represent distinctive and meaningful characteristics of different individuals that are linked to positive qualities and traits within the individual, and contribute to positive outcomes in life (Peterson \& Seligman, 2004).

Participants were instructed that a portion of the experiment will be dedicated to receiving feedback on their top strengths. They were then told to fill out the VIA Global Assessment of Character Strengths 24 and Signature Strengths Surveys characterizing their use of different strengths (VIA Institute on Character, 2018a \& b). Following, the experimenter hand-scored the above-noted questionnaires, and regardless of outcomes, provided all participants the same feedback indicating their top strength was temperance (i.e., strengths of moderation, regulation, and restraint against excess; Peterson \& Seligman, 2004). The priming feedback was randomized into two forms of deliveries: (1) resilient feedback, and (2) nonresilient/control feedback. The participants in the resilient feedback group were told their top strength was temperance and that it related to directly to stress and resilience. Participants in the second group (non-resilient/control feedback) were told their top strength was temperance, 
without any additional feedback. A detailed list of the VIA classifications is found in Appendix III.

Methods of Stress Induction. Two stressors were used in study two. To keep the stressinduction methodology consistent with study one, study two also used the modified TSST following the protocol outlined in study one. Research has documented both response habituation in the form of reduced responsivity, and response sensitization in the form of exhaustion, following repeated exposures to the TSST (Kudielka, von Kanel, Preckel, Zgraggen, Mischler, \& Fischer, 2006). Therefore, a second stressor was used in a counterbalanced experimental design to safeguard against these potential experimental effects.

The second stressor used was the $N$-Back Task (Kirchner, 1958). This task is a computerized challenge that engages participants' working memory capacity through sequential matching of various letters that appear on the computer screen to letters that have appeared previously. Participants were asked to identify $n$-back in this matching paradigm, including recalling letters one turn back (1-back), two turns back (2-back), and so forth. Participants were asked to complete both a 1-back trial to familiarize themselves with the task, and then graduated to a 3-back task of increasing difficulty. The N-Back task has been used as a stressor in laboratory conditions (Schoofs, Preuss, \& Wolf, 2008). Importantly, this computerized task does not use social evaluation to provoke stress; rather, performance is monitored by the computer, not the experimenter. A sample design of N-Back is provided in Appendix II-B.

\section{Measures}

Pre-Test Measures. The self-reported measures used for study two were identical to those used in study one, with one additional self-report measure included. Measures used from study one included: 


\section{The demographics questionnaire,}

2. the Perceived Stress Scale (PSS),

3. the Multidimensional Assessment of Interoceptive Awareness (MAIA),

4. the Coping and Appraisal, and Coping Behavior (CACB),

5. and the Spheres of Control Scale (SCS).

A novel addition to study two was the use of the Schutte Self-Report Emotional Intelligence Test (SSEIT). The SSEIT is a 33-item self-report questionnaire assessing individual global emotional intelligence across four subscales: emotion perception, utilizing emotions, managing selfrelevant emotions, and managing other's emotions (Schutte, Malouff, Hall, Haggerty, Cooper, Golden, \& Dornheim, 1998). The population average on the SSEIT is a score of 133 across studies (Schutte et al., 2001) ${ }^{3}$. The SSEIT is ranked on a Likert-type scale of 1-5. Emotional intelligence has been shown to influence both receptivity to cognitive emotional regulation instructions and reactivity to stress (Brackett, Rivers \& Salovey, 2011; Singh \& Sharma, 2012). This measure was used to assess EI in the sampled participants, and modelled as a covariate in analyses examining participants' performance and stress responsivity. Questionnaires used for both studies are found under Appendix IV. Table 7 below illustrates questionnaire means, standard deviations, and Cronbach alphas for the sampled population in study two.

\footnotetext{
${ }^{3}$ Factor scoring for the SSEIT varies, with some studies reporting a four-factor subscale while others have documented the presence of up to six factors (Jonker \& Vosloo, 2008).
} 
Table 7. Study two questionnaire means, standard deviations, and Cronbach's alphas..

\begin{tabular}{lcccc}
\hline & $\mathrm{N}$ & $\begin{array}{c}\text { Mean } \\
\text { (scales totaled) }\end{array}$ & $\begin{array}{c}\text { Std. } \\
\text { Deviation }\end{array}$ & $\begin{array}{c}\text { Cronbach's } \\
\text { Alpha }\end{array}$ \\
\hline PSS & 115 & 23.76 & 5.31 & .65 \\
MAIA & 117 & 117.45 & 22.35 & .89 \\
CACB & 120 & 50.24 & 8.58 & .66 \\
SCS & 120 & 83.51 & 9.22 & .50 \\
SSEIT & 115 & 120.74 & 11.13 & .81 \\
\hline
\end{tabular}

Note. PSS = Perceived Stress Scale; MAIA = Multidimensional Assessment of Interoceptive Awareness; $\mathrm{CACB}=$ Coping and Appraisal and Coping Behaviour; SCS $=$ Spheres of Control Scale; and SSEIT = Schutte Self-Report Emotional Intelligence Test.

\section{Outcome Measures.}

Subjective Measures of Stress and Performance. Visual Analogue Scales (VAS-Stress Perception [VAS-SP], VAS-Coping [VAS-C], and VAS - Stress Response [VAS-S]), used in study one, were also used in the current study. The VAS-SP and VAS-C were given to participants a total of four times throughout the first visit; at the start of the first visit, immediately following the reframing video, immediately following the priming feedback, and immediately following the stressor. VAS-S was given to participants twice during the first visit, at the beginning and immediately following the stressor. Each VAS scale was also distributed two times during the follow-up visit, at the beginning of visit two, and immediately following the second stressor. All subjective measures of stress and performance are found in Appendix V.

Objective Measures of Stress and Performance. Heart Rate (HR) and Blood Pressure (BP [both DBP and SBP]) were used to measure sympathetic activity during the experiment via the Biopac CNAP system. Electrodermal activity (EDA) was collected using the Biopac Electrodermal Activity Amplifier (EDA100C). Both sets of outputs were exported onto the computer, and organized using the AcqKnowledge (ACK100W) software, version 4.2.

Stressor Performance was used as a supplementary, objective indicator of stress response and performance within the mental arithmetic portion of the TSST. Measured aspects included 
the highest number achieved in the mental arithmetic task, as well as the overall accuracy of the subtraction task. These measures were independently coded to represent an individual's objective scores (Kirschbaum \& Hellhammer, 2000).

\section{Procedure}

Participants were invited for two laboratory visits to the Psychophysiology Lab at Ryerson University for a total of two course credits for the completion of the entire study. During the first visit, totalling 90-minutes, participants were first briefed on the study and then provided written consent. Following, participants were connected to the Biopac system, which included the CNAP system, and the EDA100C system. During calibration, participants completed a set of baseline questionnaires (PSS, MAIA, CACB, SCS, and SSEIT).

Following, participants were randomized to view a video about stress (see Reframing of Stress under Experimental Manipulations). Following this video, participants again responded to questions via VAS. After the second set of VAS questions, participants were provided their strength assessment (see Priming of Strengths under Experimental Manipulations), and completed the VAS questions for the third time.

Thereafter, participants underwent, in a counterbalanced order, an acute stress induction (either the TSST or the N-Back - explained under Methods of Stress Induction, Experimental Manipulations), and responded again to the set of VAS questions. Outcome measures included both subjective and objective indicators of the stress response, and are outlined under the Outcome Measures subsection. Following the questionnaires, participants were thanked for completing the study, reminded of the follow-up, and debriefed.

In one to two weeks' time, participants returned to complete the follow-up at the Psychophysiology lab. The follow-up consisted of another 30-minute visit, for which participants 
received additional course credit $(0.5$ credit $)$ for completion. The structure for the follow-up visit was similar to the initial visit. Participants were first briefed and completed a series of questionnaires. Following, participants underwent a secondary stressor (TSST or N-Back, counterbalanced), and answered post-test VAS questions. Participants did not receive any additional feedback this time. Immediately following, participants were thanked for completing all parts of the study, and debriefed in full with details regarding partial deceptions used on both the stressor task (no camera present), and the identification of temperance as top strength (not actually based on individual scores). Study protocol for both visits are detailed via Figure 5 .

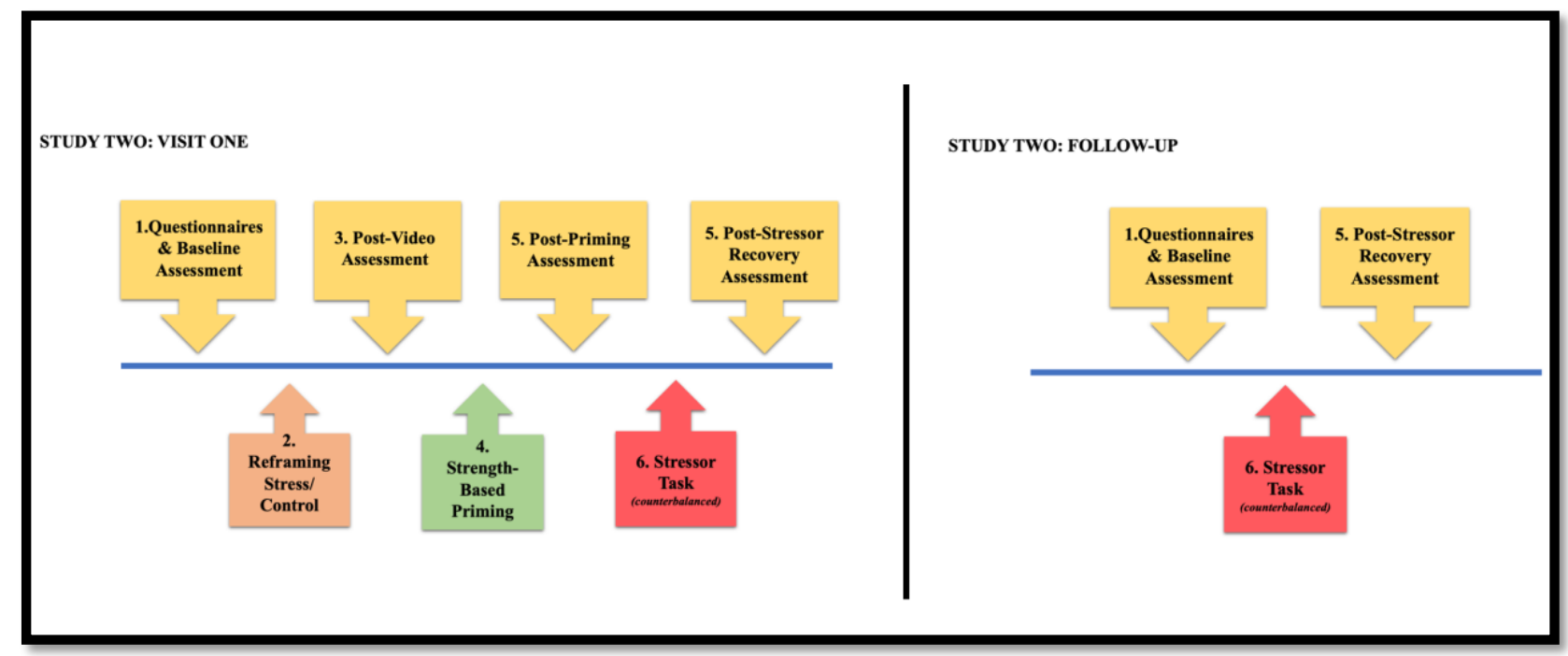

Figure 5. Procedure for study two across both visits.

\section{Analyses}

A post hoc power analysis using G*Power for a MANOVA (special effects and interactions design) with an alpha of .05 found sufficient power of 0.99 to detect small to medium effects of $\mathrm{d}=.25$ (Cohen \& Williamson, 1988), as previously found in similar research (Liu et al., 2017). All analyses were conducted using Statistical Package for Social Sciences (SPSS, version 25). Missing data on pre-test measures (ranging from $0.8 \%$ to $6.5 \%$ ) were filled using the multiple imputation method (Enders, 2017). Biopac machine errors and calibration 
problems resulted in 6 datasets missing SNS data at visit one, and EDA non-responders resulted in 10 datasets unusable at visit one. Structural equation modelling (SEM) was conducted using the Lavaan package for R Studio.

Testing Hypothesis Four. To test the effects of priming personal strengths, actual responses on the VIA were compared for changes across session one and two. Further, a Repeated-measures ANOVA examined changes in participants' VAS scores over time. To examine the complex interactions of priming on outcomes, similar Mixed-ANOVAs were used, with priming as a between-groups variable, and time as a within-participant variable.

Testing Hypothesis Five. To test for interactions of both reframing and priming, multiple two by two (2x2) Mixed-ANOVAs used both reframing and priming as between-groups factors, and time as within-group factors to examine their effects on various outcome measures over time. In a Mixed-ANOVA, both reframing and priming conditions were examined to test the efficacy and durability of experimental manipulations.

Testing Exploratory Hypothesis Six. Additional exploratory analyses examined relationships across variables via Spearman's correlation analysis and exploratory SEM.

\section{Results}

\section{Randomization Check}

A multivariate analysis of variance examined the success of experimental randomization. Pre-test measures were entered as outcome variables, and experimental groupings were entered as dependent variables. Results of the overall MANOVA were not significant for any pre-test measures $(p>.05)$. Analyses thus did not control for pre-test measures. Analyses for pre-test measures in study two are presented in Table 8 below. 
Table 8. Covariate Analyses for Pre-Test Measures.

\begin{tabular}{lcccc}
\hline & $\boldsymbol{d} \boldsymbol{f}$ & $\boldsymbol{F}$ & Sig. & $\boldsymbol{\eta}^{2}$ \\
\hline PSS & 3,119 & 0.46 & .714 & .01 \\
MAIA & 3,119 & 1.89 & .134 & .05 \\
CACB & 3,119 & 0.47 & .707 & .01 \\
SCS & 3,119 & 0.39 & .763 & .01 \\
SSEIT & 3,119 & 0.13 & .941 & $<.01$ \\
\hline
\end{tabular}

Note. PSS $=$ Perceived Stress Scale; MAIA = Multidimensional Assessment of Interoceptive Awareness; $\mathrm{CACB}=$ Coping and Appraisal and Coping Behaviour; $\mathrm{SCS}=$ Spheres of Control Scale; and SSEIT = Schutte Self-Report Emotional Intelligence Test.

\section{Strengths Priming Manipulation Check}

Pearson's Chi-Square analyses examined the ratio of the observed versus expected counts for participants who experienced changes in their self-reported strengths across the two laboratory visits. Tests revealed that the frequency distribution of observed versus expected changes in self-reported character strengths was not significantly different as a result of the strength-based priming, $X^{2}(1, N=83)=.151, p=.697$, Cramer's $V=.04$.

An examination of frequency distributions across the framing groups found that the balanced and control groups significantly differed in the reported changes in strengths across two laboratory visits, $X^{2}(1, N=83)=10.13, p=.001$, Cramer's $V=.35$. A higher proportion of individuals in the balanced framing condition $(n=12)$ experienced changes in their character strengths compared to the expected frequency $(n=7)$, while a lower proportion of individuals in the control condition $(n=1)$ experienced changes in their strengths compared to the expected frequency $(n=6)$. Figure 6 below illustrate the frequency of changes across framing groups. 


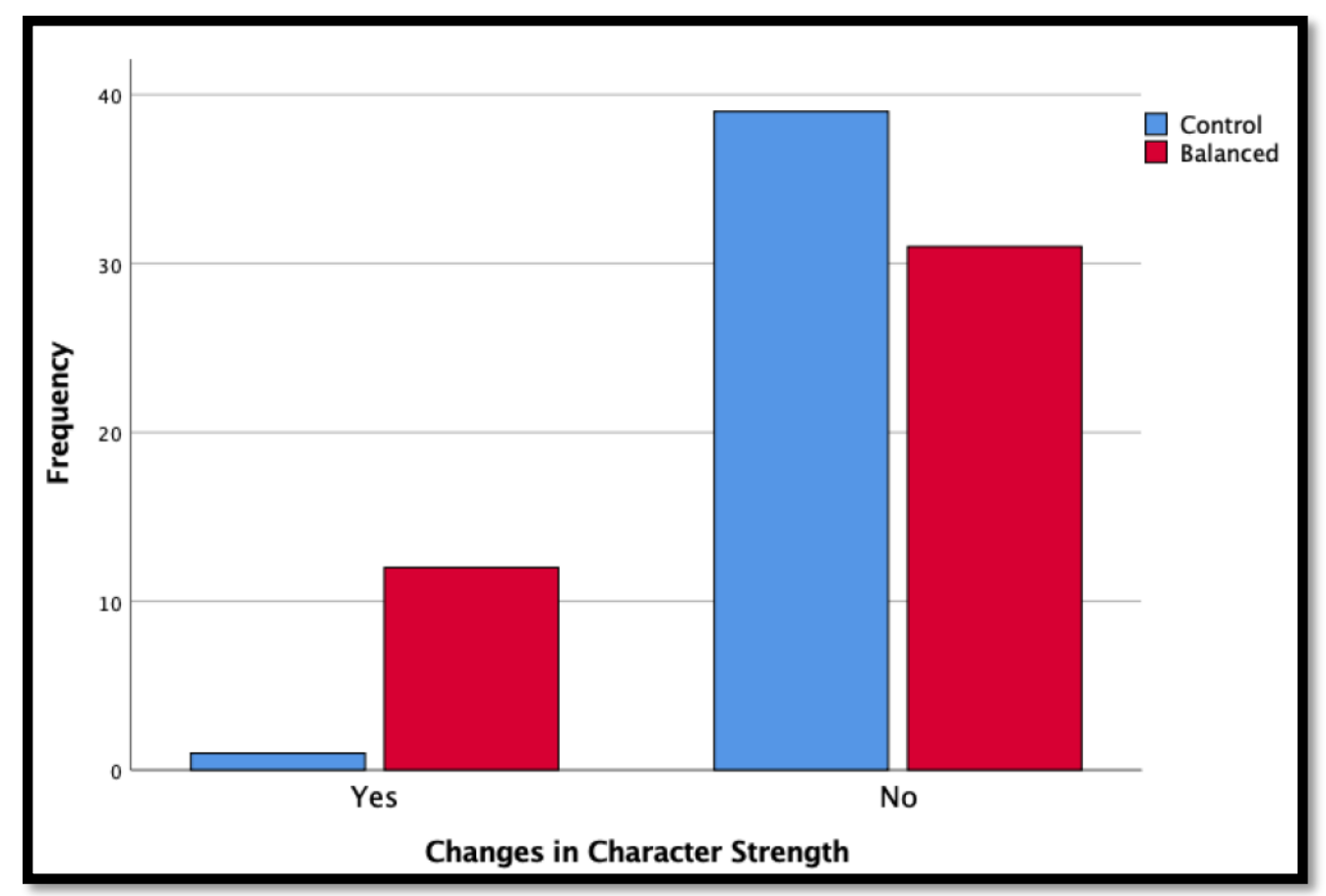

Figure 6. Changes in reported strength across framing conditions.

\section{Effects of Strengths Priming on Subjective Stress Measures}

To examine the effects of priming on subjective stress measures, two mixed-ANOVAs with time as the within-subjects factor and priming manipulation as the between-groups variable were conducted. The first test examined the effect of priming on VAS-SP and VAS-C using all four time points (baseline, post-video, post-priming, and post-stressor). The second test examined the effects of priming on VAS-S between baseline and post-stressor.

The examination of VAS-Stress Perception and VAS-Coping both violated Mauchly's Test of Sphericity, $\chi^{2}(5)=22.81, p<.001(\mathrm{VAS}-\mathrm{SP})$, and $\chi^{2}(9)=49.16, p<.001(\mathrm{VAS}-\mathrm{C})$. Degrees of freedom were adjusted using Greenhouse-Geisser estimates ( $\varepsilon=0.904$ for VAS-SP; $\varepsilon$ $=0.799$ for VAS-C). Univariate tests found a significant effect of time for VAS-SP, $F(2.71$, $309.17)=11.87, p<.001, \eta^{2}=.09$. Within-subjects contrasts confirmed that relative to baseline, VAS-SP was lower following the video, $F(1,114)=16.65, p<.001, \eta^{2}=.13$; following priming, 
$F(1,114)=25.53, p<.001, \eta^{2}=.18$; and following stressor, $F(1,114)=19.86, p<.001, \eta^{2}=$

.15. There were no observed effects of experimental priming over time on measures of VAS-SP, $F(2.71,309.17)=0.42, p=.716, \eta^{2}<.01$.

Similarly, univariate tests found a significant effect of time for VAS-C, $F(2.71,309.17)=$ $3.52, p=.023, \eta^{2}=.03$. Within-subjects contrasts found only a significant increase in selfperceived coping immediately following priming in relation to baseline values, $F(1,114)=8.61$, $p=.004, \eta^{2}=.07$. There were no observed time-by-priming interactions, $F(2.71,309.17)=1.23$, $p=.298, \eta^{2}=.01$

The examination of VAS-S found no significant effect of time, $F(1,112)=2.25, p=.136$, $\eta^{2}=.02$. Overall, self-reported levels of stress did not significantly differ at baseline $(M=45.74$, $S D=25.99)$ compared to post-stressor $(M=48.68, S D=24.86)$. Further, there were no observed time-by-priming interactions, $F(1,112)=0.69, p=.408, \eta^{2}<.01$.

\section{Interactive Effects of Stress Framing and Strengths Priming on Subjective Stress}

\section{Outcomes}

To examine the interactive effects of reframing and priming on self-reported stress, a Mixed-ANOVA was conducted with baseline and post-stressor times as the within-subjects factor, reframing and priming as the between-subjects factor, and VAS-SP, VAS-C, and VAS-S as the outcome measures.

Univariate tests found a changes in VAS-SP over time, $F(1,107)=17.73, p<.001, \eta^{2}=$ .142 , and a significant time-by-framing interaction on VAS-SP, $F(1,107)=5.16, p=.025, \eta^{2}=$ .05. On average, participants' perceptions of stress as threatening or bothersome decreased from baseline $(M=60.39, S D=20.72)$ to post-stressor $(M=54.27, S D=21.28)$. Further, the decrease from baseline to post-stressor was larger within the balanced framing condition (mean difference 
$=-9.241$ ), compared to the control condition (mean difference $=-2.76$ ). No interactions were observed in time-by-priming effects, $F(1,107)=0.45, p=.504, \eta^{2}<.01$. However, tests of between-subjects effects detected a significant framing-by-priming interaction on VAS-SP, $F(1$, $107)=4.16, p=.044, \eta^{2}=.04$. Of the four groups, participants who received the balanced framing with resilience priming experienced the largest reduction in perception of stress as threatening (mean difference $=-11.25$ ) compared to the balanced framing with non-resilient priming $($ mean difference $=-7.25)$, control framing with resilient priming $($ mean difference $=$ -2.67), and control framing with non-resilient priming (mean difference $=-2.86$ ).

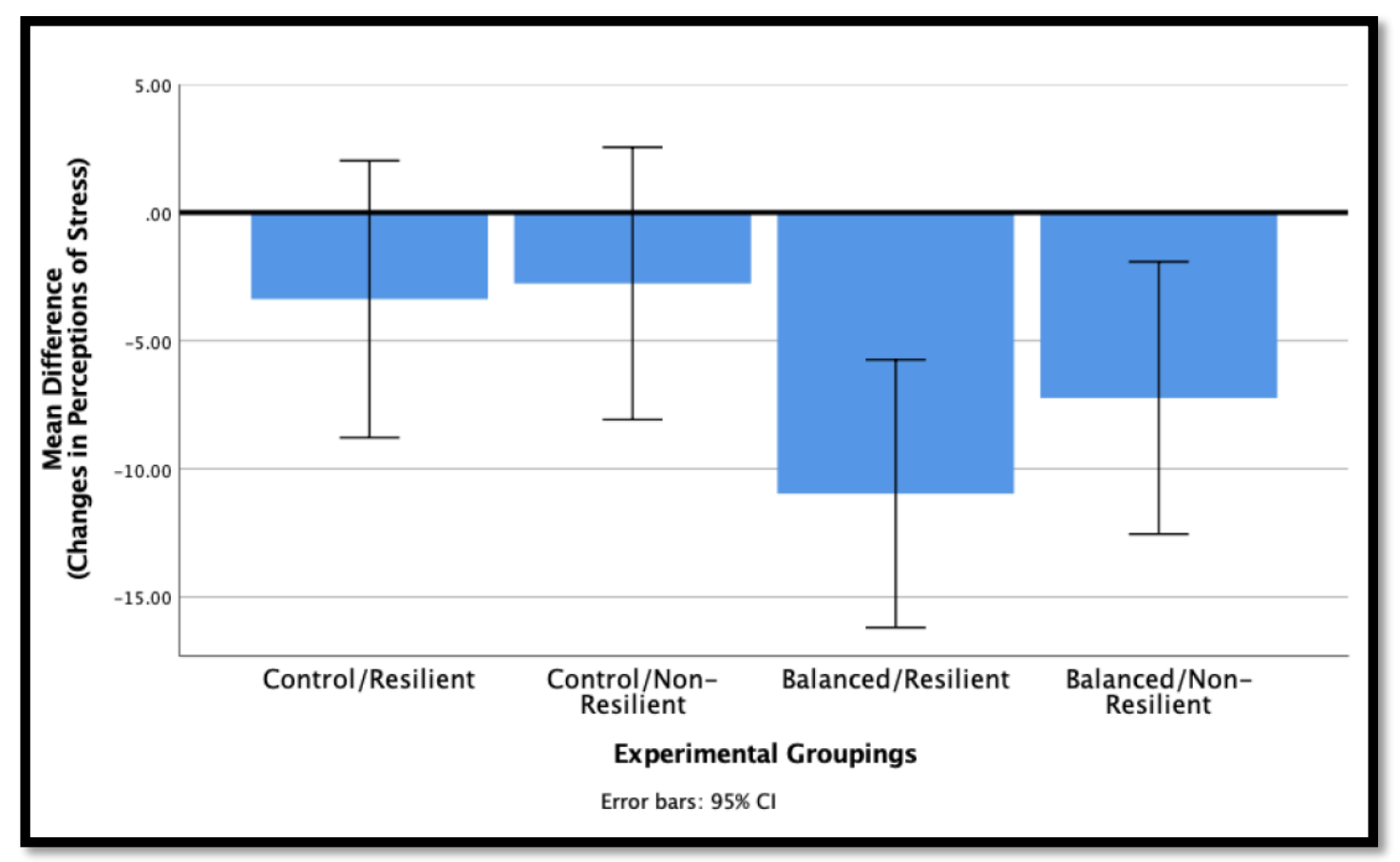

Figure 7. Changes in self-reported stress perception (VAS-SP) across experimental conditions.

On measures of self-perceived coping via VAS-C, no significant effects were detected for time, $F(1,107)=1.01, p=.316, \eta^{2}=.01$; time-by-framing, $F(1,107)=0.229, p=0.63, \eta^{2}<.01$; time-by-priming, $F(1,107)=0.51, p=.478, \eta^{2}<.01$, or framing-by-priming interactions, $F(1$, $107)=2.05, p=.155, \eta^{2}=.02$. 
On measures of self-reported stress via VAS-S, univariate tests did not detect a significant effect of time, $F(1,107)=1.98, p=.162, \eta^{2}=.02$, time-by-framing, $F(1,107)=2.51$, $p=.116, \eta^{2}=.02$, time-by-priming, $F(1,107)=0.49, p=.487, \eta^{2}<.01$, or between-subjects interactions, $F(1,107)=2.75, p=.100, \eta^{2}=.03$. However, between-subjects effects detected a significant group effect of framing, $F(1,107)=5.77, p=.018, \eta^{2}=.05$. While the control framing group reported an increase in VAS-S from baseline to post-stressor $($ mean difference $=$ 6.07), the balanced framing group reported almost no change (mean difference $=-0.36$ ). Figure 8 below illustrates group differences in framing conditions in VAS-S.

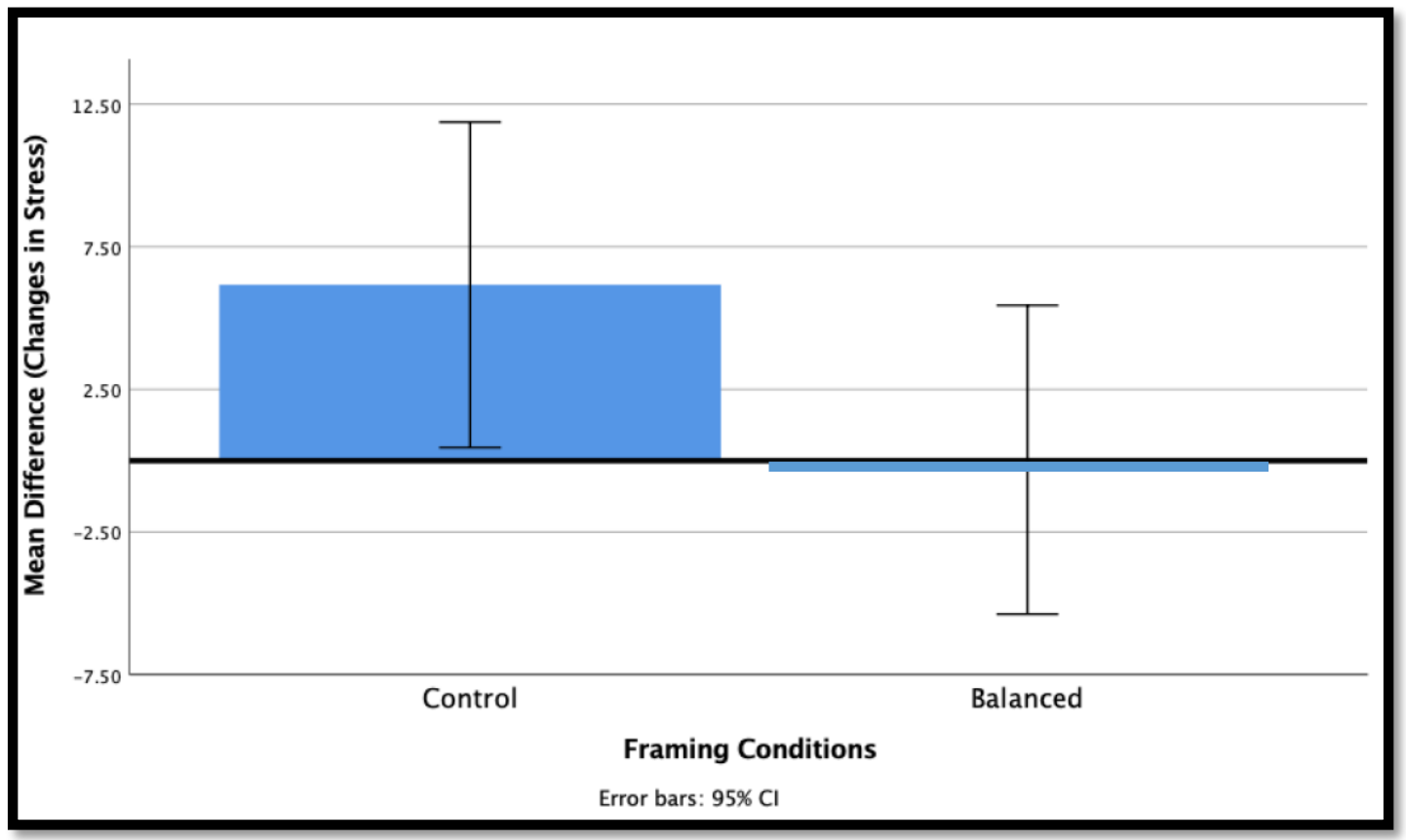

Figure 8. Changes in self-reported stress (VAS-S) across framing conditions.

\section{Interactive Effects of Stress Framing and Strengths Priming on Objective Stress Outcomes} Measures of SNS. Biopac calibration errors resulted in a total of 117 participants with complete SNS data across experimental conditions. Multivariate analysis of variance examined both within- and between-group differences in HR, SBP, and DBP across experimental groupings. Mauchly's test of sphericity was violated for all three parameters: heart rate $\left(\chi^{2}(14)=\right.$ 
209.247, $p<.001)$, systolic blood pressure $\left(\chi^{2}(14)=227.201, p<.001\right)$, and diastolic blood pressure $\left(\chi^{2}(14)=205.550, p<.001\right)$. Degrees of freedom were thus adjusted using GreenhouseGeisser estimates ( $\varepsilon=0.603$ for heart rate; $\varepsilon=0.567$ for systolic blood pressure; $\varepsilon=0.643$ for diastolic blood pressure).

Univariate tests using the Greenhouse-Geisser estimates found a significant effect of time on HR, $F(3.02,340.92)=10.33, p<.001, \eta^{2}=.08$, and DBP, $F(3.22,340.92)=10.09, p<.001$, $\eta^{2}=.08$. Tests of within-subjects contrasts found that both HR and DBP significantly increased during stressor period compared to baseline ( $p<.001, \eta^{2}=.15$ for both). Finally, tests of between-subjects effects detected a significant effect of framing on SBP, $F(1,113)=7.42, p=$ $.007, \eta^{2}=.06$. No significant effects were observed across other stress parameters (HR and DBP, $p>.05)$, or for the effects for priming and the framing-by-priming interaction, $\left(p=.185-.983, \eta^{2}\right.$ $<.01-.02)$. Parameter estimates exploring the changes in SBP between the control and balanced framing groups found that during the video period, SBP in the balanced framing groups decreased in relation to baseline, whereas SBP in the control condition increased, $t=2.543, S E=$ $3.97, p=.012, \eta^{2}=.05,(95 \% \mathrm{CI}=2.23,17.98)$. Figure 9 below illustrates changes in SBP during the course of study two, visit one. 


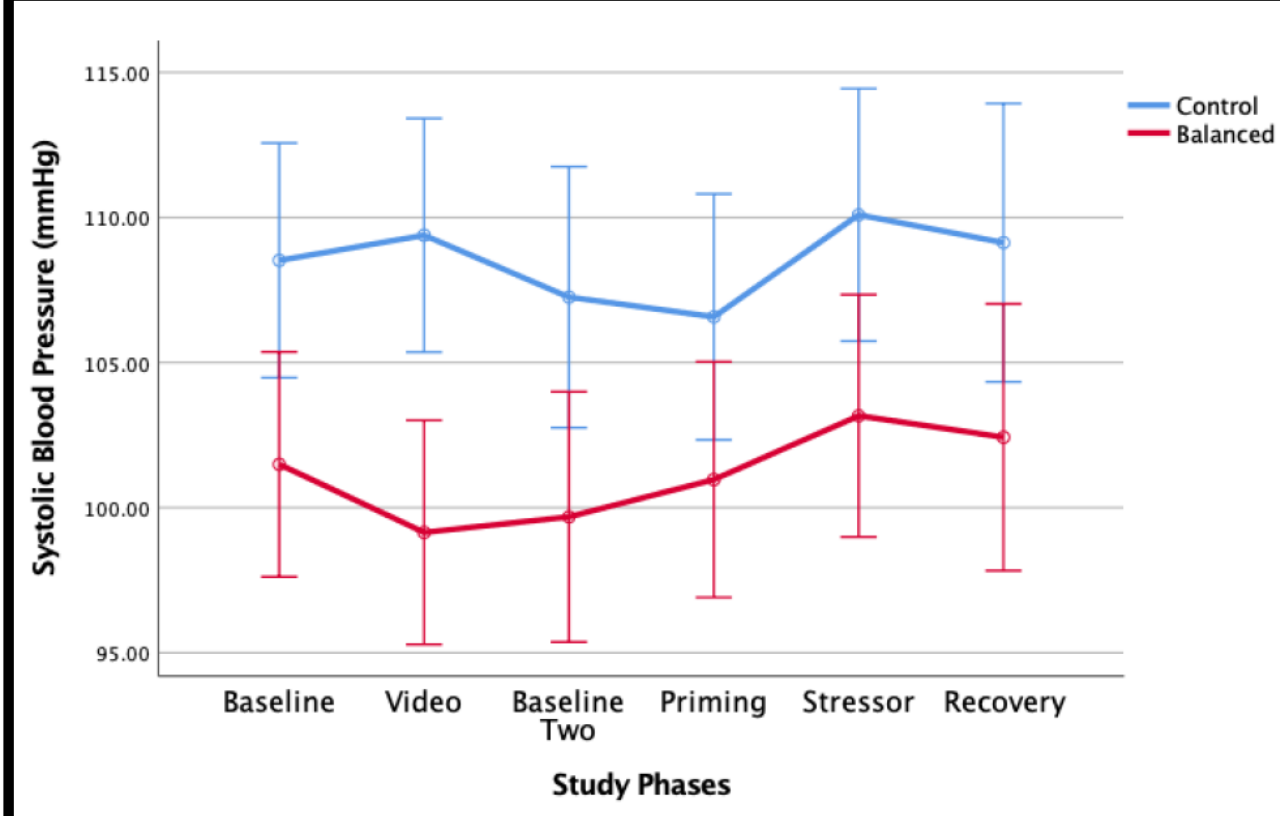

Error bars: $95 \% \mathrm{Cl}$

Figure 9. Changes in Systolic Blood Pressure (SBP) during Study Two, visit one.

Measures of PNS. Channel interference and EDA non-responders resulted in a total of 113 completed data sets across experimental conditions. The process for extracting ER-SCRs associated with various phrases of the experimental visit was identical to the procedures outlined in Study One. Multivariate analysis of variance examined within-group differences over time, as well as between-group differences across experimental conditions. Mauchly's test of sphericity was violated, $\chi^{2}(14)=59.53, p<.001$. Degrees of freedom were adjusted using the GreenhouseGeisser estimate $(\varepsilon=.833)$.

Within-subjects, there was a significant effect of time, $F(4.16,453.72)=27.53, p<.001$, $\eta^{2}=.20$. There were no significant effects for time-by-framing, $F(4.16,453.72)=1.17, p=.322$, $\eta^{2}=.01$; time-by-priming, $F(4.16,453.72)=1.10, p=.359, \eta^{2}=.01$; or framing-by-priming interaction, $F(4.16,453.72)=0.41, p=.809, \eta^{2}<.01$. Within-subjects contrasts observed a significant increase in EDA from baseline to stressor across framing conditions, $F(1,109)=$ 
5.03, $p=.027, \eta^{2}=.04$. During the stressor, the control group on average experienced greater numbers of ER-SCRs $(M=4.11, S D=2.49)$, compared to the balanced framing group $(M=3.32$, $S D=2.16$ ). Within-subjects contrasts detected a time-by-priming group difference during the video, $F(1,109)=4.83, p=.030, \eta^{2}=.04$. On average, the non-resilient/control priming group experienced lesser numbers of ER-SCRs $(M=2.03, S D=1.85)$ compared to the group that received the resilient priming $(M=2.73, S D=1.73)$. Test of between-subjects effects did not detect any group differences as a result of framing condition, $F(1,109)=1.77, p=.186, \eta^{2}=.02$; priming condition, $F(1,109)=2.27, p=.135, \eta^{2}=.02$; or time-by-framing interaction, $F(1,109)$ $=0.45, p=.506, \eta^{2}<.01$. Figure 10 below illustrates significant between-group contrasts observed across framing condition (left), and priming condition (right).

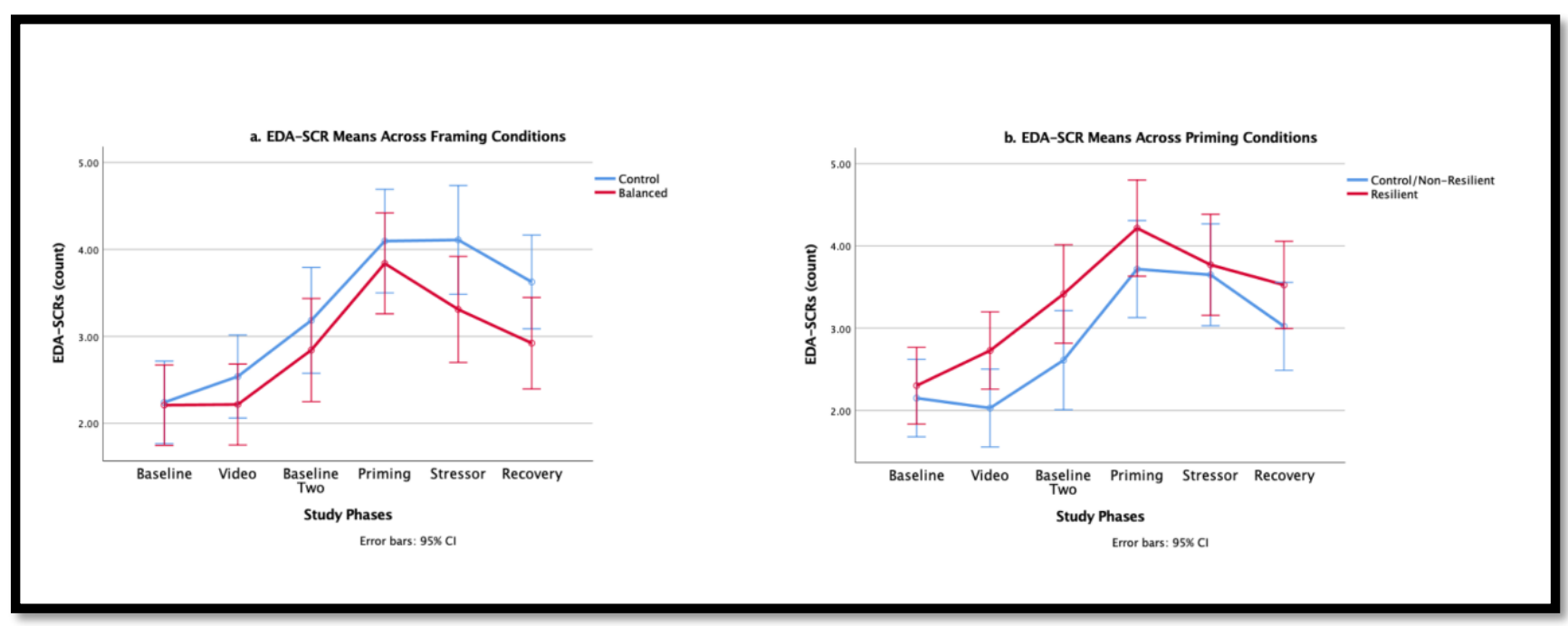

Figure 10. Group Differences in Event-Related Skin Conductance Responses (ER-SCR) across framing (left) and priming (right) manipulations.

\section{Group Differences in Stressor Task Performance}

Multivariate analysis of variance examined both the number of correct answers achieved and the number of total errors made during the TSST math performance across framing and priming conditions. No effects were observed across the framing conditions, $F(2,94)=1.54, p=$ 
$.220, \eta^{2}=.03$; priming conditions, $F(2,94)=0.34, p=.715, \eta^{2}<.01$; or framing-by-priming interactions, $F(2,94)=1.22, p=.301, \eta^{2}=.03$. Similarly, between-subject effects did not detect any group differences across performance measures across groups. Table 9 below illustrates the omnibus tests and group means for these effects.

Table 9. Between-subject effects and means across groups.

\begin{tabular}{|c|c|c|c|c|c|}
\hline & $\mathrm{F}$ & $d f$ & Sig. & $\mathrm{Eta}^{2}$ & Mean (SD) \\
\hline Framing (Num. Correct) & 0.03 & 1,95 & .854 & $<.01$ & \\
\hline Control & & & & & $12.26(9.98)$ \\
\hline Balanced & & & & & $11.90(8.68)$ \\
\hline Framing (Num. Errors) & 2.02 & 1,95 & .158 & .02 & \\
\hline Control & & & & & $3.89(1.55)$ \\
\hline Balanced & & & & & $3.48(1.66)$ \\
\hline Priming (Num. Correct) & 0.23 & 1,95 & .631 & $<.01$ & \\
\hline Control/Non-Resilient & & & & & $11.60(7.02)$ \\
\hline Resilient & & & & & $12.46(10.85)$ \\
\hline Priming (Num. Errors) & 0.11 & 1,95 & .737 & $<.01$ & \\
\hline Control/Non-Resilient & & & & & $3.62(1.68)$ \\
\hline Resilient & & & & & $3.72(1.57)$ \\
\hline
\end{tabular}

Note. $F=$ omnibus test; $d f=$ degrees of freedom; $S D=$ standard deviation; num. correct $=$ number of correct answers; num. errors = number of errors.

Follow-Up Analyses

Baseline Variations at Follow-Up. To explore the durability of experimental manipulations, baseline variations at follow-up were examined. Self-reported stress (VAS-SP, VAS-C, VAS-S) and physiological parameters of stress (HR, SBP, DBP, EDA) at follow-up baseline were compared across groups via multivariate analysis of variance. Pillai's Trace did not detect any significant differences across framing conditions, $F(7,43)=1.60, p=.162, \eta^{2}=$ .21 ; priming conditions, $F(7,43)=0.39, p=.905, \eta^{2}=.06$; and framing-by-priming interactions, $F(7,43)=0.51, p=.8236, \eta^{2}=.08$.

Self-Reported Stress during Follow-Up. Mixed analysis of variance examined framing and priming group differences in VAS measures during follow-up at baseline and post-stressor. Multivariate test statistics revealed only a within-subject effect of time, $F(3,75)=4.07, p=.010$, 
$\eta^{2}=.14$. No other between-subjects via framing or priming, or within-subjects effects were detected, $p<.05$. Univariate tests further found a significant effect of time on VAS-C, $F(1,77)=$ $5.63, p=.020, \eta^{2}=.07$; and VAS-S, $F(1,77)=10.65, p=.002, \eta^{2}=.12$. Self-perceived coping abilities decreased from baseline $(M=60.56, S D=19.64)$ compared to post-stressor $(M=58.11$, $S D=20.82)$, while self-perceived levels of stress increased from baseline $(M=48.38, S D=$ 22.09) compared to post-stressor $(M=53.73,23.39)$.

A mixed-ANOVA further examined VAS values in relation to baseline values reported at the initial visit. Mauchly's Test of Sphericity was violated for all three measures, $\chi^{2}(2)=20.34, p$ $<.001(\mathrm{VAS}-\mathrm{SP}), \chi^{2}(2)=44.26, p<.001(\mathrm{VAS}-\mathrm{C})$, and $\chi^{2}(2)=35.79, p<.001(\mathrm{VAS}-\mathrm{S})$. Degrees of freedom were adjusted using Greenhouse-Geisser estimates $(\varepsilon=0.803$ for VAS-SP; $\varepsilon$ $=0.685$ for VAS-C; $\varepsilon=0.719$ for VAS-S). Multivariate tests of within-subjects effects via Pillai's Trace found a significant effect of time, $F(6,290)=3.04, p=.007, \eta^{2}=.06$. No significant effects were detected for time-by-framing, $F(6,290)=1.15, p=.334, \eta^{2}=.02$; timeby-priming, $F(6,290)=2.01, p=.064, \eta^{2}=.04$; and the framing-by-timing interaction, $F(6,290)$ $=0.60, p=.732, \eta^{2}=.01$. Univariate tests further detected a significant a time-by-priming group interaction on VAS-C, $F(1.37,100.05)=5.05, p=.017, \eta^{2}=.07$. While both groups had similar baseline values in self-perceived coping, those in the resilient conditions experienced relatively little changes in VAS-C over the two visits, while those in the control/non-resilient priming condition experienced increases in VAS-C over-time. Figure 11 below illustrate group differences in VAS-C over time. 


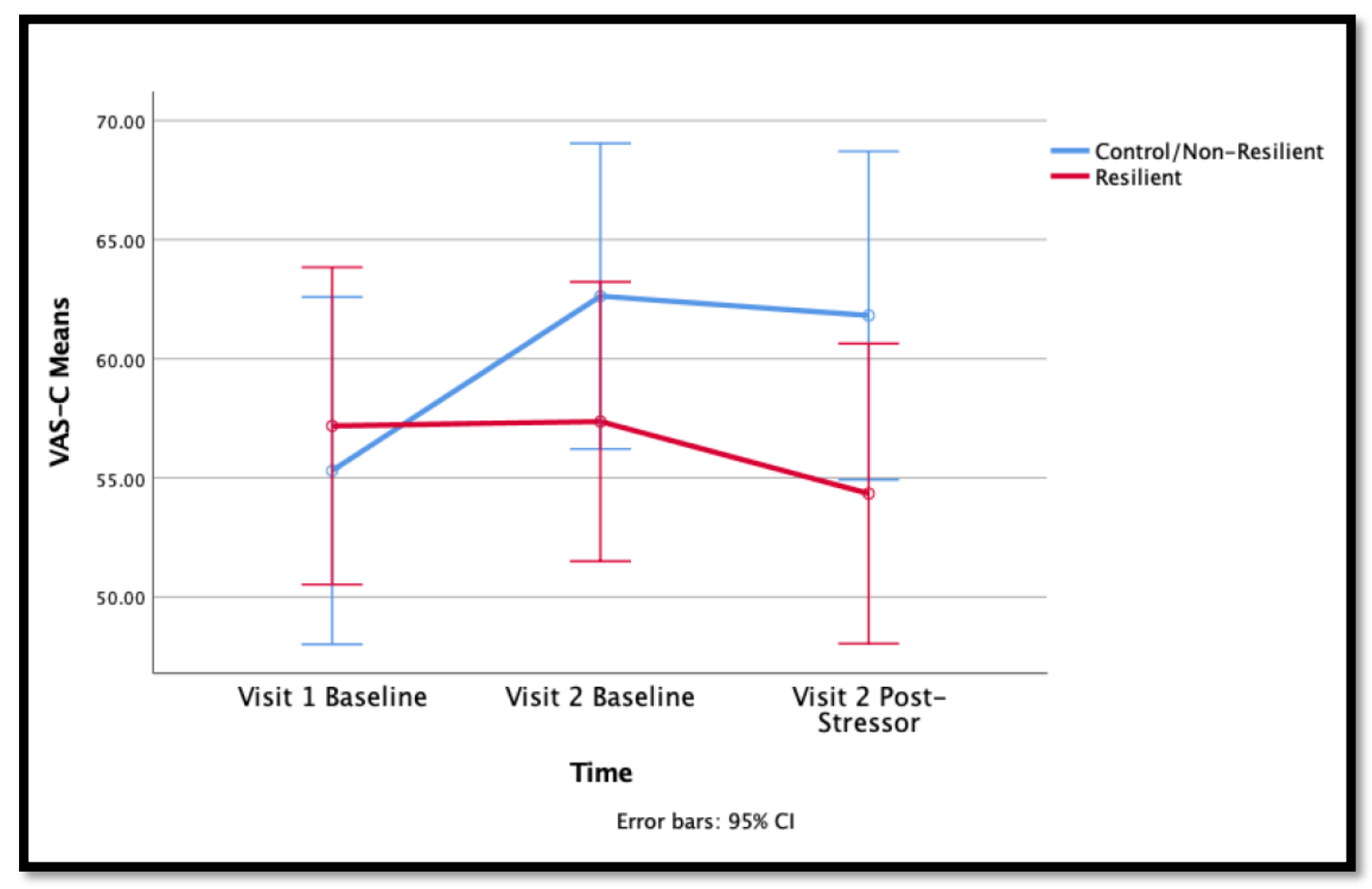

Figure 11. Self-Reported Changes in Coping (VAS-C) across two visits by priming groups.

SNS Responsivity during Follow-Up. Mixed-ANOVA examined changes in HR, SBP, and DBP during follow-up across experimental groups. Mauchly’s Test of Sphericity was violated for all three measures, $\chi^{2}(2)=35.30, p<.001(\mathrm{HR}), \chi^{2}(2)=35.22, p<.001(\mathrm{SBP})$, and $\chi^{2}(2)=24.73, p<.001$ (DBP). Degrees of freedom were adjusted using Greenhouse-Geisser estimates $(\varepsilon=0.673$ for HR; $\varepsilon=0.673$ for SBP; $\varepsilon=.728$ for DBP $)$. Multivariate tests of withinsubjects effects via Pillai's Trace detected a significant effect of time, $F(6,214)=6.29, p<.001$, $\eta^{2}=.15$. No effects were observed for time-by-framing, $F(6,214)=0.59, p=.737, \eta^{2}=.02$; time-by-priming, $F(6,214)=0.60, p=.707, \eta^{2}=.02$; and the framing-by-priming interaction, $F(6,214)=0.67, p=.678, \eta^{2}=.02$.

Univariate tests further detected a significant effect of time on $\mathrm{HR}, F(1.35,72.66)=3.82$, $p=.042, \eta^{2}=.07$; and DBP $F(1.46,78.67)=15.97, p<.001, \eta^{2}=.23$. No other significant effects were observed $(p>.05)$. Finally, between-subjects effects detected a significant effect of 
framing on HR, $F(1,54)=4.12, p=.047, \eta^{2}=.07$; and SBP, $F(1,54)=6.56, p=.013, \eta^{2}=.11$. Parameter estimates identified differences during follow-up across framing groups to be at baseline for HR, $t=2.23, S E=3.83, p=.030, \eta^{2}=.08,(95 \% \mathrm{CI}=0.85,16.19)$, and at baseline for $\mathrm{SBP}, t=2.08, S E=5.67, p=.042, \eta^{2}=.07,(95 \% \mathrm{CI}=0.45,23.18)$. Figure 12 below illustrate changes in HR (left) and SBP (right) during follow-up.

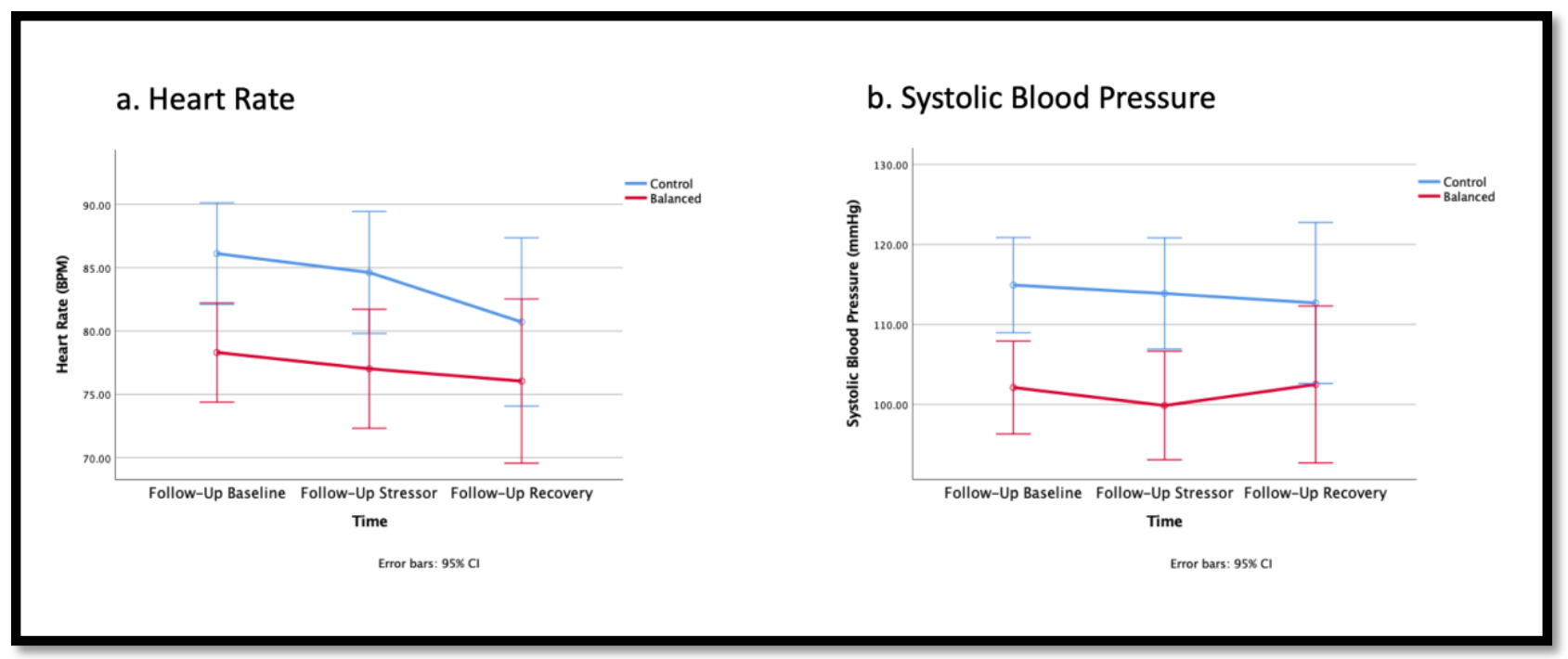

Figure 12. Changes in Heart Rate (left) and Systolic Blood Pressure (b) across framing conditions during follow-up.

PNS Responsivity during Follow-Up. Mixed-ANOVA examined changes in ER-SCRs across experimental groups during follow-up. Tests of within-subjects effects detected a significant effect of time, $F(2,106)=4.88, p=.009, \eta^{2}=.08$. No effects were detected for timeby-framing, $F(2,106)=0.75, p=.476, \eta^{2}=.01$; time-by-priming, $F(2,106)=1.85, p=.163, \eta^{2}$ $=.03$; or framing-by-priming interactions, $F(2,106)=0.15, p=.861, \eta^{2}<.01$. Tests of betweensubjects effects did not detect any effects across framing, $F(1,53)=0.26, p=.609, \eta^{2}<.01$; priming, $F(1,53)=0.02, p=.902, \eta^{2}<.01$; or the framing-by-priming interactions $F(1,53)=$ $0.14, p=.713, \eta^{2}<.01$. Across groups, ER-SCRs increased from baseline $(M=3.596, S D=$ 
$2.34)$ to stressor $(M=4.65, S D=2.19)$, and decreased during post-stressor recovery $(M=4.20$, $S D=2.35)$

\section{Exploratory Analyses}

Correlations Across Stress Parameters. Pearson's correlations were computed to explore the relationships across subjective and physiological measures of stress. Table 10 and 11

illustrate the relationship across various stress outcome measures in study two visit one and visit two. 
Table 10. Pearson's Correlations for outcome variables for study two, visit one.

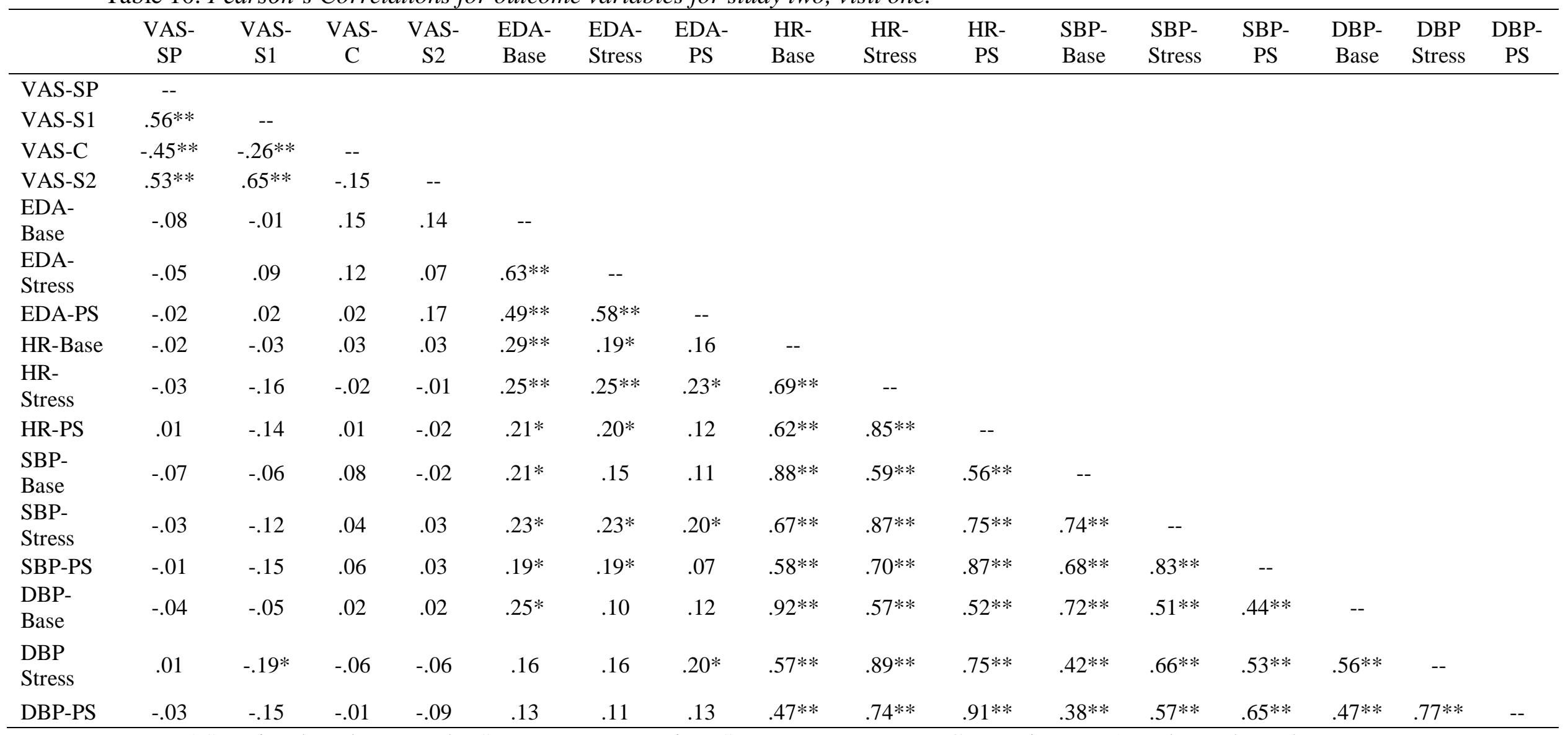

Note. $\mathrm{VAS}=$ visual analogue scale; $\mathrm{SP}=$ stress perception, $\mathrm{SR}=$ stress response; $\mathrm{C}=$ coping; EDA = electrodermal activity; $\mathrm{HR}=$ heart rate; $\mathrm{SBP}=$ systolic blood pressure; $\mathrm{DBP}=$ diastolic blood pressure; $\mathrm{PS}=$ post-stressor. $* p<.05, * * p<.01$, two-tailed. 
Table 11. Pearson's Correlations for outcome variables for study two, visit two.

\begin{tabular}{|c|c|c|c|c|c|c|c|c|c|c|c|c|c|c|c|c|}
\hline & $\begin{array}{c}\text { VAS- } \\
\text { SP }\end{array}$ & $\begin{array}{c}\text { VAS- } \\
\text { S1 }\end{array}$ & VAS-C & $\begin{array}{c}\text { VAS- } \\
\text { S2 }\end{array}$ & $\begin{array}{c}\text { EDA- } \\
\text { Base }\end{array}$ & $\begin{array}{l}\text { EDA- } \\
\text { Stress } \\
\end{array}$ & $\begin{array}{c}\text { EDA- } \\
\text { PS }\end{array}$ & $\begin{array}{l}\text { HR- } \\
\text { Base }\end{array}$ & $\begin{array}{c}\text { HR- } \\
\text { Stress } \\
\end{array}$ & $\begin{array}{c}\text { HR- } \\
\text { PS }\end{array}$ & $\begin{array}{l}\text { SBP- } \\
\text { Base }\end{array}$ & $\begin{array}{c}\text { SBP- } \\
\text { Stress } \\
\end{array}$ & $\begin{array}{c}\text { SBP- } \\
\text { PS }\end{array}$ & $\begin{array}{c}\text { DBP- } \\
\text { Base }\end{array}$ & $\begin{array}{c}\text { DBP } \\
\text { Stress } \\
\end{array}$ & $\begin{array}{c}\text { DBP- } \\
\text { PS }\end{array}$ \\
\hline VAS-SP & -- & & & & & & & & & & & & & & & \\
\hline VAS-S1 & $.66^{* *}$ & -- & & & & & & & & & & & & & & \\
\hline VAS-C & $-.32 * *$ & -.20 & -- & & & & & & & & & & & & & \\
\hline VAS-S2 & $.56^{* *}$ & $.81^{* *}$ & -.07 & -- & & & & & & & & & & & & \\
\hline $\begin{array}{l}\text { EDA- } \\
\text { Base }\end{array}$ & .02 & -.09 & -.05 & -.25 & -- & & & & & & & & & & & \\
\hline $\begin{array}{l}\text { EDA- } \\
\text { Stress }\end{array}$ & -.24 & -.23 & -.03 & -.19 & $.36^{* *}$ & -- & & & & & & & & & & \\
\hline EDA-PS & .04 & -.11 & .04 & -.21 & $.59^{* *}$ & .26 & -- & & & & & & & & & \\
\hline HR-Base & -.22 & -.21 & .05 & -.22 & .26 & $.28^{*}$ & .12 & -- & & & & & & & & \\
\hline $\begin{array}{l}\text { HR- } \\
\text { Stress }\end{array}$ & -.14 & -.21 & .12 & -.15 & .14 & $.33^{*}$ & .11 & $.76^{* * *}$ & -- & & & & & & & \\
\hline HR-PS & -.25 & -.26 & .25 & -.21 & .04 & $.29^{*}$ & .05 & $.61^{* *}$ & $.88^{* *}$ & -- & & & & & & \\
\hline $\begin{array}{l}\text { SBP- } \\
\text { Base }\end{array}$ & -.13 & -.12 & .05 & -.16 & $.26^{*}$ & $.35^{* * *}$ & .17 & $.85^{* *}$ & $.65^{* *}$ & $.49^{* *}$ & -- & & & & & \\
\hline $\begin{array}{l}\text { SBP- } \\
\text { Stress }\end{array}$ & -.04 & -.17 & .05 & -.17 & .19 & .23 & .18 & $.72^{* *}$ & $.88^{* *}$ & $.75^{* *}$ & $.78^{* *}$ & -- & & & & \\
\hline SBP-PS & -.18 & -.23 & .14 & -.20 & .03 & $.27^{*}$ & .08 & $.59^{* * *}$ & $.82^{* *}$ & $.93^{* *}$ & $.58^{* *}$ & $.84^{* *}$ & -- & & & \\
\hline $\begin{array}{l}\text { DBP- } \\
\text { Base }\end{array}$ & $-.32^{*}$ & $-.27^{*}$ & -.01 & -.20 & .16 & $.29^{*}$ & .06 & $.85^{* *}$ & $.67^{* *}$ & $.65^{* *}$ & $.55^{* *}$ & $.45^{* *}$ & $.41^{* *}$ & -- & & \\
\hline $\begin{array}{l}\text { DBP } \\
\text { Stress }\end{array}$ & $-.27^{*}$ & -.23 & .09 & -.12 & .04 & $.41^{* *}$ & .04 & $.65^{* *}$ & $.84^{* *}$ & $.76^{* *}$ & $.41^{* *}$ & $.52^{* *}$ & $.60^{* *}$ & $.81^{* *}$ & -- & \\
\hline DBP-PS & $-.30^{*}$ & $-.36^{* *}$ & .26 & $-.32^{*}$ & .04 & $.27^{*}$ & .05 & $.46^{* *}$ & $.69^{* *}$ & $.79^{* *}$ & $.30^{*}$ & $.49^{* *}$ & $.64^{* *}$ & $.54^{* *}$ & $.71^{* *}$ & -- \\
\hline
\end{tabular}

Note. VAS = visual analogue scale; $\mathrm{SP}=$ stress perception, $\mathrm{SR}=$ stress response; $\mathrm{C}=$ coping; $\mathrm{EDA}=$ electrodermal activity; $\mathrm{HR}=$ heart rate; $\mathrm{SBP}=$ systolic blood pressure; $\mathrm{DBP}=$ diastolic blood pressure; $\mathrm{PS}=$ post-stressor.

$* p<.05, * * p<.01$, two-tailed. 
Modelling Stress Responsivity Across Parameters. Variables measured in study two were used to model overall stress responsivity using the Lavaan package in R, using maximumlikelihood estimator. Stress responsivity was explanatorily modelled (Model 1) based on the hypothesized distinction between subjective (VASS) and physiological stress parameters (HR, SBP, DBP, EDA). Fit statistics included a combination of Chi-square fit, Root Mean Square Error of Approximation (RMSEA), standardized root mean square residual (SRMR), comparative fit indexes (CFI), and Tucker Lewis Index (TLI). Model fit statistics for the twofactor Model 1 of stress responsivity suggested a very good fit, with statistics illustrated in Table 12 below.

Table 12. Exploratory model fit summary indexes.

\begin{tabular}{lccccccc}
\hline & $\mathrm{X}^{2}$ & $d f$ & CFI & TLI & SRMR & RMSEA & 90\% CL \\
\hline Model 1 & 2.58 & 5 & 1.00 & 1.01 & 0.026 & 0.000 & $0.000,0.094$ \\
Model 2 & $321.26^{* *}$ & 161 & 0.835 & 0.806 & 0.116 & 0.109 & $0.092,0.127$ \\
Model 3 & $272.22^{* *}$ & 83 & 0.836 & 0.795 & 0.117 & 0.150 & $0.130,0.170$ \\
\hline
\end{tabular}

Note $. \mathrm{X}^{2}=$ chi-square; $\mathrm{df}=$ degrees of freedom; $\mathrm{CFI}=$ comparative fit index; $\mathrm{TLI}=$ TuckerLewis Index; RMSEA = root mean square error of approximation; SRMR = root mean square residual; $\mathrm{CI}=$ confidence interval. $*=p<.01, * *=p<.001$.

Structural equation modelling (SEM) was used to model the fit of overall stress responsivity, combining potential covariates, baseline measures, response measures, and group membership. Subjective stress via VAS measures were grouped as latent subjective baseline and stress responses, while physiological measures of $\mathrm{HR}, \mathrm{BP}$, and EDA were grouped as latent physiological baseline and responses. Measurement model (Model 2) statistics are presented in Table 12. Within this model, covariate measures did not account for a significant portion of the variance, and experimental groupings were only trending. Based on the findings from the measurement model, covariate measures were removed from the final structural model (Model 3). The final SEM model (Model 3) included the following latent variables: (1) baseline 
subjective stress variables (VAS-P, VAS-S, VAS-C), (2) subjective response variables (VAS-P, VAS-S), (3) baseline objective measures (HR, SBP, DBP, EDA), and (4) objective response variables (HR, SBP, DBP, EDA). Model statistics are presented in Table 12, and parameter estimates of the final SEM model are presented in Tables 13.

Model fit statistics combining both subjective and physiological parameters of stress generally indicate a poor fit of the data to the hypothesized model. Parameter estimates indicate that subjective VAS measures and physiological indexes of HR, SBP, DBP, and EDA are all significant predictors within the model. Finally, regression coefficients indicate framing, but not priming, to be a significant predictor in the overall model.

Table 13. Standardized model parameters for the SEM model.

\begin{tabular}{rccccc}
\hline & Estimate & $S E$ & $Z$ & Sig. & $95 \%$ CI \\
\hline Latent Subjective Baseline & & & & & \\
VAS-SP Baseline & 1.00 & & & & $1.00,1.00$ \\
VAS-S Baseline & 0.80 & 0.17 & 4.61 & $<.001$ & $0.46,1.13$ \\
VAS-C Baseline & -0.40 & 0.11 & -3.66 & $<.001$ & $-0.62,-0.19$ \\
VAS-SP Post-Stressor & 1.00 & & & & \\
VAS-S Stressor & 0.91 & 0.15 & 5.96 & $<.001$ & $0.61,1.21$ \\
Latent Subjective Response & & & & & \\
HR Baseline & 1.00 & & & & $1.00,1.00$ \\
SBP Baseline & 1.03 & 0.06 & 17.39 & $<.001$ & $0.92,1.15$ \\
DBP Baseline & 0.67 & 0.05 & 14.56 & $<.001$ & $0.58,0.76$ \\
EDA Baseline & 0.04 & 0.01 & 3.11 & .002 & $0.01,0.06$ \\
Latent Physiological Baseline & & & & & \\
HR Stressor & 1.00 & & & & $1.00,1.00$ \\
SBP Stressor & 0.93 & 0.07 & 14.02 & $<.001$ & $0.80,1.06$ \\
DBP Stressor & 0.67 & 0.05 & 14.52 & $<.001$ & $0.58,0.76$ \\
EDA Stressor & 0.04 & 0.01 & 2.64 & .008 & $0.01,0.06$ \\
Regressions. - Subjective & & & & & \\
Response & & & & & $-13.07,-1.97$ \\
\hline Experimental Framing & -7.52 & 2.83 & -2.66 & .008 &
\end{tabular}




\begin{tabular}{|c|c|c|c|c|c|}
\hline Experimental Priming & -0.62 & 2.72 & -0.23 & .820 & $-5.95,4.71$ \\
\hline Subjective Baseline & 0.81 & 0.11 & 7.54 & $<.001$ & $0.60,1.02$ \\
\hline \multicolumn{6}{|l|}{$\begin{array}{l}\text { Regressions. - Physiological } \\
\text { Response }\end{array}$} \\
\hline Experimental Framing & 23.56 & 1.50 & 1.70 & .089 & $-0.38,5.51$ \\
\hline Experimental Priming & -0.86 & 1.43 & -0.60 & .547 & $-3.66,1.94$ \\
\hline Physiological Baseline & 0.57 & 0.09 & 6.26 & $<.001$ & $0.40,0.75$ \\
\hline \multicolumn{6}{|l|}{ Variances } \\
\hline Subjective Baseline (latent) & 393.32 & 83.21 & 4.73 & $<.001$ & $230.23,556.41$ \\
\hline Subjective Response (latent) & 89.53 & 75.01 & 1.19 & .233 & $-57.50,236.55$ \\
\hline Physiological Baseline (latent) & 150.69 & 17.65 & 8.54 & $<.001$ & $116.11,185.28$ \\
\hline Physiological Response (latent) & 157.31 & 16.08 & 9.78 & $<.001$ & $125.79,188.83$ \\
\hline
\end{tabular}

\section{Discussion}

Study two expanded upon the findings from study one. Specifically, findings of attenuated self-reported stress and EDA ER-SCRs continued to provide support the effectiveness of a balanced stress reframing intervention in eliciting more adaptive stress responses during initial visit, though not at follow-up. Extending beyond the robustness of a balance reframing intervention, study two results also suggest that personal beliefs regarding one's own strengths may interact with reframing interventions to influence future perceptions of coping, and reduce overall perceptions of stress as threatening and uncontrollable.

\section{Effects of Priming on Stress Responsivity}

Contrary to hypothesis four hypothesizing a main effect of priming on subjective responses to stress, individuals primed to believe their character strengths were related to resilience did not experience reductions in psychological stress following exposure to stressors. Findings suggest that priming strengths alone has little effect on overall stress responsivity. Selfreflections of one's coping strengths have been utilized as a way to attenuate subsequent responsivity (Creswell et al., 2005) Additionally, strength-based priming has been proposed to 
have an interactive effect in promoting treatment and intervention efficacy (see Donker, Griffiths, Cuijpers, \& Christensen, 2009). The significant priming effects observed in the current dissertation were specific to self-perceived coping abilities measured immediately following the priming of strengths. Taken together, results from the priming manipulation employed in the current study suggest that simply telling someone that their strengths relate to resilience has little effect on shaping their stress response, beyond a momentary shift in beliefs regarding their coping abilities. In the context of encountering a stressor shortly after, these perceptions of coping had little influence over subsequent responsivity across subjective and physiological stress parameters. It may also be the case that simply telling someone their strength was related to resilience was a relatively weak form of priming. In addition, past studies have also emphasized the importance of individual differences, whereby personality differences or mood may influence responses to positive psychology exercises (Sergeant \& Mongrain, 2011; 2015). Taken together, the transient nature of the strength priming may have reduced its saliency, and thus failed to account for any outcomes beyond individual differences in relation to stress.

\section{Interactive Effects of Framing and Priming}

Consistent with partial predictions in hypothesis three (in study one) and hypothesis five (in study two; which stated that differences in responsivity to stressors may occur as a result of framing, and priming and framing interactions), results from study two confirmed previous findings that support the balanced framing of stress as the most efficacious in engendering adaptive responsivity to stressors (Liu, Vickers, Reed \& Hadad, 2017). Across measures, participants in the balanced framing condition on average reported a larger decrease in perceiving stress as threatening and uncontrollable over the course of visit one. In addition, those in the balanced framing condition reported a smaller increase in self-reported stress. On 
physiological measures of stress responsivity, the balanced framing group on average was observed to have lowered systolic blood pressure during the video portion of the experiment relative to other conditions, which may have shaped their subsequent physiological arousal and response to stressors. The lowered SBP is consistent with the idea that the content presented in the balanced stress video may have served to calm the participant. Further, participants in the balanced framing group on average were also observed to have fewer responses via ER-SCR, an indication of less effortful regulation of arousal in response to a threatening event (Jamieson, Crum, Goyer, Marotta, \& Akinola, 2018; Seery, 2013). Together, the lowered SNS and PNS parameters converge to suggest that the balanced framing group may have been calmer, and/or less aroused during post-stressor recovery. Indeed, these effects are consistent with efficacy studies examining intervention effects of relaxation on the autonomic nervous system, including decreases in HR, BP, and EDA activity (see Tsitsi, Charalambous, Papastravrou, \& Raftopoulos, 2017).

Interactive effects of experimental framing and priming together, provids limited support for an optimization of subjective stress response. While balanced framing alone showed little efficacy in reducing perceptions of stress in previous studies (Liu, Vickers, Reed \& Hadad, 2017), the interactive effect of balanced framing with a resilient priming resulted in only a significant decrease in perceptions of stress as threatening over the course of a single lab visit. This finding suggests that while new information presented on stress may aid in responsivity to stressors, personalized feedback may further help an individual internalize some of the changes in stress beliefs. More generally, this finding is also consistent with some findings from the literature on psychological intervention (e.g., Donker et al., 2009; Mongrain \& AnseloMatthews, 2012). Researchers have suggested that psychoeducation is often most efficacious 
when combined with personalized information, such as information about the challenge, coping skills of the individual, and other relevant personalized additions, which provides pathways towards change, and allow an individual to embody those changes (Donker et al., 2009; Mongrain \& Anselo-Matthews, 2012; Schaub, Hippius, Moller, \& Falkai, 2016). The balanced reframing of stress, coupled with the priming to believe an individual's strengths relate directly to resilience, may have facilitated the embodiment of the strength by incorporating the balanced framing as part of one's resilient beliefs and attitudes, and in a way that was salient and effective. However, the singular nature of this significant interaction (in the context of other null findings) should be interpreted with caution as supporting evidence of the hypothesized interactive effects of priming with framing.

Interestingly, no experimental effects were found on task performance. It appears that the experimental effects are specific to the domain of stress responsivity, and do not influence individual variations in performance, such as the number of correct responses to the subtraction task, or the overall number of errors made during performance. While past studies have documented specific advantages of reappraisal interventions in improved task performance, it should be emphasized that these studies relied on specific reappraisal instructions that were tailored to re-interpreting bodily sensations in anticipation of the upcoming specific stressor task (Jamieson et al., 2010, 2013). Findings from the current study suggest that global reframing of stress effects via balanced presentation of information on stress may not promote improved performance on tasks. One possible explanation for these discrepant findings is that tailored, stressor-specific instructions (Jamieson et al., 2010, 2013) may remove some of the uncertainties associated with the upcoming stressor, such that the anticipatory stress is less in instructionspecific reappraisal studies compared to the global reframing of stress. In contrast, a global 
approach to reframing, as occurred in the current dissertation, continues to leave the content and expectations of any subsequent stressors unknown. Indeed, many researchers have focused specifically on the study of anticipatory stress, with some modifications to the TSST consisting of only receiving the instructions, and measuring subsequent stress in anticipation of the expected activities (see Allen, Kennedy, Dockray, Cryan, Dinan, \& Clarake, 2017; Starcke, Wolf, Markowitsch, \& Brand, 2008).

\section{Durability of Experimental Manipulations}

Study two further explored whether the effects from framing and/or priming manipulations would endure in a one to two-week follow-up visit. To my knowledge, this is the first study that examined the durability of general reframing of stress on stress responsivity through a follow-up. While previous research has included self-reported measures as an optional follow-up, the researchers did not explicitly report effects, nor examine the physiological responses to subsequent stressors (Crum, Salovey, \& Achor, 2013). In study two, it was hypothesized that experimental effects would be maintained through differences at baseline. Indeed, this was evidenced in study two findings across physiological measures of stress at baseline. While no self-reported differences across experimental groups emerged at baseline of the follow-up visit, physiological measures of heart rate and systolic blood pressure showed an effect of framing at baseline, whereby those in the balanced framing condition were observed to have lowered heart rate and systolic blood pressure compared to those in the control condition. These differences across groups were present only at baseline, however. Further, no observed effects across groups were found for self-reported stress levels, or EDA responses.

Results of the follow-up provide some preliminary evidence in support of the durability of the balanced framing based on baseline physiology at follow-up. However, the specific 
mechanisms of why the balanced framing groups came to visit two with lowered baseline heart rate and systolic blood pressure is not clear. One interpretation could be that the robust effects of balanced framing resulted in less physiological arousal and better stress response regulation over time, which was illustrated through lowered baseline values of HR and SBP at follow-up. An alternative explanation could be that the content of the framing video, coupled with the prior experience of participation, puts those in the balanced condition in a more relaxed state at baseline compared to the control condition, such that the relaxed states were demonstrated through lowered HR and SBP at baseline.

Further, the finding related to the changes in self-perceived coping (non-resilient group showed improvements in self-reported coping since visit one, while resilient group's selfreported coping did not change) seems somewhat counter-intuitive, and was not consistent with any hypothesized findings. It could be speculated that similar to the false expectations of a positive stress reappraisal intervention (in study one), the expectation that one is resilient after being told of such a statement can be violated upon the experience of a stressor if that experience did not conform to prior expectations. Given the small effect size $\left(\eta^{2}=.08\right)$ of this counterintuitive finding, these effects may be much more nuanced and likely involve interactions across variables not captured by the current study design and/or data analytic plan.

\section{Complexity of the Individual Stress Response}

Once again, study two results mirrored those of study one, documenting a lack of significant relationship between subjective parameters of stress and physiological indexes of stress. Despite the lack of relationship, overall model statistics from exploratory SEM suggest that both subjective and physiological measures of stress importantly shape the overall stress response. Although model fit parameters suggest the model could be better improved, variables 
retained within the final model emphasize the importance of utilizing more than a single index or domain of stress responsivity when conducting stress research.

\section{Challenges and Limitations}

Findings from study two should also be considered in light of several important challenges and limitations. As in study one, attrition occurred from visit one to visit two. While the attrition rate improved in study two, compared to study one, the large number of participants choosing not to come to the follow-up study highlights an important challenge in conducting psychological research using undergraduate samples and student participation pools. As aforementioned, the desire to obtain study credits as quickly as possible may discourage participants from committing to a second laboratory session later in time.

The loss of data through attrition was problematic in several ways. First, it drastically reduced statistical power for more complex analyses. In addition, the voluntary nature of the follow-up may result in a sub-group of participants for whom the experimental procedures may have been more salient. For example, perhaps participants who returned for the follow-up session were those who most enjoyed the framing video, or found the strength priming to be interesting. While the experimental groups were equally likely to show up for a follow-up, there is no way to understand individual motivations for attending a follow-up, and thus this factor may be an unknown variable that may influence experimental findings to some degree. As such, it is important that the durability of the experimental manipulations are not generalized to other populations given the limitations in sample size.

An additional challenge observed during study two was the seasonal variations in EDA response. As study two was conducted during spring and summer seasons, where temperatures were generally higher, it may be that individuals' bodies are also adjusting to these seasonal 
changes by producing more sweat naturally. Although similar patterns emerged in EDA responses across framing groups, seasonal variations likely added additional variance, and may have masked or dulled the magnitude of experimental effects (Braithwaite et al., 2013).

Finally, although exploratory SEM examined the modelling of stress parameters, it is important to emphasize the small sample size as a limitation to the interpretability and generalizability of these findings. The current sample size may be underpowered for hierarchical models, with a sample size of 200+ often recommended, and thus may lack sufficient statistical power to detect smaller sized effects (Newsom, 2018; Wolf, Harrington, Clark, \& Miller, 2013).

\section{Study Two Conclusions}

Taken together, study two findings highlight the robust effects of a balanced framing of stress in promoting adaptive responsivity to subsequent stressors. Findings on the effects of

priming suggest that it does not affect stress responsivity on its own, but results suggest areas of personalization that may enhance presentation of information on stress to optimize responsivity when combined with framing. Finally, study two findings illustrate the complex interactions of subjective and physiological stress systems in response to stressors. 


\section{GENERAL DISCUSSION}

\section{Perceptions of Stress Amongst Participants}

Findings across both studies of this dissertation converge to emphasize the importance of stress-related beliefs in shaping responses to stressors. Previous evidence has underscored the importance of stress perceptions in affecting the health and wellbeing of the individual (Crum et al., 2013; Keller et al., 2012; Scult et al., 2017). Within the sampled population of undergraduate students, ratings of the word-association task revealed the pervasiveness of the negative associations with stress, whereby a large majority of those sampled associated a negatively-rated word first with stress. Findings echo previously published reports of similar ratios of negative stress ratings in an undergraduate population (Liu et al., 2017).

Importantly, results from study one suggests an association between stress ratings and subsequent individual responsivity to stressors, such that those with negative ratings exhibited a greater physiological stress response. Although the acute stress response itself is not necessarily maladaptive, in the context of lifetime development, and especially during important milestone periods such as young adulthood and life transitions, the link between beliefs about stress and responsivity to stress may be an important determinant in the health and wellbeing of the individual.

\section{The Effects of Reframing Stress on Stress Outcomes}

Central to the theme of the dissertation is the examination of the perceptions of stress, and whether beliefs regarding stress can be reframed to influence subsequent responsivity to stressors. Across both studies, results consistently replicated, sharing similar small to medium effect sizes with those from previously-published studies that have examined the effects of stress reappraisal interventions (e.g., Jamieson et al., 2012). These findings confirm prior research 
supporting the efficacy of reappraisal intervention in reducing subsequent subjective responses to stress (Beltzer, Nock, Peters, \& Jamieson, 2014; Crum et al., 2013; Jamieson et al., 2010; 2013; Liu et al., 2017). Similarly, the robust efficacy of reappraisal-based interventions in reducing subsequent subjective distress following stressor exposure was documented in a recent metaanalysis and systematic review (Liu et al., 2019).

Akin to the meta-analytic findings, results across two studies measuring objective outcomes of stress offer mixed support for the overall efficacy of reframing stress on physiological indexes of stress. Notably, there were few observed differences across measures of sympathetic activity via cardiovascular measures as a result of the reappraisal intervention. Several interpretations may be plausible in understanding these findings. First, research evidence suggests cardiovascular measures of heart rate and blood pressure to be more indicative of individual capacities to respond to various situations (Seery, 2013). In this sense, it may be that individual variabilities across cardiovascular outputs overshadowed or masked any potential group effects a reframing intervention may have had.

An alternative explanation for the lack of findings across measures of heart rate and blood pressure may be the way in which they were measured during the experiments. Across both studies, it was noted that subjective measures of stress did not correlate with physiological measures of stress, and especially with heart rate and blood pressure. Past research has reported a range of variations in the degree of association between self-reported stress and objective, physiological indexes of stress. Additionally, a similar study previously conducted reported a much higher association between self-reported stress levels and physiological measures of heart rate and blood pressure (Liu et al., 2017). Of note, in this previous study (Liu et at., 2017), participants sat facing the Biopac monitor that displayed their cardiovascular outputs. In contrast, 
in the current studies in this dissertation, participants sat facing away from the Biopac monitors, and thus did not have a clear visual of their physiological reactivity. With little visual to guide self-reported responses, it may be that participants' physiological responses were less in sync with their self-perceived levels of stress, and more indicative of their own capacities and/or bodily variations in response to task-demand. This analogy is similarly documented in a study in which researchers manipulated physiological feedback to explore the degree to which it may be in sync with self-reported stress (van Dijk, Westerink, Beute, \& Ijsselsteijn, 2015). The researchers found that when provided with physiological feedback, participants' self-reported levels of stress were more in sync with those of measured across physiological indexes.

This analogy also sheds light on the experimental findings observed on measures of the PNS via EDA. Across both studies, the only measured difference across experimental reframing groups and control were the event-related responses during stressor and post-stressor recovery, whereby the balanced framing group had fewer responses compared to other groups and controls. These differences again highlight the efficacy of stress reframing on physiological measures of stress, such that those receiving balanced information were observed to be more relaxed, calm, and/or exerted less effort to regulate arousal. Importantly, lower PNS activation observed across both studies is also consistent with findings from Jamieson et al.'s (2012) study in documenting lowered total peripheral resistance, another measure of the PNS activation that is responsible for downregulating arousal to elicit more adaptive responsivity to stressors.

Finally, follow-up analyses offered preliminary support for the durability of the reframing intervention. Although not enough to affect changes in self-reported response to stressors, participants who received the balanced reframing arrived with lower heart rate and systolic blood pressure compared to the control. This suggests that participants were less stressed 
(physiologically) upon arrival for follow-up compared to those who had not received the balanced framing previously.

Taken together, findings across both studies provide a robust rationale for the efficacy of a balanced framing condition in reducing subjective distress and facilitating post-stressor recovery. Measurements across subjective and physiological parameters of stress support the notion that a balanced reframing of stress, where positive and negative outcomes of stress are provided, helps inform the individual have an adaptive response to subsequent stressors. The novelty of the balanced framing compared to previously-used reappraisal intervention scripts that feature only positive content about stress (e.g., Jamieson et al., 2010) is the presentation of both positive and negative outcomes of stress. Presenting both sides may result in an informative presentation that is more easily accepted by the individual, and may help establish realistic expectations regarding stress that is not a dramatic departure from the overly-negative beliefs often held about stress. Indeed, social psychological researchers similarly noted that the presentation of both sides via counter-arguments is more persuasive than one-sided messages (O’Keefe, 1999).

\section{The Effects of Strengths Priming on Stress Outcomes}

A secondary goal of this dissertation was to explore whether the additive effects of a strength-based priming in tandem with effects of framing to engender adaptive responsivity to subsequent stressors. Across both studies, findings generally were inconsistent with this hypothesis and instead suggested that overall, there is little evidence to support a resilience-based strength priming beyond a momentary shift in self-perceived coping abilities. A number of factors could have contributed to the lack of effect of the priming manipulation in this study. First, it should be noted that the priming manipulation was very short in duration, with the 
distinction between resilience-based and non-resilient distilled to just one sentence relating the strength of temperance to resilience and coping. In addition, although definitions for various strengths were provided during the priming manipulation exercises, we did not gauge comprehension or degree of reflection within participants. The methodological limitations in the execution of the framing manipulation may drastically reduce any potential in eliciting robust experimental effects. Taken together, it may well be the case that this simply was not impactful enough to engender an experimental effect above and beyond individual differences in the sampled population (e.g., see Sergeant \& Mongrain, 2011).

However, the observed interaction of priming and framing effects via declines in perceptions of stress as threatening and bothersome in the balanced framing and resilient priming group suggest that attempts to personalize framing interventions to the individual through efforts such as priming may be a useful tool in extending the effects of balanced framing to broader contexts than just the subsequent responsivity to stressors. More specifically, this interaction suggests that while framing of stress was not enough to reduce perceptions of stress in similar studies, the combined effects of framing and priming resilience-based strengths were efficacious in generating a reduction in overall negative stress perceptions (Liu et al., 2017). Although this is somewhat counterintuitive, these interactive effects support prior research and recommendations for the incorporation of personal strengths in psychological interventions (Fluckiger \& Grosse, 2008; Flukiger et al., 2009; 2010; Mongrain \& Anselo-Matthews, 2012; Seligman, Steen, Park, \& Peterson, 2005). Researchers suggest that the use of strengths can be added to enhance and personalize the delivery of interventions, making the content more relatable, engaging, and acceptable to the individual (Fluckiger \& Grosse, 2008; Flukiger et al., 2009; 2010). Although strength-based priming was not effective at altering stress responses across groups, when 
combined with reframing, it may be useful in increasing the saliency of the overall reframing message. The effectiveness of the balanced framing of the general outcomes of stress may be specific to the domains of subsequent responsivity. A personal strength-priming may have helped to globalize some of these effects to influence global perceptions of stress. However, given the lack of more robust evidence in support of these theoretical prepositions, further research is needed to better distinguish experimental effects against potential anomalies in findings.

\section{Challenges in Optimizing the Individual Stress Response}

The overarching theme of the dissertation was to explore interventions and manipulations that optimize the individual stress response. To do so, the current dissertation tested the effects of various framing interventions, combined with priming individual strengths. Findings examining the interactive effects of both stress reframing and strength priming suggest that an educational reframing intervention may be effective in eliciting more adaptive responses to stress, as well as in shifting the beliefs we may hold about stress.

In addition, findings also suggest that the mind-body relationship in the context of stress responsivity is complex. Evidenced by the complex modelling of stress parameters to fit in a single model of stress, more research is needed to disentangle the stress systems as more than an autonomic set of symptoms or self-reported appraisal. Indeed, researchers have begun to emphasize the importance of examining the stress experience from a constructionist perspective, underscoring the importance of feedback between subjective beliefs and emotions regarding stressful events as constructs in shaping physiological responses to stress, and how they reinforce each other in a feedback loop over one's lifetime (Blascovich et al., 2003; Francis, 2018; Seery, 
2013). Understanding the importance of cognitive beliefs held about stress in this process can then better inform approaches to shape more adaptive outcomes to stress.

The societal preoccupation with avoiding the negative effects of stress, and resulting negative associations of stress, can have lasting consequences on the individual's ability to respond to stressors. For example, similar to the notion that some individuals hang onto labels, such as "I am a leader", or "I am an introvert", associations made about stress may be used as a way to guide future cognitions and actions in response to stressors (Darley \& Gross, 1983).

The labels that individuals associate with their abilities to respond, as well as how individuals perceive any novel stressor or event, may act as guide posts in shaping individual stress responses over time. However, problems can arise when these labels and associations do not best serve end goals. Indeed, studies have highlighted the adverse consequences of labelling individuals, such as a diagnosis of schizophrenia or bipolar disorder (Angermeyer \& Matschinger, 2003; Lam, Salkovskis, \& Hobb, 2016). The act of labelling, in turn, restricts individual actions, and sometimes results in confirmation-seeking behavior, or the manifestation of self-fulfilling prophecies. At the societal and cultural level, the labelling of stress outcomes as overly negative may in turn, generate self-fulfilling prophecies driven by unrealistic expectations and intolerance of stress. At the individual level, people may then bear the consequences of these labels by reinforcing them with our own beliefs that perpetuate the avoidance of stress, rather than build up resilience against stress.

Finally, in studying ways to promote adaptive responses to stress, it is also important to research the complexities of the individual stress systems. Yet, the complexity of delineating mechanisms within the dynamic stress responses is bound by the practical constraints of resource and measurement availability. Working within these practical constraints, the current dissertation 
highlighted important steps researchers can take in exploring ways to elicit more adaptive responses to acute stressors, while addressing some uncertainties and limitations put forth by past research.

\section{Conclusion and Future Directions}

Findings across both studies documented robust evidence to support the notion that presenting balanced information on the outcomes of stress is useful in shaping more adaptive responses to subsequent stressors. Despite the pre-test measures accounting for little variance within the current dissertations, the individual responses to stress may be influenced and shaped by additional considerations, such as past experiences, natural variations in body physiology, and other interpersonal events and/or factors. Further, the measurement tools utilized in research serve as only imperfect proxies in the attempt to better understand stress. The current dissertation findings are interpreted within the context of the statistical tools and research measures used. Future studies using alternative tools and measurements, such as hormonal assays and neuroimaging tools, may be able to gain additional insights into the complexities of the individual stress systems.

Finally, findings on the efficacy of reframing and priming interventions suggest that stress beliefs are malleable. There is much room to frame stress at the community, societal, or educational level to influence adaptive outcomes to stressors. Practical recommendations include recognizing and acknowledging the existence of stress at an early age, educating children early on about effective stress management techniques in the context of individual strengths, and finally, accepting stress as part of the daily reality not just for those in "high-stress lifestyles", but as a necessary part of everyday life. 


\section{APPENDICES}

\section{Appendix I - Reframing Scripts}

\section{I-A: Balanced}

People are concerned with stress because it permeates so many aspects of our lives. We are told all the time that stress is bad for our health, both physically and psychologically. And there is some truth to this.

Hans Selye, one of the original stress researchers in psychology proposed a three-stage model, called the General Adaptation Syndrome to explain how we react to stress. At the alarm stage, we first encounter what we find to be stressful - something that threatens our wellbeing, and our bodies' balance, that is, our homeostatic functions. Now, 'stress' doesn't have to be just one thing or event. In fact, stress is additive. This is especially true in today's world, where we are often dealing with ongoing stress that continues for long periods of time. So fast forward days, months, or years of constantly dealing with things that we find stressful, or threatening, such as pressures of graduating school, finding a job, and the continuing stresses of financial insecurities, bad relationships, health concerns etc. that many people experiences, and our bodies then enter the next stage, the resistance stage. During this time, our bodies are using up all of our resources to continue to fuel us in what we are doing to 'cope' with these stressors. Finally, as the stresses persist, our bodies' resources are depleted, and there is no relief from stress in sight. This is the third and last stage, known as the exhaustion stage. At this point, we are out of fuel, and exhausted.

While all this may be true. It paints a very unbalanced picture of what stress can do for us! Stress is not always a bad thing. In fact, it can be motivating. When we experience all these physiological signs, we often think our bodies are stressed out. in a sense, it is, but this also indicates our bodies are ready for action, to deal with what's stressing us out! To truly understand stress, we need to consider both the good and the bad. Obviously, if we have too much stress, we will get anxious and won't perform well. However, if we have too little stress, we'd just fall asleep and not perform at all! A fellow researcher at Harvard found that by simply having people reinterpret their bodies' responses at times of stress, their stress response looked a lot closer to rising up to a challenge. It's not that they no longer reacted to stress, it's that their reaction changed to something that's not to threatening.

We often hear of the phrase 'mind over matter'. We know that stress is bad for the health. However, a study found that, yes, stress is related to mortality, but only within those that believe stress is bad for health. Therefore, how we think of stress matters. In fact, people who successfully cope with stress (big or small), can even experience enhanced self-confidence and resilience! Now, the question is, how can we use stress in a positive way? Coping with stress is like playing a videogame. The more your practice, the better you get, and the better you get, the higher the level you climb to, until finally, you have a chance at beating the game! And so to with stress. 


\section{I-B: Unbalanced-Positive}

People are concerned with stress because it permeates so many aspects of our lives. We are told all the time that stress is bad for our health, both physically and psychologically.

While all this may be true. It paints a very unbalanced picture of what stress can do for us! Stress is not always a bad thing. In fact, it can be motivating. When we experience physiological signs of stress, such as sweating, heart palpitations, we often think our bodies are stressed out. In a sense, it is, but this also indicates our bodies are ready for action, to deal with what's stressing us out!

In fact, our bodies need stress in order to survive. Obviously, if we have too much stress, we will get anxious and won't perform well. However, if we have too little stress, we'd just fall asleep and not perform at all! Therefore, stress is adaptive.

A fellow researcher at Harvard found that by simply having people reinterpret their bodies' responses at times of stress, their stress response looked a lot closer to rising up to a challenge. It's not that they no longer reacted to stress, it's that their reaction changed to something that's not to threatening.

This research found that people can rethink stress in order to reap the benefit of the positive effects of stress! Think of your heart rate quickening as preparation for you to make quicker decisions; when you're increasing your oxygen intake, it's readying you for action. Your pupils dilate because you can see better, your ears can hear better - all of these are indications that your body is preparing your internal resources to cope with the anticipated stress!

We often hear of the phrase 'mind over matter'. We know that stress is bad for the health. However, a study found that, yes, stress is related to mortality, but only within those that believe stress is bad for health. Therefore, how we think of stress matters. In fact, people who successfully cope with stress (big or small), can even experience enhanced self-confidence, personal growth, and resilience! In this sense, coping stress is like a muscle, and needs to be exercised constantly in order to keep it in top shape!

Of course, it's impossible to rid our lives of stress entirely. Therefore, instead of thinking of stress as a threat, it's time to think of it as a challenge! Next time you feel stress coming on, you can begin to think of all the great things that it can do for you, and all the great skills you can gain as a result of your experiences.

Now, the question is, how can we use stress in a positive way and continue to reap only the benefits of stress? Coping with stress is like playing a videogame. The more your practice, the better you get, and the better you get, the higher the level you climb to, until finally, you have a chance at beating the game! And so to with stress. 


\section{I-C: Unbalanced-Negative}

People are concerned with stress because it permeates so many aspects of our lives. This is even more so in our modern word. We have more and more reasons to be worried and stressed out. And there are just cause to be worried about the stresses we all bear, because dealing with this stress can have detrimental effects on our bodies and our minds.

Hans Selye, one of the original stress researchers in psychology proposed a three-stage model, called the General Adaptation Syndrome to explain how we react to stress.

At the alarm stage, we first encounter what we find to be stressful - something that threatens our wellbeing, and our bodies' balance, that is, our homeostatic functions. Now, 'stress' doesn't have to be just one thing or event. In fact, stress is additive. This is especially true in today's world, where we are often dealing with ongoing stress that continues for long periods of time. So fast forward days, months, or years of constantly dealing with things that we find stressful, or threatening, such as pressures of graduating school, finding a job, and the continuing stresses of financial insecurities, bad relationships, health concerns etc that many people experiences, and our bodies then enter the next stage, the resistance stage. During this time, our bodies are using up all of our resources to continue to fuel us in what we are doing to 'cope' with these stressors. Finally, as the stresses persist, our bodies' resources are depleted, and there is no relief from stress in sight. This is the third and last stage, known as the exhaustion stage. At this point, we are out of fuel, and exhausted.

Biologically, the stress response is a complex physiological process. Stress affects the cardiovascular system, increasing our heart rate and blood pressure. It tenses up our muscles, it slows down our digestion, increases our oxygen intake, cools down our skin, dilates our pupils and makes our hearing more acute, and produces many other chemicals, such as cortisol. In short, our bodies really take a beating from stress!

Now, we see the problem. If many of our everyday stresses are ongoing, our bodies are bound to run out of resources eventually. And, once our bodies are depleted of its resources as a result of chronic stress we so often experience today, our immune systems are compromised, our energies are down, and this is where we are vulnerable to physical maladies, from cold or flus (which are popular co-occurrences during the final exam period), or heart attacks.

So it's easy to see why when we are stressed, we sometimes experience tensions in our muscles, dry throat and mouth, trembling, cold hands and feet, weakness, fatigue, and other feelings that might negatively impair our performance. And this, could stress us out even more. Research on stress has linked the experience of stress to many mental and physical illnesses, including bipolar disorder, depression, post-traumatic stress disorder, coronary heart disease, diabetes, and arthritis. And to make matters worse, when we are stressed, we tend to engage in adverse health behaviors, such as smoking, drinking, or eating, which are also disruptive to our abilities to cope with stress and maintain health. In this sense, stress can act as both triggers to new health issues, or worsen existing health conditions. Therefore, it is important to promote a healthy lifestyle that coincidentally also acts as a strategy for reducing stress. This includes plenty of exercise, restful sleep, good nutrition, and taking breaks to recharge and refuel the mind and the body. 


\section{I-D: Reframing Control}

Sleep is both a naturally occurring phenomenon and an important component of our daily lives. According to statistics, we will spend approximately one third of our lifetime sleeping. That's a lot of time spent on a single activity! While everyone needs sleep, we are just beginning to learn about the mechanisms and purpose of sleep.

There are two internal biological mechanisms that guide and regulate us between our sleep and wakeful states. The first mechanism is called the circadian rhythm, or C-Drive. This drive serves as an internal, biological clock that guides our wakefulness throughout the day. It is roughly on a 24-hour schedule, and is synchronized and influenced by environmental cues, such as light, temperature, and time of the day. It is also the drive that pushes you out of the bed when it's really sunny outside, or makes you drowsy when it gets chilly or dark outside.

A competing drive, and the second internal biological mechanism that regulate our sleep, is called the homeostatic sleep drive, or S-Drive. This drive focuses on our need to sleep. Basically, it tracks our body's wakefulness, and becomes stronger the longer we are awake, increasing the intensity of our sleep in both length and depth in response to how long we have been awake. If you've worked non-stop for 12 hours, you might feel your S-Drive kicking in, knocking you out for a longer and more intense sleep.

In fact, the S-Drive and C-Drive compete and work in opposition to regulate our sleep. As our CDrive gets awakened and strengthened by environmental input such as sunlight, our $\mathrm{S}$-Drive is at its lowest intensity as we have just awaken. In contrast, as our C-Drive decreases in its intensity throughout the day, our S-Drive continues to build its strength, ultimately culminating in our need to fall asleep at the end of the day.

However, one mechanism that trumps both drives of sleep is arousal - whether physiological or psychological. No matter how dark it is outside, or how long we have stayed up, if we are anxious or excited about something - maybe an upcoming exam, or a first date, we will likely find it difficult to fall asleep. Physiologically-speaking, if we have just exercised, or maybe had a few too many coffees after a long night, we may also find ourselves counting sheep in bed as our body is still too aroused to sink into sleep. On the other hand, on a lazy Sunday, where not many plans were made, and we are just lounging around in our pajamas, perhaps we will find ourselves quickly dozing off to sleep, despite waking up just a few hours earlier.

Although there is no 'normal' or 'standard' length of sleep, the average sleep ranges from 6-9 hours. This is because our bodies have different needs for sleep based on many factors, such as seasonal changes, weather, age, and overall health. Despite these variations, it is still important to practice 'good sleep hygiene' in order to reap the benefits and restorative effects of sleep on our health and wellbeing. These include sticking to a regular sleep schedule, relaxing both physically and psychologically before bedtime, minimizing distractions during bedtime, and avoiding things that might disrupt our biological clocks - such as excessive caffeine and other substances like alcohol or drugs, especially before bed. 


\section{Appendix II - Stressor Protocol}

\section{II-A: TSST}

General Protocol and Procedure. Each research participant will undergo the TSST individually. There are three components within the Trier Social Stress Test: anticipatory task, speech task, and mental arithmetic task. Each task will be five minutes in length, for a total of 15 minutes. The experimenter will be neutral and non-committal throughout the experiment.

Pre-TSST: Introduction. The researcher introduces the TSST, and gives the participant an overview of the upcoming tasks. This room is set up with a video camera in the corner, and the researcher seated next to the participant. The experimenter explains to the research participants their first task, which is to give a talk in front of the experimenter, while being recorded, on the topic of Ryerson University, and how the research participant see him or herself, his or her skills and qualifications, and their future roles in Ryerson University. The experimenter reminds the research participant it is for a 5-minute length presentation, and that he or she will have 5 minutes to prepare.

TSST: Preparation Phase. The experimenter provides the researcher with paper and pen to doodle and take notes, and reminds the participant he or she will have to give back their notes at the end of the preparation period. The experimenter then instructs the participant to begin when ready. The experimenter then presses start on a countdown clock, and turns away from the participant. At the end of the five minutes, the experimenter presses the timer to indicate the termination of the task, and takes back the note pad.

TSST: Speech Task. The experimenter then reminds the participant it is now time to give a filmed presentation about what his or her roles, skills and qualifications are at Ryerson, and how it is tied to the future of Ryerson. The camera and recorder are switched on and the research participant is asked to stand in front of the video and start presenting upon pressing of timer. The experimenter then sits down on the side, takes out a note pad, and begins taking down notes. Only after a pause of more than twenty seconds prior to the end of the five-minute period are questions asked (see sample prompts below). The experimenter will note how long the speech lasted without a significant pause or need for prompt.

TSST: Mental Arithmetic Task. After the five-minute period the research participant is then informed by the experimenter they will now proceed to a backwards subtraction task, counting back in multiples of 7 from the number 2071. The experimenter will instruct the participant that if he/she makes a mistake, they have to start over from the very beginning. The experimenter will note how many total correct responses have been made, as well as the maximum number of correct responses without making an error. Upon completion of the task, the experimenter will turn off the camera and proceed to the next part of the experiment. 
Materials Required:

1. Notepad and pen (for participant, and for experimenter)

2. Timer

3. Video camera

Questions/Prompts during Presentation Task:

- What do your family/friends especially appreciate about you?

- What do you appreciate about being at Ryerson University?

- What skills and knowledge have your learned here so far?

- How have your learning shaped your future?

- Please list your strengths!

- Please list your weaknesses!

- What do you like about Ryerson University?

- What do you wish Ryerson University will change?

- What courses are you interested in taking in the future?

- What skills are you hoping to learn here?

- How will being at Ryerson shape your future?

Arithmetic Task Calculations:

$\begin{array}{lllll}2071 & 1931 & 1791 & 1651 & 1511 \\ 2064 & 1924 & 1784 & 1644 & 1504 \\ 2057 & 1917 & 1777 & 1637 & 1497 \\ 2050 & 1910 & 1770 & 1630 & 1490 \\ 2043 & 1903 & 1763 & 1623 & 1483 \\ 2036 & 1896 & 1756 & 1616 & 1476 \\ 2029 & 1889 & 1749 & 1609 & 1469 \\ 2022 & 1882 & 1742 & 1602 & 1462 \\ 2015 & 1875 & 1735 & 1595 & 1455 \\ 2008 & 1868 & 1728 & 1588 & 1448 \\ 2001 & 1861 & 1721 & 1581 & 1441 \\ 1994 & 1854 & 1714 & 1574 & 1434 \\ 1987 & 1847 & 1707 & 1567 & 1427 \\ 1980 & 1840 & 1700 & 1560 & 1420 \\ 1973 & 1833 & 1693 & 1553 & 1413 \\ 1966 & 1826 & 1686 & 1546 & 1406 \\ 1959 & 1819 & 1679 & 1539 & 1399 \\ 1952 & 1812 & 1672 & 1532 & 1392 \\ 1945 & 1805 & 1665 & 1525 & 1385 \\ 1938 & 1798 & 1658 & 1518 & 1378\end{array}$

Should the participant miscalculate, respond with: "Incorrect. 2071." 
II-B: Cognitive N-Back Task

The N-back test is a test of cognitive working memory capacity, and requires participants to decide whether the stimulus in a sequence matches the one that appeared N- trials previously. It's a memory matching task that is programmed and delivered in the E-Prime software. The N-Back Test include overall accuracy of responses, and the general speed of responses for each trial.

\section{Verbal n-back}

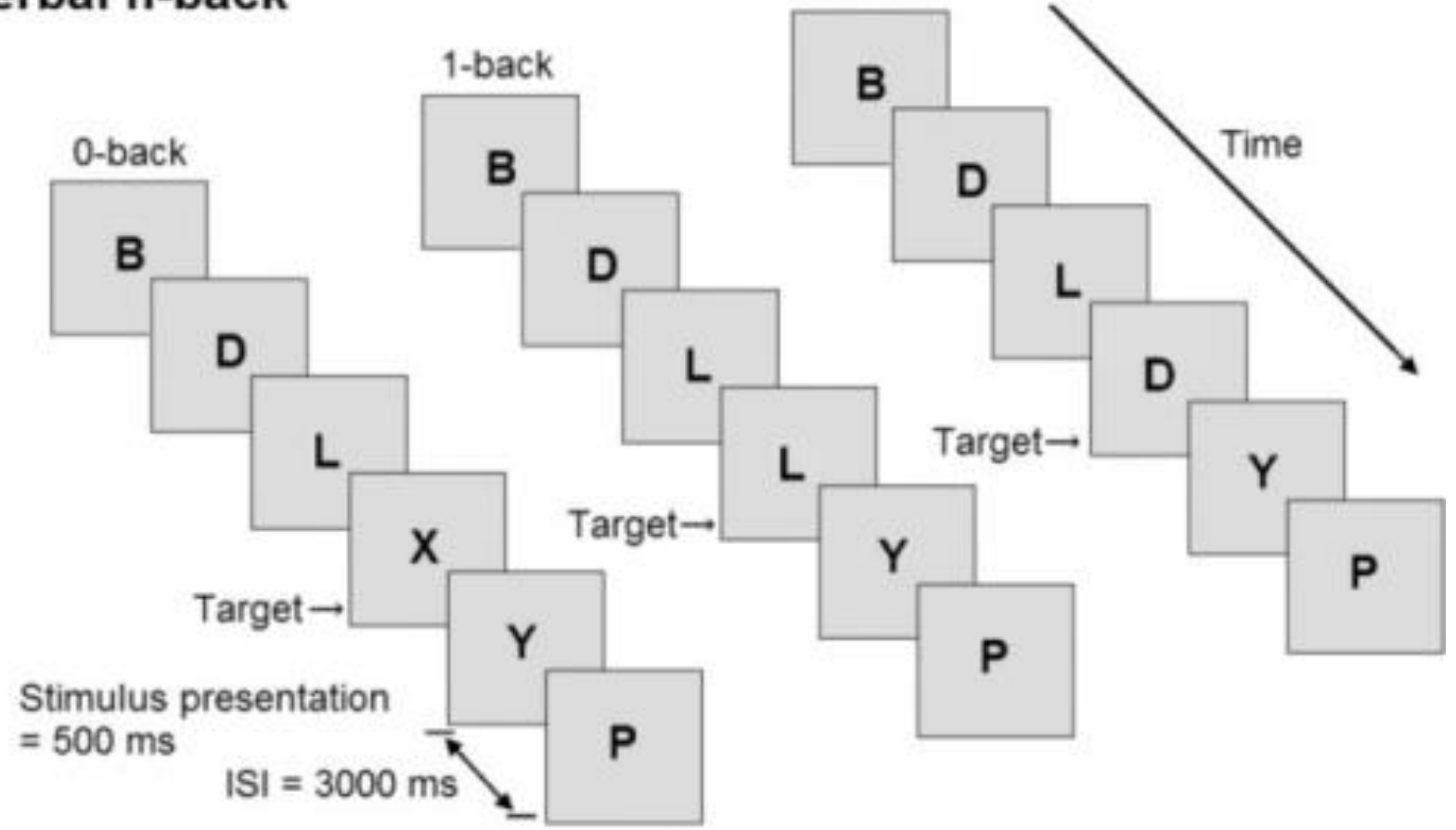

Figure 13. Sample figure for N-Back task demonstrating task sequence.

(Source: Vermeij, van Beek, Olde Rikkert, Claassen, \& Kessels, 2012). 


\section{Appendix III - VIA Classification}

\section{III-A: Signature Strengths Survey}

\section{Instructions}

\section{The Signature Strengths \\ Survey}

Read the following descriptions of 24 character strengths. Everyone uses these strengths at times.

What we would like you to do is to put a check in the box next those strengths that are

absolutely

essential to you, that define who you are as a person, that are part of who you are. For example, someone who has devoted their life to helping others might choose Kindness as one of his essential strengths, someone who prides herself on being able to figure out other people might consider Social Intelligence key to who she is, and someone who is constantly seeking out new information might consider Love of Learning to be essential. Most people check just a few essential strengths.

There are some people who believe none of these characteristics is more essential to who they are than any of the others. If so, don't check any of the strengths. In the last row, check None of these characteristics is more essential to who I am than any of the others .

Please describe the person you are, NOT the person you wish you could be. Also, think about your life in general, not how you behaved in 1-2 situations.

\begin{tabular}{|l|l|}
\hline $\begin{array}{l}\text { Essential } \\
\text { Strength? }\end{array}$ & Character Strengths \\
\hline $\begin{array}{l}\text { 1. Creativity: You are viewed as a creative person; you see, do, and/or create } \\
\text { things that are of use; you think of unique ways to solve problems and be } \\
\text { productive. }\end{array}$ \\
\hline $\begin{array}{l}\text { 2. Curiosity: You are an explorer; you seek novelty; you are interested in new } \\
\text { activities, ideas, and people; you are open to new experiences. }\end{array}$ \\
\hline $\begin{array}{l}\text { 3. Judgment/Critical Thinking: You are analytical; you examine things from all } \\
\text { sides; you do not jump to conclusions, but instead attempt to weigh all the } \\
\text { evidence when making decisions. }\end{array}$ \\
\hline $\begin{array}{l}\text { 4. Love of Learning: You often find ways to deepen your knowledge and } \\
\text { experiences; you regularly look for new opportunities to learn; you are passionate } \\
\text { about building knowledge. }\end{array}$ \\
\hline $\begin{array}{l}\text { 5. Perspective/Wisdom : You take the "big picture" view of things; others tum } \\
\text { to you for wise advice; you help others make sense of the world; you learn from } \\
\text { your mistakes. }\end{array}$ \\
\hline
\end{tabular}




\begin{tabular}{|c|c|}
\hline & $\begin{array}{l}\text { 6. Bravery/Courage: You face your fears and overcome challenges and } \\
\text { adversity; you stand up for what is right; you do not shrink in the face of pain or } \\
\text { inner tension or turmoil. }\end{array}$ \\
\hline \multirow[t]{14}{*}{\begin{tabular}{|l|} 
Essential \\
Strength?
\end{tabular}} & $\begin{array}{l}\text { 7. Perseverance: You keep going and going when you have a goal in mind; you } \\
\text { attempt to overcome all obstacles; you finish what you start. }\end{array}$ \\
\hline & $\begin{array}{l}\text { 8. Honesty: You are a person of high integrity and authenticity; you tell the truth, } \\
\text { even when it hurts; you present yourself to others in a sincere way; you take } \\
\text { responsibility for your actions. }\end{array}$ \\
\hline & $\begin{array}{l}\text { 9. Zest: You are enthusiastic toward life; you are highly energetic and activated; } \\
\text { you use your energy to the fullest degree. }\end{array}$ \\
\hline & $\begin{array}{l}\text { 10. Love: You are warm and genuine to others; you not only share but are open to } \\
\text { receiving love from others; you value growing close and intimate with others. }\end{array}$ \\
\hline & $\begin{array}{l}\text { 11. Kindness: You do good things for people; you help and care for others; you } \\
\text { are generous and giving; you are compassionate. }\end{array}$ \\
\hline & $\begin{array}{l}\text { 12. Social Intelligence: You pay close attention to social nuances and the } \\
\text { emotions of others; you have good insight into what makes people "tick"; you } \\
\text { seem to know what to say and do in any social situation. }\end{array}$ \\
\hline & $\begin{array}{l}\text { 13. Teamwork: You are a collaborative and participative member on groups and } \\
\text { teams; you are loyal to your group; you feel a strong sense of duty to your } \\
\text { group; you always do your share. }\end{array}$ \\
\hline & $\begin{array}{l}\text { 14. Fairness: You believe strongly in an equal and just opportunity for all; you } \\
\text { don't let personal feelings bias your decisions about others; you treat people the } \\
\text { way you want to be treated. }\end{array}$ \\
\hline & $\begin{array}{l}\text { 15. Leadership: You positively influence those you lead; you prefer to lead than } \\
\text { to follow; you are very good at organizing and taking charge for the collective } \\
\text { benefit of the group. }\end{array}$ \\
\hline & $\begin{array}{l}\text { 16. Forgiveness/Mercy: You readily let go of hurt after you are wronged; you } \\
\text { give people a second chance; you are not vengeful or resentful; you accept } \\
\text { people's shortcomings. }\end{array}$ \\
\hline & $\begin{array}{l}\text { 17. Humility/Modesty: You let your accomplishments speak for themselves; } \\
\text { you see your own goodness but prefer to focus the attention on others; you do } \\
\text { not see yourself as more special than others; you admit your imperfections. }\end{array}$ \\
\hline & $\begin{array}{l}\text { 18. Prudence: You are wisely cautious; you are planful and conscientious; you } \\
\text { are careful to not take undue risks or do things you might later regret. }\end{array}$ \\
\hline & $\begin{array}{l}\text { 19. Self-Regulation: You are a very disciplined person; you manage your vices } \\
\text { and bad habits; you stay calm and cool under pressure; you manage your } \\
\text { impulses and emotions. }\end{array}$ \\
\hline & $\begin{array}{l}\text { 20. Appreciation of Beauty \& Excellence: You notice the beauty and excellence } \\
\text { around you; you are often awe-struck by beauty, greatness, and/or the moral } \\
\text { goodness you witness; you are often filled with wonder. }\end{array}$ \\
\hline
\end{tabular}




\begin{tabular}{|l|l|}
\hline & $\begin{array}{l}\text { 21. Gratitude: You regularly experience and express thankfulness; you don't take } \\
\text { the good things that happen in your life for granted; you tend to feel blessed in } \\
\text { many circumstances. }\end{array}$ \\
\hline $\begin{array}{l}\text { Essential } \\
\text { Strength? }\end{array}$ & $\begin{array}{l}\text { 22. Hope: You are optimistic, expecting the best to happen; you believe in and } \\
\text { work toward a positive future; you can think of many pathways to reach your } \\
\text { goals. }\end{array}$ \\
\hline & $\begin{array}{l}\text { 23. Humor: You are playful; you love to make people smile and laugh; your } \\
\text { sense of humor helps you connect closely to others; you brighten gloomy } \\
\text { situations with fun and/or jokes. }\end{array}$ \\
\hline & $\begin{array}{l}\text { 24. Spirituality/Sense of Meaning: You hold a set of beliefs, whether religious } \\
\text { or not, about how your life is part of something bigger and more meaningful; } \\
\text { those beliefs shape your behavior and provide a sense of comfort, } \\
\text { understanding, and purpose. }\end{array}$ \\
\hline $\begin{array}{l}\text { None of these characteristics is more essential to who I am than any of the } \\
\text { others. Remember, you should choose this option if the strengths are all equally } \\
\text { essential to you, NOT because you think they should be equally essential. }\end{array}$ \\
\hline
\end{tabular}




\section{III-B: Global Assessment of Character Strengths 72}

\section{Global Assessment of Character Strengths-72}

Instructions: This questionnaire asks you to describe aspects of your personality. The first page describes 24 elements of personality. On the other pages you will be asked questions about each of those elements. Be as honest as you can.

1. Creativity: You are viewed as a creative person; you see, do, and/or create things that are of use; you think of unique ways to solve problems and be productive.

2. Curiosity: You are an explorer; you seek novelty; you are interested in new activities, ideas, and people; you are open to new

experiences.

3. Judgment/Critical Thinking: You are analytical; you examine things from all sides; you do not jump to conclusions, but instead attempt to weigh all the evidence when making decisions.

4. Love of Learning: You often find ways to deepen your knowledge and experiences; you regularly look for new opportunities to learn; you are passionate about building knowledge.

5. Perspective/iW sdom : You take the "big picture" view of things; others turn to you for wise advice; you help others make sense $\Phi$

the world; you learn from your mistakes.

6. Bravery/Courage: You face your fears and overcome challenges and adversity; you stand up for what is right; you do not shrink in

the face of pain or inner tension or turmoil.

7. Perseverance: You keep going and going when you have a goal in mind; you attempt to overcome all obstacles; you finish what

you start.

8. Honesty: You are a person of high integrity and authenticity; you tell the truth, even when it hurts; you present yourself to others

in a sincere way; you take responsibility for your actions.

9. Zest: You are enthusiastic toward life; you are highly energetic and activated; you use your energy to the fullest degree.

10. Love: You are warm and genuine to others; you not only share but are open to receiving love from others; you value growing

close and intimate with others.

11. Kindness: You do good things for people; you help and care for others; you are generous and giving; you are compassionate.

12. Social Intelligence: You pay close attention to social nuances and the emotions of others; you have good insight into what makes

people "tick"; you seem to know what to say and do in any social situation.

13. Teamwork: You are a collaborative and participative member on groups and teams; you are loyal to your group; you feel a

strong sense of duty to your group; you always do your share.

14. Fairness: You believe strongly in an equal and just opportunity for all; you don't let personal feelings bias your decisions about

others; you treat people the way you want to be treated.

15. Leadership: You positively influence those you lead; you prefer to lead than to follow; you are very good at organizing and taking

charge for the collective benefit of the group. 
16. Forgiveness/Mercy: You readily let go of hurt after you are wronged; you give people a second chance; you are not vengeful or

resentful; you accept people's shortcomings.

17. Humility/Modesty: You let your accomplishments speak for themselves; you see your own goodness but prefer to focus the

attention on others; you do not see yourself as more special than others; you admit your imperfections.

18. Prudence: You are wisely cautious; you are planful and conscientious; you are careful to not take undue risks or do things you

might later regret.

19. Self-Regulation: You are a very disciplined person; you manage your vices and bad habits; you stay calm and cool under

pressure; you manage your impulses and emotions.

20. Appreciation of Beauty \& Excellence: You notice the beauty and excellence around you; you are often awestruck by beauty,

greatness, and/or the moral goodness you witness; you are often filled with wonder.

21. Gratitude: You regularly experience and express thankfulness; you don't take the good things that happen in your life for

granted; you tend to feel blessed in many circumstances.

22. Hope: You are optimistic, expecting the best to happen; you believe in and work toward a positive future; you can think of many

pathways to reach your goals.

23. Humor: You are playful; you love to make people smile and laugh; your sense of humor helps you connect closely to others; you

brighten gloomy situations with fun and/or jokes.

24. Spirituality/Sense of Meaning: You hold a set of beliefs, whether religious or not, about how your life is part of something bigger

and more meaningful; those beliefs shape your behavior and provide a sense of comfort, understanding, and purpose. 


\begin{tabular}{|c|c|c|c|c|c|c|c|}
\hline & $\begin{array}{c}\text { Very } \\
\text { Strongly } \\
\text { Disagree }\end{array}$ & $\begin{array}{l}\text { Strongly } \\
\text { Disagree }\end{array}$ & Disagree & Neutral & Agree & $\begin{array}{l}\text { Strongly } \\
\text { Agree }\end{array}$ & $\begin{array}{l}\text { Very Strongly } \\
\text { Agree }\end{array}$ \\
\hline \multicolumn{8}{|l|}{$\begin{array}{l}\text { Creativity is an essential part of who I am in } \\
\text { this world. }\end{array}$} \\
\hline \multicolumn{8}{|l|}{$\begin{array}{l}\text { Curiosity is an essential part of who I am in } \\
\text { this world. }\end{array}$} \\
\hline \multicolumn{8}{|l|}{$\begin{array}{l}\text { Judgment/Critical Thinking is an essential } \\
\text { part of who I am in this world. }\end{array}$} \\
\hline \multicolumn{8}{|l|}{$\begin{array}{l}\text { Love of Learning is an essential part of who I } \\
\text { am in this world. }\end{array}$} \\
\hline \multicolumn{8}{|l|}{$\begin{array}{l}\text { Perspective/Wisdom is an essential part of } \\
\text { who I am in this world. }\end{array}$} \\
\hline \multicolumn{8}{|l|}{$\begin{array}{l}\text { Bravery/Courage is an essential part of who } \\
\mathrm{I} \text { am in this world. }\end{array}$} \\
\hline \multicolumn{8}{|l|}{$\begin{array}{l}\text { Perseverance is an essential part of who I } \\
\text { am in this world. }\end{array}$} \\
\hline \multicolumn{8}{|l|}{$\begin{array}{l}\text { Honesty is an essential part of who I am in } \\
\text { this world. }\end{array}$} \\
\hline \multicolumn{8}{|l|}{$\begin{array}{l}\text { Zest is an essential part of who I am in this } \\
\text { world. }\end{array}$} \\
\hline \multicolumn{8}{|l|}{$\begin{array}{l}\text { Love is an essential part of who I am in this } \\
\text { world. }\end{array}$} \\
\hline \multicolumn{8}{|l|}{$\begin{array}{l}\text { Kindness is an essential part of who I am in } \\
\text { this world. }\end{array}$} \\
\hline \multicolumn{8}{|l|}{$\begin{array}{l}\text { Social Intelligence is an essential part of } \\
\text { who I am in this world. }\end{array}$} \\
\hline \multicolumn{8}{|l|}{$\begin{array}{l}\text { Teamwork is an essential part of who I am } \\
\text { in this world. }\end{array}$} \\
\hline \multicolumn{8}{|l|}{$\begin{array}{l}\text { Fairness is an essential part of who I am in } \\
\text { this world. }\end{array}$} \\
\hline \multicolumn{8}{|l|}{$\begin{array}{l}\text { Leadership is an essential part of who I am } \\
\text { in this world. }\end{array}$} \\
\hline $\begin{array}{l}\text { Forgiveness/Mercy is an essential part of } \\
\text { who I am in this world. }\end{array}$ & & & & & & & \\
\hline
\end{tabular}




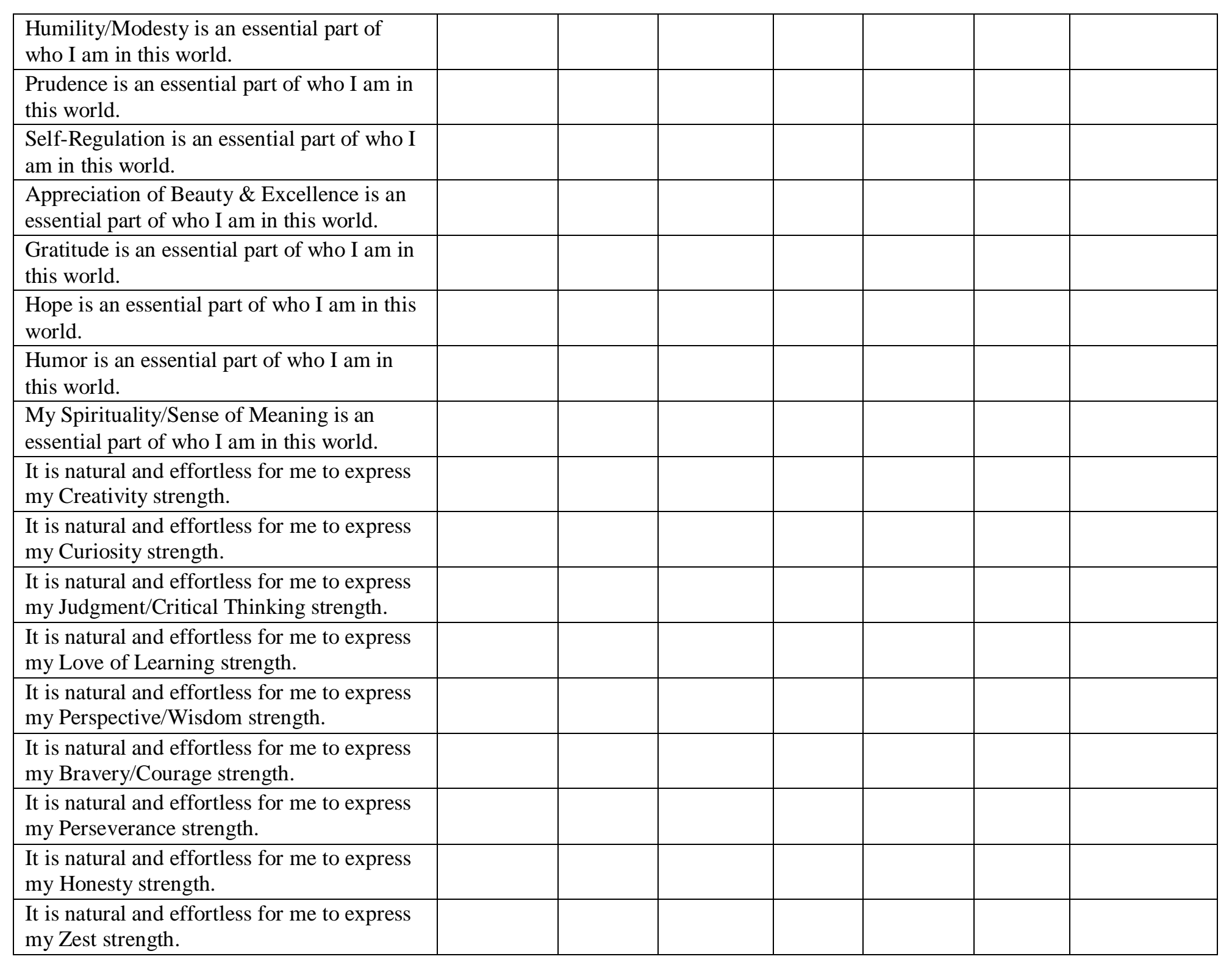




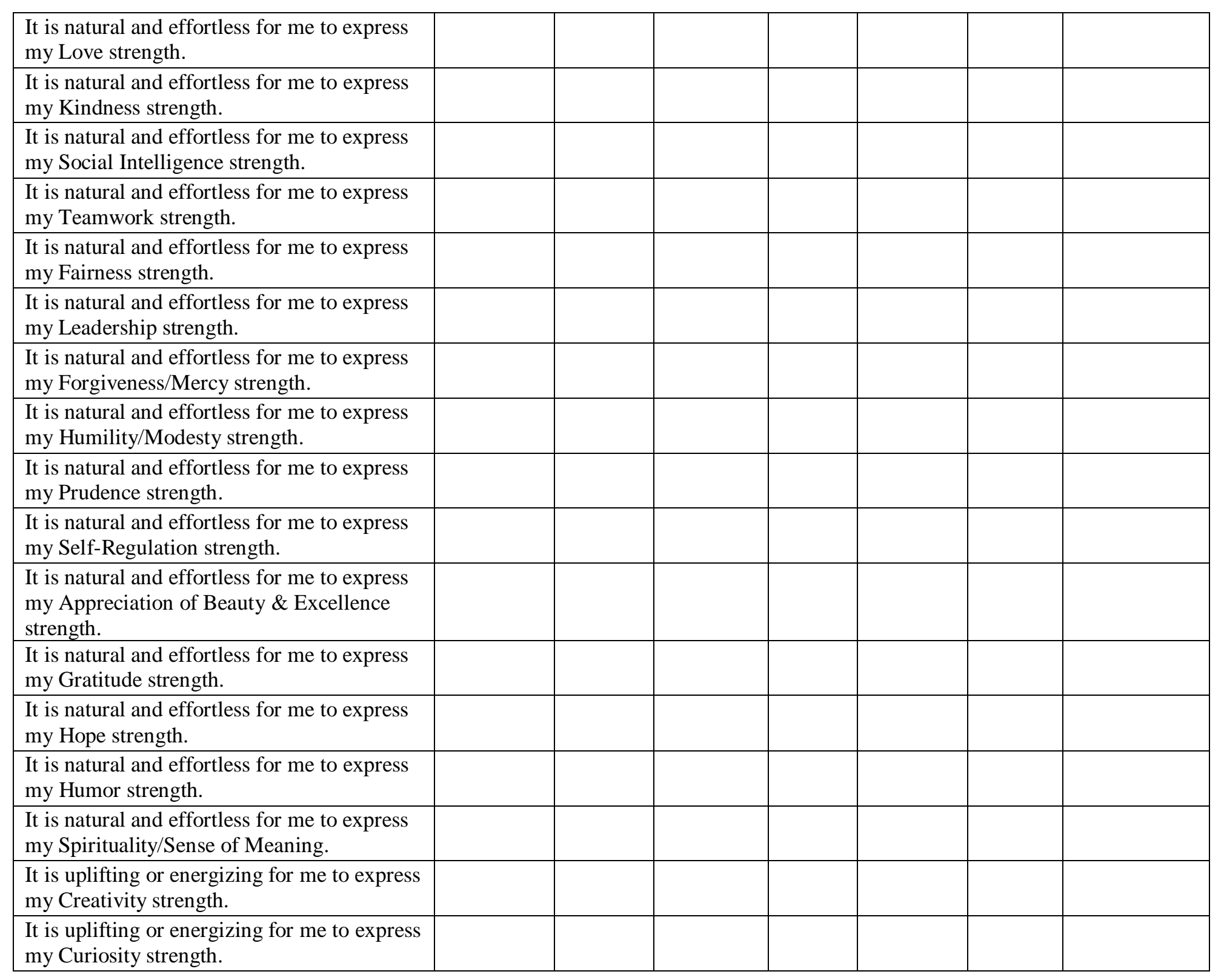




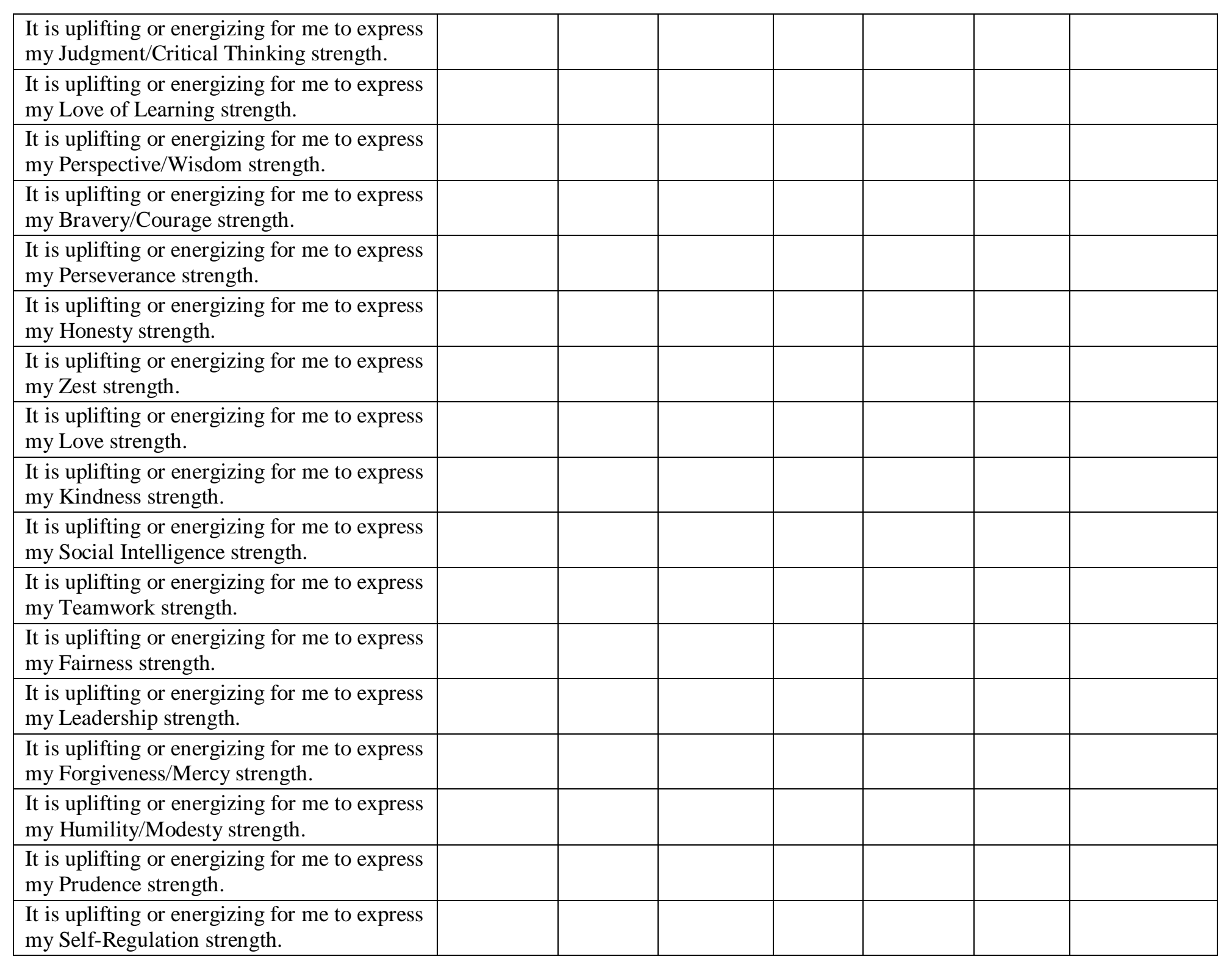




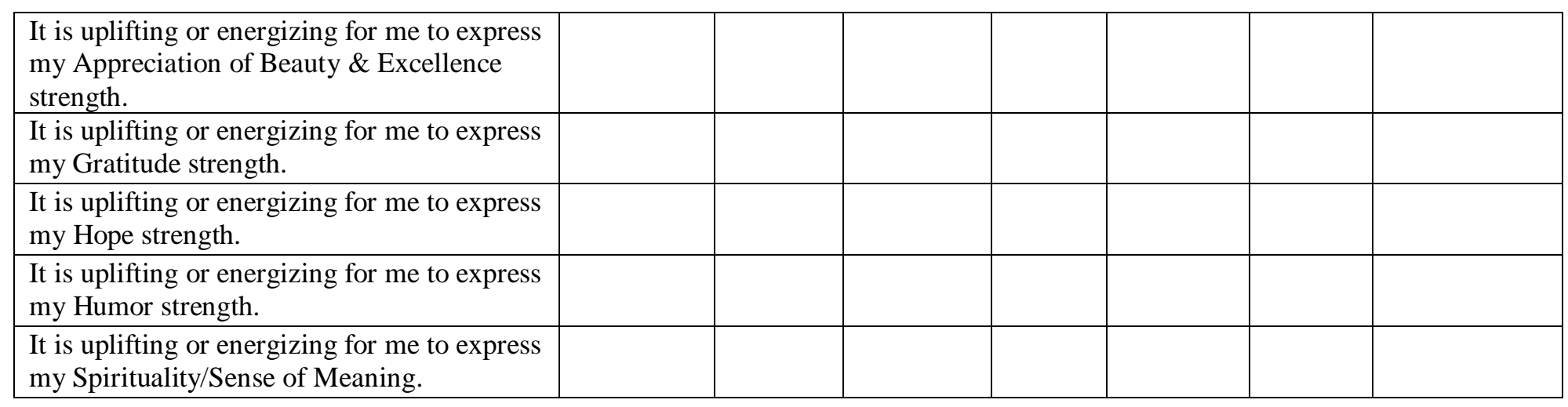




\section{Appendix IV - Pre-Test Measures}

IV-A: Demographics Questionnaire

Participant Number

1. Sex (circle one): $\mathrm{M} \quad \mathrm{F}$

2. Age:

3. Ethnicity:

4. Year(s) in Canada:

5. Year of Study (circle one): $\quad \begin{array}{lllllllll}1 & 2 & 3 & 4 & 5 & 6 & 7 & 8\end{array}$

6. When thinking of stress, please identify up to four words that comes to mind.

1.

2.

3.

4.

7. Please identify up to five (5) stressors you are currently experiencing in your daily lives, and rate each stressor from 0 (not at all stressful) to 10 (extremely stressful).

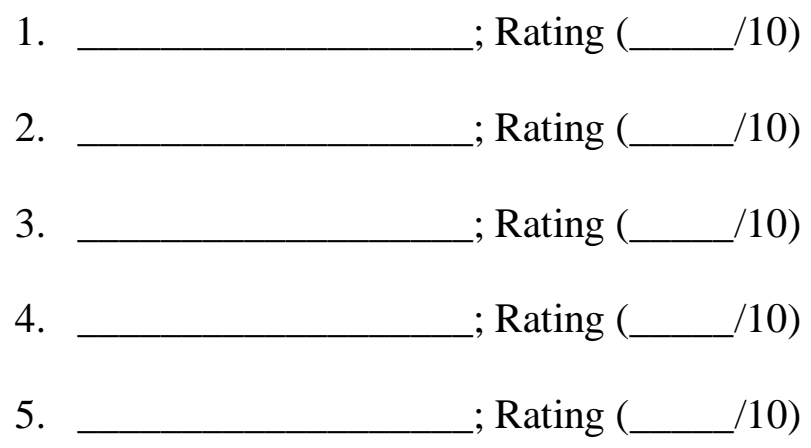

6.

8. Do you have any major/diagnosed health condition (e.g., heart disease, depression)? Yes No

8b. If yes, please indicate which condition(s): 
IV-B: Perceived Stress Scale

PSS

\begin{tabular}{|c|c|c|c|c|}
\hline 0 - Never & $\begin{array}{c}1 \text { - Almost } \\
\text { Never }\end{array}$ & 2 - Sometimes & 3 - Fairly Often & 4 - Very Often \\
\hline
\end{tabular}

\begin{tabular}{|l|l|l|l|l|l|}
\hline $\begin{array}{l}1 . \quad \text { In the last month, how often have you been upset because of } \\
\text { something that happened unexpectedly }\end{array}$ & 0 & 1 & 2 & 3 & 4 \\
\hline $\begin{array}{l}\text { 2. In the last month, how often have you felt that you were unable to } \\
\text { control the important things in your life }\end{array}$ & 0 & 1 & 2 & 3 & 4 \\
\hline $3 . \quad$ In the last month, how often have you felt nervous and "stressed" & 0 & 1 & 2 & 3 & 4 \\
\hline $\begin{array}{l}4 . \quad \text { In the last month, how often have you felt confident about your ability } \\
\text { to handle your personal problems }\end{array}$ & 0 & 1 & 2 & 3 & 4 \\
\hline $\begin{array}{l}\text { 5. In the last month, how often have you felt that things were going your } \\
\text { way } \quad 0\end{array}$ & 1 & 2 & 3 & 4 \\
\hline $\begin{array}{l}6 . \quad \text { In the last month, how often have you found that you could not cope } \\
\text { with all the things that you had to do }\end{array}$ & 0 & 1 & 2 & 3 & 4 \\
\hline $\begin{array}{l}7 . \quad \text { In the last month, how often have you been able to control irritations } \\
\text { in your life }\end{array}$ & 0 & 1 & 2 & 3 & 4 \\
\hline $\begin{array}{l}\text { 8. In the last month, how often have you felt that you were on top of } \\
\text { things } \quad\end{array}$ & 0 & 1 & 2 & 3 & 4 \\
\hline $\begin{array}{l}\text { 9. In the last month, how often have you been angered because of things } \\
\text { that were outside of your control }\end{array}$ & 0 & 1 & 2 & 3 & 4 \\
\hline $\begin{array}{l}10 . \quad \text { In the last month, how often have you felt difficulties were piling up } \\
\text { so high that you could not overcome them }\end{array}$ & 0 & 1 & 2 & 3 & 4 \\
\hline
\end{tabular}




\section{IV-C: Multidimensional Assessment of Interoceptive Awareness}

Below you will find a list of statements. Please indicate how often each statement applies to you generally in daily life.

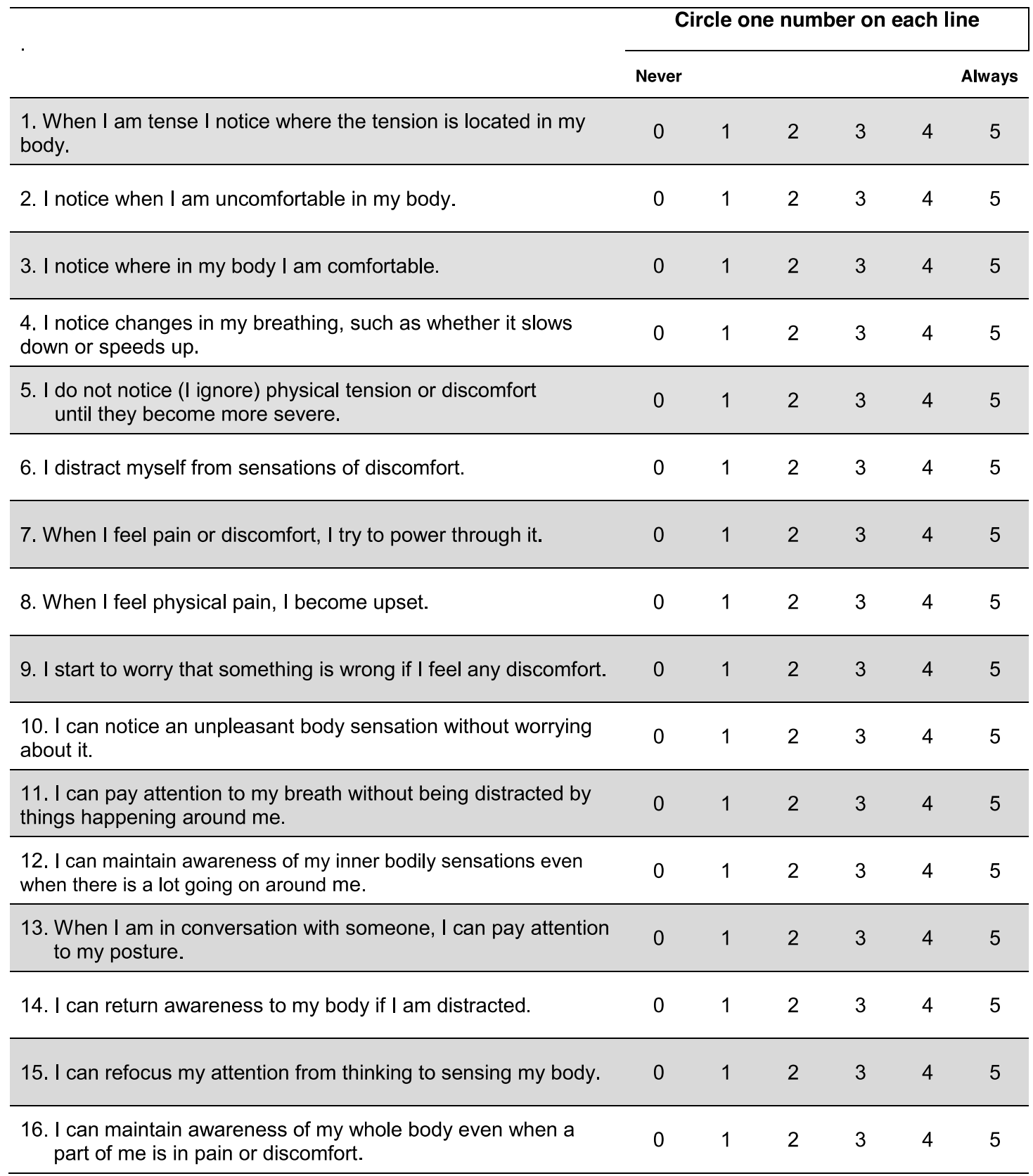


Please indicate how often each statement applies to you generally in daily life.

\begin{tabular}{|c|c|c|c|c|c|c|}
\hline & \multicolumn{6}{|c|}{ Circle one number on each line } \\
\hline & Never & & & & & Always \\
\hline 17. I am able to consciously focus on my body as a whole. & 0 & 1 & 2 & 3 & 4 & 5 \\
\hline 18. I notice how my body changes when I am angry. & 0 & 1 & 2 & 3 & 4 & 5 \\
\hline 19. When something is wrong in my life I can feel it in my body. & 0 & 1 & 2 & 3 & 4 & 5 \\
\hline $\begin{array}{l}\text { 20. I notice that my body feels different after a peaceful } \\
\text { experience. }\end{array}$ & 0 & 1 & 2 & 3 & 4 & 5 \\
\hline $\begin{array}{l}\text { 21. I notice that my breathing becomes free and easy when I feel } \\
\text { comfortable. }\end{array}$ & 0 & 1 & 2 & 3 & 4 & 5 \\
\hline 22. I notice how my body changes when I feel happy / joyful. & 0 & 1 & 2 & 3 & 4 & 5 \\
\hline 23. When I feel overwhelmed I can find a calm place inside. & 0 & 1 & 2 & 3 & 4 & 5 \\
\hline 24. When I bring awareness to my body I feel a sense of calm. & 0 & 1 & 2 & 3 & 4 & 5 \\
\hline 25. I can use my breath to reduce tension. & 0 & 1 & 2 & 3 & 4 & 5 \\
\hline $\begin{array}{l}\text { 26. When I am caught up in thoughts, I can calm my mind by } \\
\text { focusing on my body/breathing. }\end{array}$ & 0 & 1 & 2 & 3 & 4 & 5 \\
\hline $\begin{array}{l}\text { 27. I listen for information from my body about my emotional } \\
\text { state. }\end{array}$ & 0 & 1 & 2 & 3 & 4 & 5 \\
\hline 28. When I am upset, I take time to explore how my body feels. & 0 & 1 & 2 & 3 & 4 & 5 \\
\hline 29. I listen to my body to inform me about what to do. & 0 & 1 & 2 & 3 & 4 & 5 \\
\hline 30. I am at home in my body. & 0 & 1 & 2 & 3 & 4 & 5 \\
\hline 31. I feel my body is a safe place. & 0 & 1 & 2 & 3 & 4 & 5 \\
\hline 32. I trust my body sensations. & 0 & 1 & 2 & 3 & 4 & 5 \\
\hline
\end{tabular}


IV-D: Coping and Appraisal, and Coping Behavior

\section{Coping Appraisal}

1. When dealing with a problem, I spend time trying to understand what happened.
a. Mostly true about me 4
b. Somewhat true about me ........................... 3
c. A little true about me ............................... 2
d. Not true about me ................................ 1

2. When dealing with a problem, I try to see the positive side of the situation.
a. Mostly true about me 4
b. Somewhat true about me ........................... 3
c. A little true about me ................................ 2
d. Not true about me .................................. 1

3. When dealing with a problem, I try to step back from the problem and think about it from a different point of view.
a. Mostly true about me 4
b. Somewhat true about me .......................... 3
c. A little true about me ............................... 2
d. Not true about me ................................... 1

4. When dealing with a problem, I consider several alternatives for handling the problem.
a. Mostly true about me 4
b. Somewhat true about me ........................... 3
c. A little true about me ............................... 2
d. Not true about me ................................. 1

5. When dealing with a problem, I try to see the humor in it.
a. Mostly true about me 4
b. Somewhat true about me .......................... 3
c. A little true about me ............................. 2
d. Not true about me ................................. 1

6. When dealing with a problem, I think about what it might say about bigger lifestyle changes I need to make.
a. Mostly true about me 4
b. Somewhat true about me ......................... 3
c. A little true about me .............................. 2
d. Not true about me .................................. 1 
7. When dealing with a problem, I often try to remember that the problem is not as serious as it seems.
a. Mostly true about me 4
b. Somewhat true about me ........................... 3
c. A little true about me ................................ 2
d. Not true about me .................................... 1

\section{Coping Behaviors Self-Care}

1. When dealing with a problem, I often use exercise, hobbies, or meditation to help me get through a tough time.
a. Mostly true about me 4
b. Somewhat true about me ........................... 3
c. A little true about me ................................. 2
d. Not true about me ..................................... 1

2. When dealing with a problem, I make jokes about it or try to make light of it.
a. Mostly true about me 4
b. Somewhat true about me
c. A little true about me
d. Not true about me 1

3. When dealing with a problem, I take steps to take better care of myself and my family for the future.
a. Mostly true about me 4
b. Somewhat true about me .......................... 3
c. A little true about me ............................... 2
d. Not true about me .................................. 1

4. When dealing with a problem, I work on making things better for the future by changing my habits, such as diet, exercise, budgeting, or staying in closer touch with people I care about.
a. Mostly true about me 4
b. Somewhat true about me 3
c. A little true about me
d. Not true about me 1

\section{Managing}

1. When dealing with a problem, I often wait it out and see if it doesn't take care of itself.
a. Mostly true about me 4
b. Somewhat true about me .......................... 3
c. A little true about me .............................. 2
d. Not true about me 
2. When dealing with a problem, I often distract myself by watching television, listening to music, or surfing the internet.
a. Mostly true about me 4
b. Somewhat true about me .......................... 3
c. A little true about me .............................. 2
d. Not true about me ................................. 1

3. When dealing with a problem, I have used professional help, such as calling the police or going to a doctor or therapist.
a. Mostly true about me 4
b. Somewhat true about me
c. A little true about me 2
d. Not true about me 1

4. When dealing with a problem, I make compromises.
a. Mostly true about me 4
b. Somewhat true about me ........................... 3
c. A little true about me ............................... 2
d. Not true about me ................................... 1

Other coping items

1. When dealing with a problem, I sometimes drink more alcohol, smoke more, or take more medication to help me get through a tough time.
a. Mostly true about me 4
b. Somewhat true about me .......................... 3
c. A little true about me ............................... 2
d. Not true about me ................................. 1

2. When dealing with a problem caused by someone I know, I try to avoid the person or stay away from them.
a. Mostly true about me 4
b. Somewhat true about me ........................... 3
c. A little true about me ............................. 2
d. Not true about me ................................ 1 
IV-E: Spheres of Control Scale

SCS

\begin{tabular}{|c|c|c|c|c|c|c|}
\hline $\begin{array}{c}1- \\
\text { Very } \\
\text { Strongly } \\
\text { Disagree }\end{array}$ & $\begin{array}{c}2- \\
\text { Strongly } \\
\text { Disagree }\end{array}$ & $\begin{array}{c}3- \\
\text { Mildly } \\
\text { Disagree }\end{array}$ & $\begin{array}{c}4- \\
\text { Neutral }\end{array}$ & $\begin{array}{c}5- \\
\text { Mildly } \\
\text { Agree }\end{array}$ & $\begin{array}{c}6- \\
\text { Strongly } \\
\text { Agree }\end{array}$ & $\begin{array}{c}7- \\
\text { Very } \\
\text { Strongly } \\
\text { Agree }\end{array}$ \\
\hline
\end{tabular}

\begin{tabular}{|c|c|c|c|c|c|c|c|}
\hline Wher & 1 & 2 & 3 & 4 & 5 & & 7 \\
\hline $\mathrm{Wh}$ & 1 & 2 & 3 & 4 & 5 & 6 & 7 \\
\hline I prefer games involving some luck over games rec & 1 & 2 & 3 & 4 & 5 & 6 & 7 \\
\hline I can learn almo & 1 & 2 & 3 & 4 & 5 & 6 & 7 \\
\hline $\begin{array}{l}5 . \quad \text { My major accomplishments are entirely due to my hard work and } \\
\text { ability. }\end{array}$ & 1 & 2 & 3 & 4 & 5 & 6 & 7 \\
\hline $\begin{array}{l}\text { 6. I usually don't set goals because I have a hard time following through } \\
\text { on them. }\end{array}$ & 1 & 2 & 3 & 4 & 5 & 6 & 7 \\
\hline Competitiol & 1 & 2 & 3 & 4 & 5 & 6 & 7 \\
\hline Oft & 1 & 2 & 3 & 4 & 5 & 6 & 7 \\
\hline $\begin{array}{l}\text { 9. On any sort of exam or competition I like to know how well I do } \\
\text { relative to everyone else. }\end{array}$ & 1 & 2 & 3 & 4 & 5 & 6 & 7 \\
\hline 10. $\quad$ It is $\mathrm{pc}$ & 1 & 2 & 3 & 4 & 5 & 6 & 7 \\
\hline $\begin{array}{l}\text { 11. Even when I'm feeling self-confident about most things, I still seem to } \\
\text { lack the ability to control social situations. }\end{array}$ & 1 & 2 & 3 & 4 & 5 & 6 & 7 \\
\hline keeping friends. & 1 & 2 & 3 & 4 & 5 & 6 & 7 \\
\hline $\begin{array}{l}\text { 13. I'm not good at guiding the course of a conversation with several } \\
\text { others. }\end{array}$ & 1 & 2 & 3 & 4 & 5 & 6 & 7 \\
\hline $\begin{array}{l}\text { 14. I can usually establish a close personal relationship with someone I } \\
\text { find attractive. }\end{array}$ & 1 & 2 & 3 & 4 & 5 & 6 & 7 \\
\hline $\begin{array}{l}\text { 15. When being interviewed I can usually steer the interviewer toward the } \\
\text { topics I want to talk about and away from those I wish to avoid. }\end{array}$ & 1 & 2 & 3 & 4 & 5 & 6 & 7 \\
\hline $\begin{array}{l}\text { 16. If I need help in carrying off a plan of mine, it's usually difficult to get } \\
\text { others to help. }\end{array}$ & \begin{tabular}{|l|l} 
\\
\end{tabular} & 2 & 3 & 4 & 5 & 6 & 7 \\
\hline
\end{tabular}




\begin{tabular}{|c|c|c|c|c|c|c|c|}
\hline If there's someone I want to meet I can usually arrange it. & 1 & 2 & 3 & 4 & 5 & 6 & 7 \\
\hline I often find it hard to get my point of view across to others. & 1 & 2 & 3 & 4 & 5 & 6 & 7 \\
\hline 19. In attempting to smooth over a disagreement I usually make it worse. & 1 & 2 & 3 & 4 & 5 & 6 & 7 \\
\hline 20. I find it easy to play an important part in most group situations. & 1 & 2 & 3 & 4 & 5 & 6 & 7 \\
\hline $\begin{array}{l}\text { 21. By taking an active part in political and social affairs we, the people, } \\
\text { can control world events. }\end{array}$ & 1 & 2 & 3 & 4 & 5 & 6 & 7 \\
\hline 22. The average citizen can have an influence on government decisions. & 1 & 2 & 3 & 4 & 5 & 6 & 7 \\
\hline $\begin{array}{l}\text { 23. It is difficult for people to have much control over the things } \\
\text { politicians do in office. }\end{array}$ & 1 & 2 & 3 & 4 & 5 & 6 & 7 \\
\hline $\begin{array}{l}\text { 24. Bad economic conditions are caused by world events that are beyond } \\
\text { our control. }\end{array}$ & 1 & 2 & 3 & 4 & 5 & 6 & 7 \\
\hline 25. With enough effort we can wipe out political corruption. & 1 & 2 & 3 & 4 & 5 & 6 & 7 \\
\hline $\begin{array}{l}\text { 26. One of the major reasons we have wars is because people don't take } \\
\text { enough interest in politics. }\end{array}$ & 1 & 2 & 3 & 4 & 5 & 6 & 7 \\
\hline $\begin{array}{l}\text { 27. There is nothing we, as consumers, can do to keep the cost of living } \\
\text { from going higher. }\end{array}$ & 1 & 2 & 3 & 4 & 5 & 6 & 7 \\
\hline $\begin{array}{l}\text { 28. When I look at it carefully I realize it is impossible to have any really } \\
\text { important influence over what big businesses do. }\end{array}$ & 1 & 2 & 3 & 4 & 5 & 6 & 7 \\
\hline $\begin{array}{l}\text { 29. I prefer to concentrate my energy on other things rather than on } \\
\text { solving the world's problems. }\end{array}$ & 1 & 2 & 3 & 4 & 5 & 6 & 7 \\
\hline $\begin{array}{l}\text { 30. In the long run we, the voters, are responsible for bad government on a } \\
\text { national as well as a local level. }\end{array}$ & 1 & 2 & 3 & 4 & 5 & 6 & 7 \\
\hline
\end{tabular}




\section{IV-F: Schutte Self-Report Emotional Intelligence Test}

\section{SSEIT}

Instructions: Indicate the extent to which each item applies to you using the following scale:

$$
\begin{aligned}
& 1=\text { strongly disagree } \\
& 2=\text { disagree } \\
& 3=\text { neither disagree nor agree } \\
& 4=\text { agree } \\
& 5=\text { strongly agree }
\end{aligned}
$$

1. I know when to speak about my personal problems to others.

2. When I am faced with obstacles, I remember times I faced similar obstacles and overcame them.

3. I expect that I will do well on most things I try.

4. Other people find it easy to confide in me.

5. I find it hard to understand the nonverbal messages of other people.

6. Some of the major events of my life have led me to re-evaluate what is important and not important.

7. When my mood changes, I see new possibilities.

8. Emotions are some of the things that make my life worth living.

9. I am aware of my emotions as I experience them.

10. I expect good things to happen.

11. I like to share my emotions with others.

12. When I experience a positive emotion, I know how to make it last.

13. I arrange events others enjoy.

14. I seek out activities that make me happy.

15. I am aware of the nonverbal messages I send to others.

16. I present myself in a way that makes a good impression on others.

17. When I am in a positive mood, solving problems is easy for me.

18. By looking at their facial expressions, I recognize the emotions people are experiencing.

19. I know why my emotions change.

20. When I am in a positive mood, I am able to come up with new ideas.

21. I have control over my emotions.

22. I easily recognize my emotions as I experience them.

23. I motivate myself by imagining a good outcome to tasks I take on.

24. I compliment others when they have done something well.

25. I am aware of the nonverbal messages other people send.

26. When another person tells me about an important event in his or her life, I almost feel as though I have experienced this event myself.

27. When I feel a change in emotions, I tend to come up with new ideas.

28. When I am faced with a challenge, I give up because I believe I will fail.

29. I know what other people are feeling just by looking at them.

30. I help other people feel better when they are down.

31. I use good moods to help myself keep trying in the face of obstacles.

32. I can tell how people are feeling by listening to the tone of their voice.

33. It is difficult for me to understand why people feel the way they do. 


\section{Appendix V - Subjective Measures of Stress and Performance}

\section{VAS-Stress Perception}

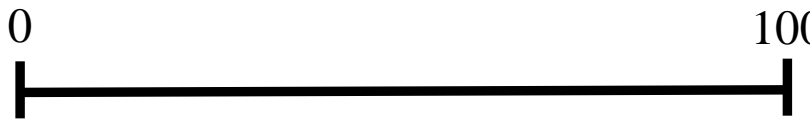

stress does not

bother me

I find stress to be extremely

bothersome and

threatening

VAS - Stress Response

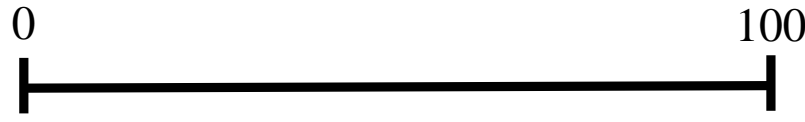

not at all

stressed

extremely

stressed

\section{VAS - Coping}

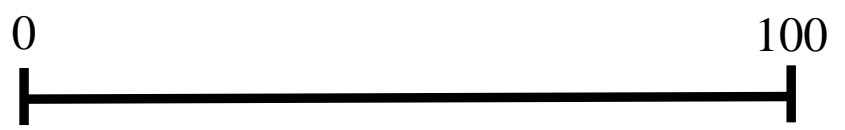

not good at coping at all

copes extremely well 


\section{REFERENCES}

Allen, A. P., Kennedy, P. J., Dockray, S., Cryan, J. F., Dinan, T. G., \& Clarke, G. (2016). The Trier Social Stress Test: Principles and practice. Neurobiology of Stress, 6, 113-126. doi:10.1016/j.ynstr.2016.11.001

Andersen, J.P., \& Gustafsberg, H. (2016). A training method to improve police use of force decision making: A randomized controlled trial. Sage Open, 1-13. doi: $10.1177 / 2158244016638708$

Angermeyer, M.C., \& Matschinger, H. (2003). The stigma of mental illness: Effects of labelling on public attitudes towards people with mental disorder. Acta Psyhiatrica Scandinavica, 108, 304-309.

Belzer, M.L., Nock, M.K., Peters, B.J., \& Jamieson, J.P. (2014). Rethinking butterflies: The affective, physiological, and performance effects f reappraising arousal during social evaluation. Emotion, 14, 761-768. doi: 10.1037/a0036326

Benedek, M., \& Kaernbach, C. (2010). A continuous measure of phasic electrodermal activity. Journal of Neuroscience Methods, 190, 80-91. doi: 10.1016/j.jneumeth.2010.04.028

BIOPAC Systems Inc. (2018). Negative EDA (GSR). Retrieved from https://www.biopac.com/knowledge-base/negative-eda-gsr

Blascovich, J., Mendes, W.B., Tomaka, J., Salomon, K., \& Seery, M. (2003). The robust nature of the biopsychosocial model challenge and threat: A reply to Wright and Kirby. Personality and Social Psychology Review, 7, 234-243. doi:

10.1207/S15327957PSPR0703_03

Bollini, A.M., Walker, E.F., Hamann, S., \& Kestler, L. (2004). The influence of perceived 
control and locus of control on the cortisol and subjective responses to stress. Biological Psychology, 67, 245-60. doi:1016/j.biopsycho.2003.11.002

Brackett, M.A., Rivers, S.E., \& Salovey, P. (2011). Emotional intelligence: Implications for personal, social, academic, and workplace success. Social and Personality Psychology Compass, 5(1), 88-103. doi: 10.111/j.1751-9004.2010.00334.x

Braithwaite, J. J., Watson, D. G., Jones, R., \& Rowe, M. (2013). A guide for analysing electrodermal activity (EDA) \& skin conductance responses (SCRs) for psychological experiments. Psychophysiology, 49, 1017-1034.

Breske, M.P. (2016). The effects of motivational goal priming on cortisol and psychological responses in males exposed to an ego-involving climate. (Master's thesis). Retrieved from ProQuest. (ProQuest 10163076).

Brickenkamp, R., \& Zillmer, E. (1998). D2: Test of Attention. Bostin, MA: Hogrefe Publishing.

Brodal, P. (2004). The central nervous system: Structure and functions. US: Oxford University Press.

Campbell, J.L., Quincy, C., Osserman, J., \& Pederson, O.K. (2013). Coding in-depth semistructured interviews: Problems of utilization and intercoder reliability and agreement. Sociological Methods \& Research, 42, 294-320. doi:

$10.1177 / 0049124113500475$

Castro-Schilo, L., \& Grimm, K.J. (2017). Using residualized change versus difference scores for longitudinal research. Journal of Social and Personal Relationships, 35, 35-58. doi: $10.1177 / 0265407517718387$

Cohen, S., Kamarack, T., \& Mermelstein, R. (1983). A global measure of perceived stress. Journal of Health and Social Behavior, 24(4), 386-396. Retrieved from 
http://www.ncbi.nlm.nih.gov/pubmed/6668417

Cohen, S., \& Williamson, G. (1988). Perceived stress in a probability sample of the United States. In Spacapan, S. and Oskamp, S. (Eds.), The Social Psychology of Health. Newbuy Park, CA: Sage.

Creswell, J.D., Welch, W.T., Taylor, S.E., Sherman, D.K., Gruenewald, T.L., \& Mann, T. (2005). Affirmation of personal values buffers neuroendocrine and psychological stress responses. Psychological Science, 16(11), 846-851.

Crum, A. \& Lyddy, C. (2014). De-stressing stress: The power of mindsets and the art of stressing mindfully. In A. Ie, C.T. Ngnoumen, \& E. J. Langer (Eds.), The Wiley Blackwell Handbook of Mindfulness. New Jersey: Wiley-Blackwell.

Crum, A.J., Salovey, P. \& Achor, S. (2013). Rethinking stress: The role of mindsets in determining the stress response. Personality Processes and Individual Differences, 104(4), 716-733. doi: 10.1037/a0031201

Darley, J.M., Gross, P.H. (1983). A hypothesis-confirming bias in labeling effects. Journal of Personality and Social Psychology, 44, 20-33.

Del Giudice, M., Ellis, B.J., \& Shirtcliff, E.A. (2011). The Adaptive Calibration Model of stress responsivity. Neuroscience and Biobehavioral Reviews, 35(7), 1562-1592.

Delawalla, Z. (2010). Stress reactivity, stress appraisal and coping responses in schizophrenia. All Theses and Dissertations (ETDs). 84. Retrieved from http://openscholarship.wustl.edu/etd/84

Dickerson, S. S., \& Kemeny, M. E. (2004). Acute stressors and cortisol responses: A theoretical integration and synthesis of laboratory research. Psychological Bulletin, 130, 355-391. doi:10.1037/0033-2909.130.3.355 
Donker, T., Griffiths, K.M., Cuijpers, P., \& Christensen, H. (2009). Psychoeducation for depression, anxiety and psychological distress: A meta-analysis. BMC Medicine, 7, 79. doi: 10.1186/1741-7015-7-79

Dweck, C.S. (2008). Can personality be changed? The role of beliefs in personality and change. Current Directions in Psychological Science, 17, 391-394. doi: 10.1111/j.1467-87212..8.00612.x

Ekeberg, O., Kjeldsen, S.E., Greenwood, D.T., \& Enger, E. (1990). Correlations between psychological and physiological responses to acute flight phobia stress. Scandinavian Journal of Clinical Lab Investigations, 50, 671-677.

Enders, C.K. (2017). Multiple imputation as a flexible tool for missing data handling in clinical research. Behavioral Research and Theory, 98, 4-18. doi: 10.1016/j.brat.2016.11.008

Fluckiger, C., \& Grosse Holtforth, M. (2008). Focusing the therapist's attention on the patient's strengths: A preliminary study to foster a mechanism of change in outpatient psychotherapy. Journal of Clinical Psychology, 64, 876-890.

Flukiger, C., Caspar, F., Grosse Holtforth, M., \& Willutzki, U. (2009). Working with patients' strengths: A microprocess approach. Psychotherapy Research, 19, 213-223.

Fluckiger, C., \& Wusten, G., Zinbarg, R. E., \& Wampold, B. E. (2010). Resource activation: Using client's own strengths in psychotherapy and counseling. Cambridge, MA: Hogrefe.

Folkman, S. (1997). Positive psychological states and coping with severe stress. Social Science and Medicine, 45, 1207-1221.

Folkman, S. (2008). The case for positive emotions in the stress process. Anxiety, Stress \& Coping, 21(1), 3-14. doi: 10.1080/10615800701740457

Folkman, S., Moskowitz, J.T., Ozer, E.M., \& Park, C.L. (1997). Positive meaningful events and 
coping in the context of HIV/AIDS. In B.H. Gottlieb (ed.), Coping with chronic stress (pp. 293-314). New York: Plenum Press.

Francis, A.L. (2018). The Embodied Theory of Stress: A constructionist perspective on the experience of stress. Review of General Psychology, 22, 398-405. doi: $10.1037 / g p r 0000164$

Fu, R., \& Holmer, H.K. (2015). Change Score or Followup Score? An Empirical Evaluation of the Impact of Choice of Mean Difference Estimates [Internet]. Rockville (MD): Agency for Healthcare Research and Quality (US). Retrieved from: https://www.ncbi.nlm.nih.gov/books/NBK294288/

González-Ramírez, M., Rodríguez-Ayán, M., \& Hernández, R. (2013). The Perceived Stress Scale (PSS): Normative data and factor structure for a large-scale sample in Mexico. The Spanish Journal of Psychology, 16. doi:10.1017/sjp.2013.35

Hayes, A. F. (2017). Introduction to mediation, moderation, and conditional process analysis. New York, NY: The Guilford Press

Hobfoll, S.E. (2004). Stress, culture, and community. New York: Springer.

Holahan, C. J., \& Moos, R. H. (1987). Personal and contextual determinants of coping strategies. Journal of Personality and Social Psychology, 52(5), 946-955.

Jackson, B., Compton, J., Thornton, A.L., \& Dimmock, J.A. (2017) Re-Thinking anxiety: Using inoculation messages to reduce and reinterpret public speaking fears. PLoS ONE 12(1): e0169972. doi:10.1371/journal.pone.0169972

Jamieson, J.P., Crum, A.J., Goyer, J.P., Marotta, M.E., \& Akinola, M. (2018). Optimizing stress responses with appraisal and mindset interventions: An integrated model. Anxiety, Stress \& Coping, 31, 245-261. doi: 10.1080/10615806.2018.144261 
Jamieson, J.P., Mendes, W.B., Blackstock, E., \& Schmader, T. (2010). Turning the knots in your stomach into bows: Reappraisal arousal improves performance on the GRE. Journal of Experimental Social Psychology, 46, 208-212. doi: 10.1016/j.jesp.2008.08.015

Jamieson, J.P., Nock, M.K., \& Mendes, W.B. (2013). Changing the conceptualization of stress in social anxiety disorder: Affective and physiological consequences. Clinical Psychological Science. Advance online publication. doi: 10.1177/2167702613482119

Jamieson, J.P., Nock, M.K., \& Mendes, W.B. (2012). Mind over matter: Reappraising arousal improves cardiovascular and cognitive responses to stress. Journal of Experimental Psychology: General, 141(3), 417-422. doi: 10.1037/a0025719

Kane, L., \& Ashbaugh, A.R. (2017). Simple and parallel mediation: A tutorial exploring anxiety sensitivity, sensation seeking, and gender. The Quantitative Methods for Psychology, 13, 148-160. doi: 10.20982/tqmp.13.3.p148

Keller, A., Litzelman, K., Eisk, L.E., Maddox, T., Cheung, E.R., Creswell, P.D., et al. (2012). Does the perception that stress affects health matter? The association with health and mortality. Health Psychology, 31, 677-681. doi: 10.1037/a0026743

Kirchner, W.K. (1958). Age differences in short-term retention of rapidly changing information. Journal of Experimental Psychology, 55, 352-358. doi: 10.1037/h0043688

Kirschbaum, C., \& Hellhammer, D. (2000). Salivary Cortisol and Challenge Tests: Allostatic Load working group. Retrieved online from http://www.macses.ucsf.edu/research/allostatic/challenge.php

Kirschbaum, C., Pirke, K., \& Hellhammer, D.H. The 'Triers Social Stress Test' - a tool for 
investigating psychobiological stress responses in a laboratory setting. Neuropsychobiology, 28, 76-81. Retrieved from http://www.ncbi.nlm.nih.gov/pubmed/8255414

Fluckiger, C., \& Grosse Holtforth, M. (2008). Focusing the therapist's attention on the patient's strengths: A preliminary study to foster a mechanism of change in outpatient psychotherapy. Journal of Clinical Psychology, 64, 876-890.

Fluckiger, C., \& Wusten, G., Zinbarg, R. E., \& Wampold, B. E. (2010). Resource activation: Using client's own strengths in psychotherapy and counseling. Cambridge, MA: Hogrefe.

Goodman, W.K., Janson, J., \& Wolf, J.M. (2017). Meta-analytical assessment of the effects of protocol variations on cortisol responses to the Trier Social Stress Test. Psychoneuroendocrinology, 80, 26-35.

Hausler, M., Strecker, C., Huber, A., Brenner, M., Höge, T., \& Höfer, S. (2017). Distinguishing relational aspects of character strengths with subjective and psychological well-being. Frontiers in Psychology, 8, 1159. doi: 10.3389/fpsyg.2017.01159

Höfer, S., Gander, F., Höge, T., \& Ruch, W. (2019). Special Issue: Character strengths, well being, and health in educational and vocational settings. Applied Research in Quality of Life, 1-6. doi: 10.1007/s11482-018-9688-y

Koole, S.L., Smeets, K., van Knippenberg, A., \& Dijksterhuis, A. (1999). The cessation of rumination through self-affirmation. Journal of Personality and Social Psychology, 77, $111-125$.

Kudielka, B.M., von Kanel, R., Preckel, D., Zgraggen, L., Mischler, K., \& Fischer, J.E. (2006). 
Exhaustion is associated with reduced habituation of free cortisol responses to repeated acute psychosocial stress. Biological Psychology, 72(2), 147-153. doi:

10.1016/j.biopsycho.2005.09.001

Lam, D. C., Salkovskis, P. M. and Hogg, L. I. (2016), 'Judging a book by its cover’: An experimental study of the negative impact of a diagnosis of borderline personality disorder on clinicians' judgements of uncomplicated panic disorder. British Journal of Clinical Psychology, 55, 253-268. doi:10.1111/bjc.12093

Lazarus, R. S. \& Folkman, S. (1984). Stress, appraisal, and coping. New York, NY: Springer Publishing Company.

Lee, E. (2012). Review of the psychometric evidence of the Perceived Stress Scale. Asian Nursing Research, 6(4), 121-127. doi: 10.1016/j.anr.2012.08.004

Lesage, F.X., Berjot, S., Deschamps, F. (2012). Clinical stress assessment using a visual analogue scale. Occupational Medicine, 62, 600-605. doi: 10.1093/occmed/kqs140

Liu, J.J.W., Ein, N., Gervasio, J., \& Vickers, K. (2019). The efficacy of stress reappraisal interventions on stress responsivity: A meta-analysis and systematic review of existing evidence. PLoS ONE, 14, e0212854. doi: 10.1371/journal.pone.0212854

Liu, J.J.W, Ein, N., Peck, K., Huang, V., Pruessner, J., \& Vickers, K. (2017). Sex differences in salivary cortisol to the Trier Social Stress Test (TSST): A meta-analysis.

Psychoneuroendocrinology, 82, 26-37. doi: 10.1016/j.psyneuen.2017.04.007

Liu, J.J.W. \& Vickers, K. (2015). New developments in stress research - Is stress all that bad? New evidence for mind over matter. In A.M., Columbus (Ed.) Advances in psychology research, $106^{\text {th }}$ ed. (pp. 125-136). Hauppauge, NY: Nova Publishers.

Liu, J.J.W, Vickers, K., Reed, M., \& Hadad, M. (2017). Re-Conceptualizing stress: Shifting 
views on the consequences of stress and its effects on stress reactivity. PLoS ONE 12(3): e0173188.. doi: 10.1371/journal.pone.017318

Mazis, M. (1973). Cognitive tuning and receptivity to novel information. Journal of Experimental Social Psychology, 9(4), 307-319. doi:10.1016/0022-1031(73)90068-1

McEwen, B.S., \& Schmeck, H.M.J. (1994). The hostage brain. New York: The Rockfeller University Press.

McGuire, W.J. (1968). Personality and attitude change: An information-processing theory. In A. G. Greenwald et al. (Eds.) Psychological foundations of attitude change. New York: Academic Press.

Mehling, W.E., Price, C., Daubenmier, J.J., Acree, M., Bartmess, E., \& Stewart, A. (2012). The Multidimensional Assessment of Interoceptive Awareness (MAIA). PLoS ONE 7(11): e48230. doi:10.1371/journal.pone.0048230

Mendes, W. B. \& Koslov, K. (2013). Brittle smiles: Positive biases towards stigmatized and outgroup targets. Journal of Experimental Psychology: General, 142, 923-933.

Mongrain, M., \& Anselo-Matthews, T. (2012). Do positive psychology exercises work? A replication of Seligman et al. (2005). Journal of Clinical Psychology, 68, 382-398. doi: $10.1002 /$ jclp. 21839

Nelson, D.L., Mcevoy, C.L. \& Dennis, S. (2000). Memory \& Cognition, 28, 887. doi: 10.3758/BF03209337

Newsom, J. (2018). Psy 523/623 Structural Equation Modeling, Spring 2018 [PDF Slides]. Retrieved from http://web.pdx.edu/ newsomj/semclass/ho_sample\%20size.pdf

O'Keefe, D.J. (1999). How to handle opposing arguments in persuasive messages: A meta 
analytic review of the one-sided and two-sided message. Annals of the International Communication Association, 22, 209-249. doi: 10.1080/23808985.1999.11678963

Peterson, C., \& Seligman, M. E. P. (2004). Character strengths and virtues: A handbook and classification. New York: Oxford University Press and Washington, DC: American Psychological Association. www.viacharacter.org

Sapolsky, R.M. (1998). Why zebras don't get ulcers: An updated guide to stress, stress-related diseases, and coping. New York: W. H. Freeman and Co.

Schaub, A., Hippius, H., Moller, H.J, \& Falkai, P. (2016). Psychoeducational and cognitive behavioral treatment programs: Implementation and evaluation from 1995 to 2015 in Kraepelin's Former Hospital. Schizophrenia Bulletin, 42, s81-9. doi:

$10.1093 / \mathrm{schbul} / \mathrm{sbw} 057$

Schulz, A., \& Vögele, C. (2015). Interoception and stress. Frontiers in Psychology, 6, 993. doi: 10.3389/fpsyg.2015.00993

Schutte, N. S., Malouff, J. M., Hall, L. E., Haggerty, D. J., Cooper, J. T., Golden, C. J., \& Dornheim, L. (1998). Development and validation of a measure of emotional intelligence. Personality and Individual Differences, 25, 167-177.

Schutte, N. S., Malouff, J. M., Bobik, C., Coston, T. D., Greeson, C., Jedlicka, C., Rhodes, E., ... Wendorf, G. (2001). Emotional intelligence and interpersonal relations. Journal of Social Psychology, 141(4), 523-36.

Schutte, N.S., \& Malouff, J. M. (2012). Priming ability emotional intelligence. Intelligence, 40, 614-621. doi: 10.1016/j.intell.2012.09.001.

Scult, M.A., Knodt, A.R., Swartz, J.R., Brigidi, B.D., \& Hariri, A.R. (2017). Thinking and 
feeling: Individual differences in habitual emotion regulation and stress-related mood are associated with prefrontal executive control. Clinical Psychological Science, 5(1), 150157. doi: $10.1177 / 2167702616654688$

Seery, M. D. (2013). The biopsychosocial model of challenge and threat: Using the heart to measure the mind. Social and Personality Psychology Compass, 7, 637-653. doi: $10.1111 / \mathrm{spc} 3.12052$

Seligman, M. E. P. Steen, T. A., Park, N., \& Peterson, C. (2005). Positive psychology progress: Empirical validation of interventions. American Psychologist, 60, 410-421. doi: 10.1037/0003-066x.60.5.410

Selye, H. (1950). Stress and the General Adaptation Syndrome. British Medical Journal, 46637, 1383-1392.

Sergeant, S., \& Mongrain, M. (2011) Are positive psychology exercises helpful for people with depressive personality styles? The Journal of Positive Psychology, 6, 260-272. doi: $10.1080 / 17439760.2011 .577089$

Sergeant, S., \& Mongrain, M. (2015). Distressed users report a better response to online positive psychology interventions than nondistressed users. Canadian Psychology/Psychologie Canadienne, 56, 322-331. http://dx.doi.org/10.1037/cap0000034

Sherman, D.K., \& Cohen, G. (2002). Accepting threatening information: Self-affirmation and the reduction of defensive biases. Current Directions in Psychological Science, 11, 119-123.

Shirtcliff, E.A., Peres, J.C., Dismukes, A.R., Lee, Y., \& Phan, J.M. (2014). Riding the physiological roller coaster: Adaptive significance of cortisol stress reactivity to social contexts. Journal of Personality Disorders, 28(1), 40-51.

Singh, Y., \& Sharma, R. (2012). Relationships between general intelligence, emotional 
intelligence, stress levels and stress reactivity. Annals of Neurosciences, 19(3), 107-111. doi: 10.5214/ans.097.7531.190304

Skoluda, N., Strahler, J., Schlotz, W., Niederberger, L., Marques, S., Fischer, S., Thoma, M.V., Spoerri, C., Ehlert, U., \& Nater, U.M. (2015). Intra-individual psychological and physiological response to acute laboratory stressors of different intensity. Psychoneoroendocrinology, 51, 227-236. doi: 10.1016/j.psyneuen.2014.10.002

Schoofs, D., Preuss, D., \& Wolf, O.T. (2008). Psychosocial stress induces working memory impairments in an n-back paradigm. Psychoneuroendocrinology, 33, 643-53. doi: 10.1016/j.psyneuen.2008.02.004

Schneiderman, N., Ironson, G., \& Siegel, S. D. (2005). Stress and health: Psychological, Behavioral, and Biological Determinants. Annual Review of Clinical Psychology, 1, 607-628. doi: 10.1146/annurev.clinpsy.1.102803.144141

Sommerfeldt, S.L., Schaefer, S.M., Brauer, M., Ryff, C.D., \& Davidson, R.J. (2019). Individual differences in the association between subjective stress and heart rate are related to psychological and physical well-being. Psychological Science, 1-14. doi:

\section{$10.1177 / 0956898619849555$}

Souza-Talarico, J.N., Wan, N., Santos, S., Fialho, P.P.A., Chaves, E.C., Carmelli, P., Bianchi, E.F., Santos, A.T., \& Lupien, S.J. (2016). Cross-country discrepancies on public understanding of stress concepts: Evidence for stress-management psychoeducational programs. BMC Psychiatry, 16, 181. doi: 10.1186/s12888-016-0886-6

Spittal, M.J., Siegert, R.J., McClure, J.L., \& Walkey, F.H. (2002). The Spheres of Control scale: the identification of a clear, replicable three-factor structure. Personality and Individual Differences, 32, 121-131. 
Spitzberg, B., \& Cupach, W. (2008). Managing unwanted pursuit. In M. Motley (Ed.), Studies in applied interpersonal communication (pp. 3-25). Thousand Oaks, CA: Sage.

Stark, K., Wolf, O.T., Markowitsch, H.J., \& Brand, M. (2008). Anticipatory stress influence decision making under explicit risk conditions. Behavioral Neuroscience, 122, 13521360. doi: $10.1037 / \mathrm{a} 0013281$

Steketee, G., \& Chambless, D. L. (1992). Methodological issues in prediction of treatment outcome. Clinical Psychology Review, 12, 387-400. doi: 10.1016/0272-7358(92)90123-P

Stroop, J.R. (1935). Studies of interference in serial verbal reactions. Journal of Experimental Psychology, 18, 643-662.

Telch, M.J., Harrington, P.J., Smits, J.A.J., \& Powers, M.B. (2011). Unexpected arousal, anxiety sensitivity, and their interaction on $\mathrm{CO}_{2}$-induced panic: Further evidence for the contextsensitivity vulnerability model. Journal of Anxiety Disorders, 25, 645-653. doi: 10.1016/j.janxdis.2011.02.005

Tsitsi, T., Charalambous, A., Papastravrou, E., \& Raftopoulos, V. (2017). Effectiveness of a relaxation intervention (progressive muscle relaxation and guided imagery techniques) to reduce anxiety and improve mood of parents of hospitalized children with malignancies: A randomized controlled trial in Republic of Cyprus and Greece. European Journal of Oncology Nursing, 26, 9-18. doi: 10.1016/j.ejon.2016.10.007

Undem, B.J. (2009). Autonomic nervous system: Respiratory control. Encyclopedia of Neuroscience, 975-981. doi: 10.1016/B978-008045046-9.00635-5

van Dijk, E.T., Westerink, J.H., Beute, F., \& Ijsselsteijn, W.A. (2015). In sync: The effects of physiology feedback on the match between heart rate and self-reported stress. BioMed Research Central, 2015, 134606. doi: 10.1155/2015/134606 
Vermeij, A., van Beek, A.H., Olde Rikkert, M.G., Claassen, J.A., \& Kessels, R.P. (2012). Effects of aging on cerebral oxygenation during working-memory performance: A functional near-infrared spectroscopy study. PLoS ONE, e0046210. doi: 10.1371/journal.pone.0046210

VIA Institute on Character. (2018a). Global Assessment of Character Strengths 24. Retrieved from www.viacharacter.org

VIA Institute on Character. (2018b). Signature Strengths Survey. Retrieved from www.viacharacter.org

Wewers, M.E., \& Lowe, N.K. (1990). A critical review of visual analogue scales in the measurement of clinical phenomena. Research in Nursing and Health, 13, 402-407.

Widmer, I.E., Puder, J.J., Konig, C., Pargger, H, Zerkowski, H.R., Girard, J., \& Muller, B. (2005). Cortisol response in relation to the severity of stress and illness. The Journal of Clinical Endocrinology \& Metabolism, 90, 4579-4586. doi: 10.1210/jc.2005-0354

Williams, J.M.G., Mathews, A., \& MacLeod, C. (1996). The emotional Stroop Task and psychopathology. Psychological Bulletin, 120(1), 3-24.

Wolf, E. J., Harrington, K. M., Clark, S. L., \& Miller, M. W. (2013). Sample size requirements for structural equation models: An evaluation of power, bias, and solution propriety. Educational and psychological measurement, 76, 913-934. doi: $10.1177 / 0013164413495237$

Zygmunt, A., \& Stanczyk, J. (2010). Methods of evaluation of autonomic nervous system function. Archives of Medical Science: AMS, 6, 11-18. doi: 10.5114/aoms.2010.13500 